\title{
Gastrosquise fetal isolada: relação entre dilatação intestinal e resultados perinatais adversos
}

Dissertação apresentada à Faculdade de Medicina da Universidade de São Paulo para obtenção do título de Mestre em Ciências

Programa de Obstetrícia e Ginecologia

Orientadora: Prof ${ }^{\mathrm{a}}$. Dra. Maria de Lourdes Brizot

São Paulo

2011 
Dados Internacionais de Catalogação na Publicação (CIP)

Preparada pela Biblioteca da

Faculdade de Medicina da Universidade de São Paulo

Creprodução autorizada pelo autor

\section{Garcia, Luciana de Freitas}

Gastrosquise fetal isolada : relação entre dilatação intestinal e resultados perinatais adversos / Luciana de Freitas Garcia. -- São Paulo, 2011.

Dissertação(mestrado)--Faculdade de Medicina da Universidade de São Paulo. Programa de Obstetrícia e Ginecologia.

Orientadora: Maria de Lourdes Brizot.

Descritores: 1.Gastrosquise 2.Feto 3.Diâmetro da alça intestinal 4.Dilatação 5.Ultrassonografia 6.Diagnóstico pré-natal 7.Prognóstico

USP/FM/DBD-326/11 
Podes dizer-me, por favor, que caminho devo seguir para sair daqui? Isso depende muito de para onde queres ir - respondeu o gato Preocupa-me pouco aonde ir - disse Alice Nesse caso, pouco importa o caminho que sigas - replicou o gato 


\section{Dedicatória}

Esta tese é dedicada:

Aos meus amados pais, Ademir e Neusa, porto seguro de minha vida, por sempre acreditarem, me impulsionarem e possibilitarem a realização de todos os meus sonhos

Ao Mateus, o verdadeiro "encontro" da minha vida, pelo amor construído e vivido dia-a-dia. Obrigada pelo apoio e paciência, tão fundamentais, durante a minha trajetória

Às minhas irmãs Adriana, Karla, Renata e meus sobrinhos Tatá, Gui e Léo, luzes da minha vida, pelo Amor incondicional e pela família que somos

À querida Vó Cida, pelo carinho, proteção e dedicação na minha educação e ao meu querido Vô Tonico (in memorian), eternamente em meu coração e pensamento

Renato, Rodrigo e João, meus cunhados-irmãos de coração

Às queridas Letícia, Gabriela e D. Irene, por complementar o meu bem maior - a minha família. Obrigada pelo carinho nesta jornada (assim como em todas as ocasiões), pela convivência amorosa e edificadora. 


\section{Agradecimentos especiais}

À minha orientadora, Prof ${ }^{\text {a }}$ Dra. Maria de Lourdes Brizot, agradeço por acreditar em mim desde o primeiro momento, pelos ensinamentos de vida e de pesquisa científica, pelo exemplo de caráter íntegro. Minha enorme admiração e gratidão por me conduzir com sabedoria na elaboração deste trabalho e pelas portas que abriu em minha caminhada. 


\section{Agradecimentos}

Deus não fez tudo num só dia; o que me faz pensar que eu possa? William Shakespeare 
Ao Prof. Dr. Marcelo Zugaib, digníssimo Professor Titular de Obstetrícia do Departamento de Obstetrícia e Ginecologia da Faculdade de Medicina da Universidade de São Paulo, pelo apoio e oportunidade de realizar esta tese na mais concentuada Clínica Obstétrica do país e pelo exemplo de liderança.

Ao Prof.Dr. Adolfo Wenjaw Liao, o "meu muito obrigada" pela contribuição fundamental na elaboração e concretização deste trabalho. Também sou grata pelas valiosas observações na fase da qualificação, e, pelos ensinamentos de pesquisa científica, ensinamentos de Medicina Fetal e em procedimentos invasivos durante o meu estágio na Clínica Obstétrica, com sua já característica didática e forma elucidativa de expressar seu conhecimento imensurável.

À Profa. Dra. Roseli M. Y. Nomura, pela disponibilidade em sempre esclarecer minhas dúvidas e pelas sugestões e orientações na avaliação desta tese na fase da qualificação.

Ao Dr. Fábio Cabar, pelo cuidado e atenção dispensados a este estudo na fase da qualificação.

Ao Prof. Dr. Mário Henrique Burlacchini de Carvalho, pela contribuição dispensada na fase da qualificação. Agradeço pelos ensinamentos médicos, pela amizade e pelas oportunidades que me deu ao acreditar em mim.

Ao Dr. Marco Aurélio Galetta, pela atenção e colaboração dispensada na fase da qualificação.

Ao Dr. Guilherme Loureiro Fernandes, que foi o início de tudo, pois me inspirou à paixão pela Medicina Fetal, pelo seu admirável conhecimento médico e habilidade na especialidade, e pelo seu constante exemplo de caráter humano e ético com as nossas gestantes. Serei eternamente grata pelos seus ensinamentos e pelo carinho e atenção com os quais sempre me tratou. Meu grande e querido mestre. 
Ao Dr. Wagner Jou Hisaba, excelente e dedicado professor, que me intrigou para os conhecimentos das gestações de alto risco e de medicina fetal, quando eu ainda estava no quinto ano do internato. Tornou-se um querido amigo, com quem aprendi e ainda aprendo muito. Meu sincero agradecimento.

À grande amiga, de longa data, Carolina Meyer Corsini Steiner, exresidente desta casa, por ter me apresentado à equipe de Medicina Fetal do HCFMUSP, foi o primeiro passo para uma trajetória ainda desconhecida, mas repleta de expectativas. Obrigada por trazer esta reviravolta em um momento tão delicado de minha vida!

À Dra. Estela Nishie e Dra. Marina Yamamoto Kiyohara pela amizade valiosa que construímos ao longo desses anos, pela convivência agradável e amistosa, e, pelo companheirismo no atendimento às gestantes no ambulatório. Foi um período que guardarei em meu coração.

Às Dras. Renata de Almeida de Assunção, Milena Ninno Nozaki, Patrícia da Rocha Pennachioti, Lilia Araújo Lima, Renata Lopes Ribeiro, Ana Paula Mosconi, Julianny Nery, Helenice Julio Kang, Tatiana Benáth Liao, Verbênia Nunes Costa, Rita Alan Machado, Lorena Mesquita, Janaína Wittckind, Mary Nalza Rodrigues, Cristiane Ortigosa, Rita de Cássia Santos de Souza e Dr. Alexandre Massao Nozaki, amigos queridos que fiz no HCFMUSP, minha gratidão pela amizade, pela momentos de descontração e pelo incentivo nos momentos difíceis. Aprendi muito com todos vocês, tanto ensinamentos médicos e científicos, como experiências de vida.

À Dra. Clarissa Oliveira Lamberty, pela amizade construtiva e tão querida, pelo companheirismo desde que iniciamos juntas nesta jornada, pelos seus conselhos e dicas inestimáveis durante a elaboração desta tese. Pelas diversas vezes que me substituiu quando necessitei, sem hesitar. Muito Obrigada! 
À Dra. Juliana Carvalho, Dra. Karine Tosta e Dr. Eduardo Pimenta pela amizade desde que iniciamos nesta casa e fortalecemos no período em que trabalhamos juntos no Hospital Estadual Sapopemba. Foi um tempo precioso de convivência e amadurecimento que tenho muitas saudades.

Às colegas da pós-graduação Priscila Beirigo e Letícia Paiva, participamos juntas deste desafio. Minha gratidão pela convivência e apoio durante a elaboração desta tese, pelos momentos de alegria e pelas palavras otimistas.

Aos assistentes Dra. Eliane Azeka, Dra. Joelma Queiroz, Prof.Dr. Marco Antônio B. Lopes, Dr. Javier Miguelez, Dr. Antônio Gomes de Amorim Filho e Dr. Vitor Bunduki pela amizade e ensinamentos de medicina fetal que contribuíram para minha formação profisssional e científica.

A todos os colegas e amigos da medicina fetal e pós-graduandos do departamento, pela amizade e companheirismo que sempre tivemos em nosso grupo.

A todos assistentes da Clínica Obstétrica do HCFUMSP, por estarem sempre dispostos a dividir seus conhecimentos.

Ao Sr. Amadeu F. dos Santos, pela recepção carinhosa, pelo apoio e amizade durante todo período que acompanhei o ambulatório de Medicina Fetal do HCFMUSP.

Às Sras. Soraya Cristina F. Silva e Myriam R.R. Souto, além da ajuda admnistrativa, pela amizade e conselhos em momentos difíceis da minha vida particular. 
Às Sras. Claudia Vieira, Inez Muras Fuentes e Fátima Abdul, por todo apoio e disponibilidade em esclarecer e resolver minhas dúvidas referentes à pósgraduação.

À Sra. Marina M. Silva e à todas funcionárias da recepção e de enfermagem do ambulatório de Medicina Fetal do HCFMUSP, pelo convivência carinho no dia-a-dia.

Aos Srs. Allan Garcia, William Santos e Alexandre Emmanoel, sempre solícitos quando precisei (e foram muitas vezes). Agradeço pela presteza, colaboração e pelos preciosos conhecimentos de informática.

À Sra Mitsuko Miyadahira, pelo auxílio da correção e revisão gramatical.

À Sra. Creusa Dal bó, pela gentileza com que me recebeu em sua casa, e, pelas contribuições e ensinamentos em Estatística.

Agradeço a todos que, direta ou indiretamente, contribuíram para a realização deste estudo.

À minha família, sem vocês eu nunca teria conseguido.

Às gestantes, pacientes da clínica obstétrica da FMUSP e aos seus recémnascidos, motivo deste estudo.

Principalmente à Deus, tenho meu coração verdadeiramente grato. Pela minha existência, pelas pessoas maravilhosas que fazem parte da minha vida familiar e pelos meus prestimosos amigos mais íntimos. Agradeço não somente pelas oportunidades que tive e tenho, mas também pelas dificuldades que já vivi e me fizeram "crescer e amadurecer", obrigada pela "presença" e força na superação dos obstáculos. 
Esta dissertação está de acordo com as seguintes normas, em vigor no momento desta elaboração:

Referências: adaptado de International Committee of Medical Journals Editors (Vancouver)

Universidade de São Paulo. Faculdade de Medicina. Serviço de Biblioteca e Documentação. Guia de apresentação de dissertações, teses e monografias. Elaborado por Anneliese Carneiro da Cunha, Maria Julia de A. L. Freddi, Maria F. Crestana, Marinalva de Souza Aragão, Suely Campos Cardoso, Valéria Vilhena. $3^{\text {a }}$ ed. São Paulo: Serviço de Biblioteca e Documentação; 2011.

Abreviaturas dos títulos dos periódicos de acordo com List of Journals Indexed in Index Medicus. 


\section{Sumário}

Lista de abreviaturas e siglas

Lista de símbolos

Lista de figuras

Lista de tabelas

Lista de gráficos

Resumo

Summary

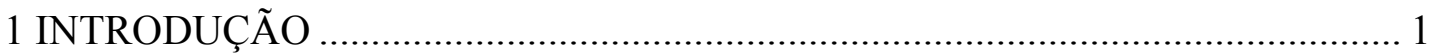

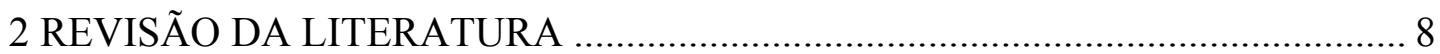

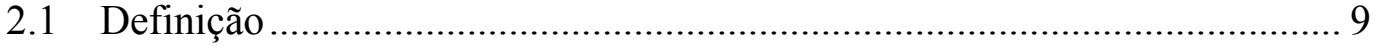

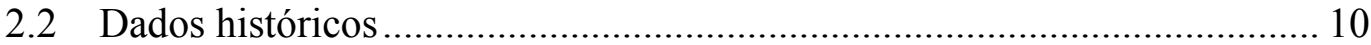

2.3 Embriogênese da parede abdominal e formação dos defeitos de fechamento da parede abdominal ............................................................ 11

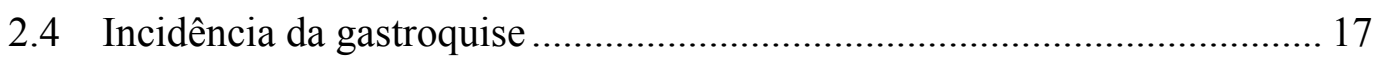

2.5 Aspectos epidemiológicos da gastroquise............................................... 20

2.6 Diagnóstico ultrassonográfico da gastroquise............................................ 25

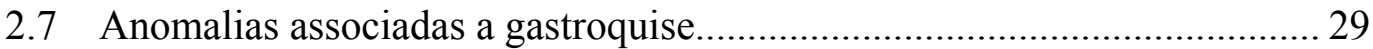

2.8 Evolução antenatal e pós-natal................................................................. 31

2.9 Avaliação ultrassonográfica das alças intestinais exteriorizadas ................ 33

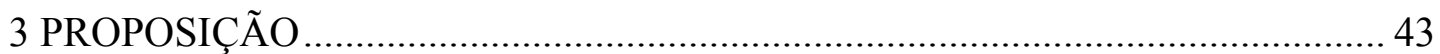

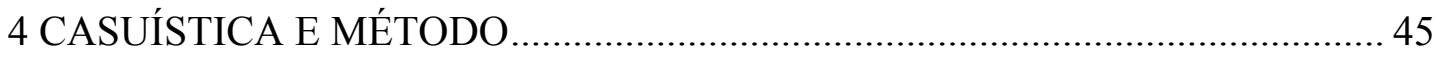

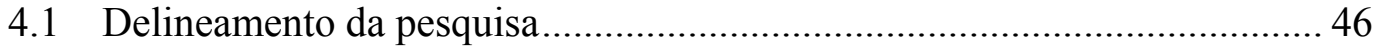

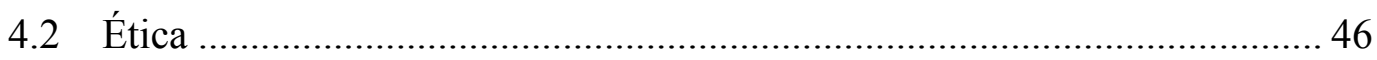

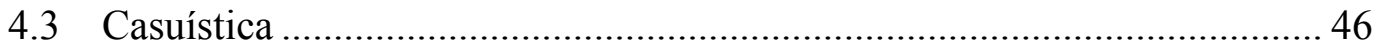

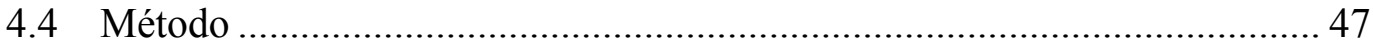

4.4.1 Seleção do grupo de estudo........................................................ 47

4.4.1.1 Critérios de inclusão......................................................... 47

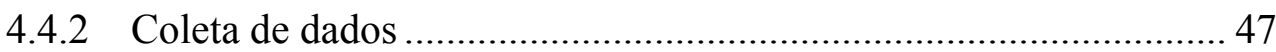

4.4.3 Protocolo de atendimento das gestantes com feto portador de gastroquise 
4.4.3.1 Metodologia do exame ultrassonográfico no seguimento dos casos ...................................................... 48

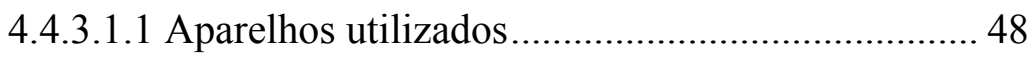

4.4.3.1.2 Diagnóstico de gastroquise ................................ 48

4.4.3.1.3 Avaliação fetal .................................................. 49

4.4.3.1.4 Datação da gestação ............................................ 51

4.4.3.1.5 Seguimento dos casos ........................................ 52

4.4.4 Variáveis analisadas na população do estudo ............................... 52

4.4.4.1 Variáveis maternas - dados demográficos.......................... 52

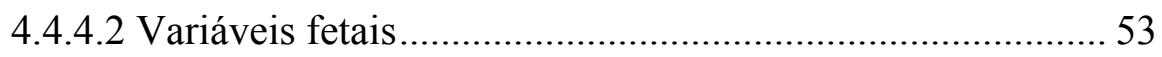

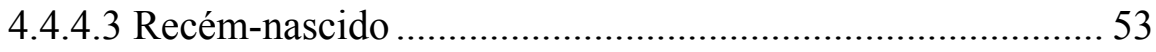

4.4.5 Análise estatística dos resultados .................................................5 54

4.4.6 Caracterização da população do estudo .......................................... 55

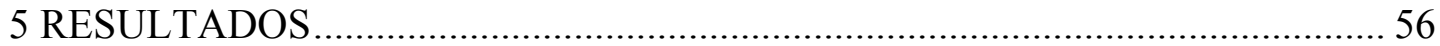

5.1 Descrição dos dados demográficos das gestantes ..................................... 57

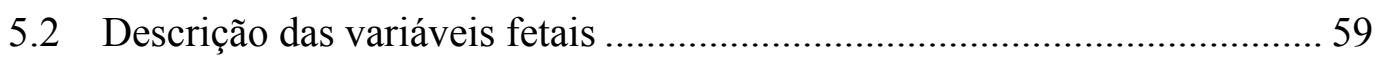

5.3 Descrição das variáveis do recém-nascido................................................ 60

5.4 Comparação das variáveis maternas, fetais e do recém-nascido entre os grupos com e sem resultados perinatais adversos .................................... 63

5.5 Correlação entre idade gestacional e o diâmetro transverso da alça intestinal ao longo da gestação. 66

5.6 Obtenção do melhor valor de corte na predição dos resultados adversos

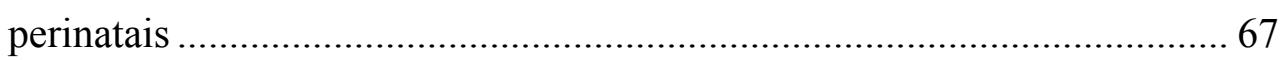

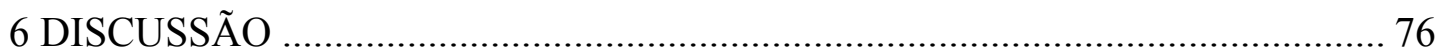

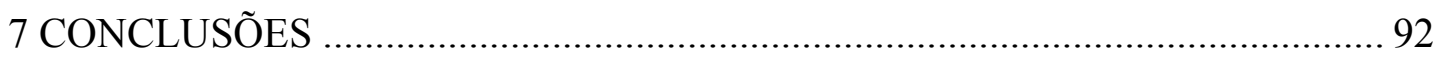

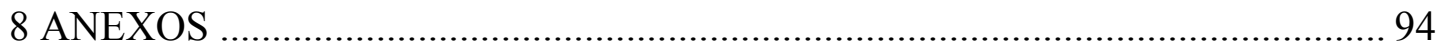

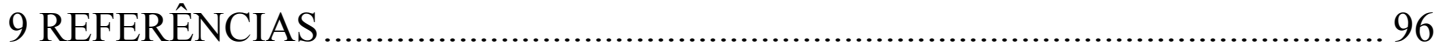




\section{Listas}

\section{LISTA DE ABREVIATURAS E SIGLAS}

\begin{tabular}{|c|c|}
\hline AIG & adequado para a idade gestacional \\
\hline $\mathrm{AOM}$ & artéria onfalomesentérica \\
\hline CAPPesq & Comissão de Ética para Análise de Projetos de Pesquisa \\
\hline DI & dilatação intestinal \\
\hline DP & desvio padrão \\
\hline DTA & diâmetro transverso da alça intestinal \\
\hline DTA O/E & diâmetro transverso da alça observada sobre esperada \\
\hline DUM & data da última menstruação \\
\hline $\mathrm{E}$ & esperado \\
\hline ECLAMC & $\begin{array}{l}\text { Estudio Colaborativo Latino Americano de Malformaciones } \\
\text { Congénitas }\end{array}$ \\
\hline et al. & e outros \\
\hline EUA & Estados Unidos da América \\
\hline HCFMUSP & Hospital das Clínicas da Faculdade de Medicina da \\
\hline & Universidade de São Paulo \\
\hline HPV & Human Papiloma Vírus \\
\hline IC & intervalo de confiança \\
\hline IG & idade gestacional \\
\hline $\mathrm{IJ}$ & interrupção judicial \\
\hline IMC & índice de massa corporal \\
\hline INCA & Instituto Nacional do Câncer \\
\hline M & média \\
\hline máx & máximo \\
\hline mín & mínimo \\
\hline $\mathrm{n}$ & número de casos \\
\hline NPP & nutrição parenteral prolongada \\
\hline
\end{tabular}




$\begin{array}{ll}\text { NV } & \text { nascidos vivos } \\ \text { O } & \text { observado } \\ \text { OF } & \text { óbito fetal } \\ \text { ONN } & \text { óbito neonatal } \\ \text { OR } & \text { Odds ratio } \\ \text { PIG } & \text { pequeno para a idade gestacional } \\ \text { PN } & \text { peso ao nascimento } \\ \text { RCF } & \text { restrição de crescimento fetal } \\ \text { RN(s) } & \text { recém-nascido (s) } \\ \text { ROC } & \text { Receiver operating characteristic (Curva de característica de } \\ & \text { operação do receptor) } \\ \text { RR } & \text { risco relativo } \\ \text { sem } & \text { semanas } \\ \text { USG } & \text { ultrassonografia } \\ \text { UTI } & \text { unidade de tratamento intensivo } \\ \text { VPN } & \text { valor preditivo negativo } \\ \text { VPP } & \text { valor preditivo positivo } \\ \text { vs } & \text { versus }\end{array}$




\section{LISTA DE SÍMBOLOS}

$\begin{array}{ll}\Delta \mathrm{t} & \text { intervalo de tempo } \\ \mathrm{g} & \text { gramas } \\ \mathrm{MHz} & \text { mega hertz } \\ \mathrm{mm} & \text { milímetro } \\ p & \text { nível descritivo de probabilidade } \\ \% & \text { porcento, percentual } \\ = & \text { igual } \\ > & \text { maior } \\ \geq & \text { maior ou igual } \\ < & \text { menor } \\ \pm & \text { mais ou menos }\end{array}$




\section{LISTA DE FIGURAS}

Figura 1 - Apresentação clínica da gastrosquise em recém-nascido, com conteúdo visceral exteriorizado antes do procedimento cirúrgico corretivo

Figura 2 - Corte transverso do embrião mostrando a migração dos folhetos laterais em direção ao celoma extraembrionário, obliterando-o

Figura 3 - Corte médio da metade caudal do embrião no final da 5a semana. A seta indica a comunicação da cavidade peritoneal com o celoma extra embrionário. Herniação fisiológica temporária do intestino em direção ao celoma extraembrionário na porção inicial do cordão umbilical.

Figura 4 - Corte longitudinal do embrião mostrando artéria mesentérica superior, que faz parte do pedículo vascular e acompanha o intestino herniado, e a veia umbilical $(\mathrm{A}, \mathrm{B}, \mathrm{C})$. Retorno do intestino para a cavidade abdominal $(\mathrm{D}, \mathrm{E})$

Figura 5 - Corte mediano do embrião na 4a semana mostrando o sistema digestório e sua vascularização, como a artéria vitelínica (B). O intestino primitivo é um tubo longo que se estende por todo o comprimento do embrião e se comunica com o saco vitelínico pelo pedículo vitelínico (A)

Figura 6 - Aspecto ultrassonográfico de gastrosquise no segundo trimestre de gestação, abertura na parede abdominal localizada à direita da inserção do cordão umbilical (IC). Alças intestinais herniadas pela abertura sem membrana peritoneal recobrindo-as.

Figura 7 - Imagem ultrassonográfica da parede abdominal íntegra e o cordão umbilical nela inserido, com (à esquerda) e sem (à direita) o Doppler colorido, em feto de 22 semanas sem defeito de fechamento da parede abdominal.

Figura 8 - $\quad \grave{A}$ esquerda: imagem sagital de feto portador de gastrosquise demonstrando alças intestinais exteriorizadas livres no líquido amniótico através da parede abdominal, sem membrana peritoneal recobrindo-as. À direita: corte transverso de abdome demonstrando conteúdo exteriorizado delimitado por membrana peritoneal característica de onfalocele 
Figura 9 - $\quad$ À esquerda: recém-nascido com gastrosquise, com conteúdo exteriorizado livre e cordão umbilical inserido na parede abdominal e à direita da abertura. À direita: apresentação clínica de onfalocele em recém-nascido, com saco herniário recobrindo conteúdo exteriorizado e cordão umbilical inserido no ápice do saco

Figura 10 - Corte transverso do abdome demonstrando aspecto ultrassonográfico das alças intestinais em feto com gastrosquise. Alças exteriorizadas no líquido amniótico sem sinais sugestivos de dilatação do lúmen

Figura 11 - Imagem ultrassonográfica de alças intestinais exteriorizadas com aspecto sugestivo de dilatação do lúmen

Figura 12 - Demonstração da técnica para medida do diâmetro da alça intestinal exteriorizada em corte transverso da mesma. Calipers posicionados nas faces internas da alça, delimitando apenas o lúmen $(28,2 \mathrm{~mm})$

Figura 13 - Demonstração ultrassonográfica de alças intestinais intraabdominais dilatadas $(18,8 \mathrm{~mm})$ no terceiro trimestre de gestação, no corte transverso do abdome fetal 


\section{LISTA DE TABELAS}

Tabela 1 - Estudos epidemiológicos com incidência de gastrosquise

Tabela 2 - Revisão dos estudos em gastrosquise fetal que avaliam a associação entre dilatação das alças intestinais exteriorizadas e o prognóstico perinatal

Tabela 3 - Distribuição do número de gestações, etnia, hábito do tabagismo e presença de doenças prévias entre as gestantes de fetos portadores de gastrosquise

Tabela 4 - Descrição do tempo médio entre a última medida da alça intestinal e o parto nas 94 gestações avaliadas.

Tabela 5 - Descrição do tipo de parto, gênero, resultado da gestação e sobrevida dos recém-nascidos com gastrosquise

Tabela 6 - Evolução dos 16 casos de gastrosquise fetal isolada com resultados adversos

Tabela 7 - Comparação das variáveis fetais e do recém-nascido de acordo com os resultados perinatais

Tabela 8 - Descrição das variáveis do recém-nascido com gastrosquise isolada segundo os grupos de resultados perinatais adversos .....

Tabela 9 - Valores descritivos do diâmetro transverso da alça obtido e esperado para a idade gestacional, e a relação entre essas medidas, segundo os grupos de resultados.

Tabela 10 - Predição de resultado adverso na gestação de acordo com maior medida do diâmetro transverso da alça aferido até 3 semanas antes do parto

Tabela 11 - Comparação das variáveis dos recém-nascidos com gastrosquise no grupo geral, no grupo com dilatação intestinal $\geq 25 \mathrm{~mm}$ e no grupo com dilatação intestinal $<25 \mathrm{~mm}$ 


\section{LISTA DE GRÁFICOS}

Gráfico 1 - Distribuição do maior diâmetro transverso da alça exteriorizada identificado durante o exame ultrassonográfico, em 94 casos de gastrosquise fetal isolada (253 medidas).

Gráfico 2 - Curva ROC para predição de resultados adversos em 94 gestações com gastrosquise fetal isolada, de acordo com valores de observado/esperadodo maior diâmetro transverso da alça (área sob a curva $=0,67$ )

Gráfico 3 - Curva ROC para predição de resultados adversos em 94 gestações com gastrosquise fetal isolada, de acordo com valores do maior diâmetro transverso da alça observados até três semanas antes do parto (área sob a curva $=0,58$ ) 


\section{Resumo}

Garcia LF. Gastrosquise fetal isolada: relação entre dilatação intestinal e resultados perinatais adversos [Dissertação]. São Paulo: Faculdade de Medicina, Universidade de São Paulo; 2011. 109 p.

Objetivos: Este estudo foi desenvolvido para avaliar o diâmetro transverso da alça intestinal exteriorizada como fator preditor de resultado adverso, nas gestações com gastrosquise fetal isolada. Métodos: Estudo retrospectivo envolvendo 94 gestações únicas. Foi realizada a medida do diâmetro transverso da alça intestinal (DTA) herniada, por meio da ultrassonografia antenatal, até 3 semanas antes do parto. Foi considerado resultado perinatal adverso: óbito intra-útero, óbito neonatal e complicações intestinais. Resultados: a última medida ultrassonográfica do DTA foi realizada com 35,6 $\pm 1,6$ semanas e o tempo médio do intervalo entre a última medida e o parto foi de 6,2 $\pm 5,0$ dias. Ocorreram $10(10,6 \%)$ casos de óbitos intraútero e neonatal; foram observadas complicações intestinais em $8(8,5 \%)$ casos. DTA $\geq 15, \geq 20, \geq 25$ e $\geq 30 \mathrm{~mm}$ foram identificadas em $87,46,13$ e 4\% das gestações com prognóstico favorável, respectivamente. O DTA $\geq 25 \mathrm{~mm}$ apresentou valores de sensibilidade de $38 \%$, e, valores preditivo positivo e preditivo negativo de $38 \%$ e $87 \%$, na predição de resultados adversos. Para o DTA $\geq 30 \mathrm{~mm}$, os valores foram: 19, 50 e 85\%. A área sob a curva ROC do valor observado/esperado do DTA para cada idade gestacional foi de 0,67 , sendo o melhor ponto-de-corte em 1,39; e, seus valores preditivos foram semelhantes aos do DTA $\geq 25 \mathrm{~mm}$. Dilatação intestinal esteve significantemente associada com baixa taxa de fechamento primário da parede abdominal, longo período para iniciar a dieta via oral e internação hospitalar prolongada. Conclusões: Dilatação intestinal demonstrada até 3 semanas antes do parto é preditora de complicações intestinais e está associado a baixa taxa de fechamento primário da parede abdominal, longo período para iniciar a dieta via oral e de internação hospitalar.

Descritores: 1. Gastrosquise 2. Feto 3. Diâmetro da alça intestinal 4. Dilatação 5. Ultrassonografia 6. Diagnóstico pré-natal 7. Prognóstico 


\section{Summary}

Garcia LF. Isolated fetal gastroschisis: relation between bowel dilation and adverse perinatal outcome [Dissertation]. São Paulo: "Faculdade de Medicina, Universidade de São Paulo"; 2011. 109 p.

Objectives: Evaluate bowel diameter as a predictor of adverse outcome in isolated fetal gastroschisis. Methods: Retrospective study involving 94 singleton pregnancies. Ultrasound measurements of herniated bowel transverse diameter (BTD) were performed up to 3 weeks before delivery. Adverse outcome was intrauterine/neonatal death and/or bowel complications. Results: Last BTD was recorded at 35,6 $\pm 1,6$ weeks and mean interval to delivery was $6,2 \pm 5,0$ days. Intrauterine/neonatal death occurred in $10(10,6 \%)$ cases; bowel complications were observed in $8(8,5 \%)$. BTD $\geq 15, \geq 20, \geq 25$ and $\geq 30 \mathrm{~mm}$ were found in $87,46,13$ and $4 \%$ of pregnancies with a favorable outcome, respectively. BTD $\geq 25 \mathrm{~mm}$ sensitivity was $38 \%$, positive and negative predictive values, $38 \%$ and $87 \%$. For BTD $\geq 30 \mathrm{~mm}$, the values were: 19,50 and $85 \%$. Observed/expected BTD ROC curve showed an area of 0,67 , with best cut-off at 1,39; prediction values were similar to those for BTD $\geq 25 \mathrm{~mm}$. Bowel dilatation was also significantly associated with lower rate of primary surgical closure, longer period to full oral feeding and prolonged hospital stay. Conclusions: Bowel dilatation demonstrated up to 3 weeks before delivery is a predictor of intestinal complications and is associated with lower rate of primary surgical closure, longer period to achieve full oral feeding and hospital stay.

Descriptors: 1. Gastroschisis 2. Fetus 3. Bowel diameter 4. Dilation 5. Ultrasound 6. Prenatal diagnosis 7. Outcome 


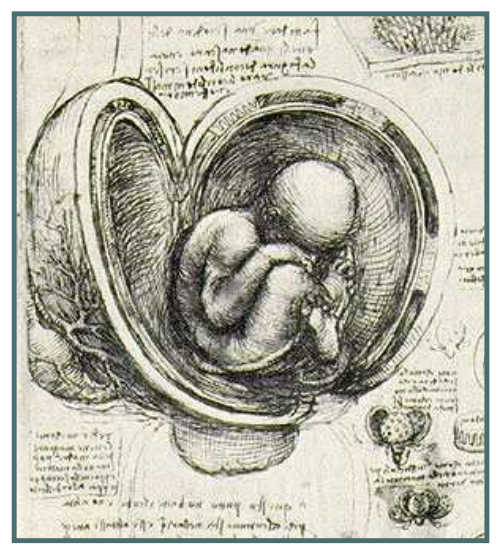


Os defeitos da parede abdominal ocorrem em 2,15/10.000 nascidos vivos $(\mathrm{NV})^{(1)}$. Dentre os defeitos de parede abdominal, os mais comuns são a gastrosquise e a onfalocele, sendo menos frequentes a extrofia da cloaca ou da bexiga, anormalidades do úraco, ectopia cordis e anomalias do pedúnculo (body-stalk). A gastrosquise apresenta incidência média descrita na literatura de 1,36 para cada $10.000 \mathrm{NV}$, variando entre 0,4 a $3,01^{(2)}$.

Gastrosquise é o termo utilizado para denominar o defeito de fechamento da parede abdominal paraumbilical que compromete toda a sua espessura, localizandose entre o músculo reto abdominal e o cordão umbilical, sendo que os músculos retos abdominais estão intactos e normais. É caracterizada anatomicamente por apresentar pequena abertura (raramente maior que $3,0 \mathrm{~cm}$ ) na parede abdominal, geralmente localizada à direita do cordão umbilical (95\%), usualmente justaposta ao cordão e, em raras ocasiões, separada dele por uma faixa fina de pele. Por meio dessa abertura, ocorre a evisceração dos órgãos abdominais sem membrana peritoneal recobrindo o conteúdo exteriorizado, ficando as vísceras herniadas imersas no líquido amniótico ${ }^{(3)}$. Embora seja extremamente raro, também pode estar situada à esquerda da inserção do cordão, com etiologia diferente daquela localizada à direita ${ }^{(4)}$.

Em relação ao conteúdo abdominal herniado, é mais frequente encontrar exteriorizado o intestino delgado; algumas vezes, o estômago e a bexiga; e, raramente, o fígado e as gônadas. As alças intestinais exteriorizadas, livres no líquido amniótico, encontram-se, em geral, espessadas, edemaciadas, encurtadas e cobertas por grossa membrana composta de fibrina e colágeno denominada de "peel" - na literatura de língua inglesa (traduzida para a língua portuguesa como casca) ${ }^{(5)}$.

Para Moore, a gastrosquise é resultado da fusão incompleta dos folhetos laterais do mesoderma, durante a formação da parede abdominal anterior, na quarta semana de gestação $^{(6)}$, porém os fatores etiológicos que levam ao fechamento incompleto da parede abdominal ainda permanecem desconhecidos.

Apesar de ainda não haver, na literatura, consenso sobre o estágio da embriogênese em que se origina esse defeito, o diagnóstico da gastrosquise já pode 
ser realizado, precocemente, entre a $11^{\mathrm{a}}$ e $14^{\mathrm{a}}$ semana de gestação, devido às melhorias dos recursos tecnológicos utilizados na ultrassonografia do $1^{\mathrm{o}}$ trimestre $^{(7,}$ 8).

O diagnóstico de gastrosquise no período pré-natal auxilia tanto no aconselhamento, como no adequado seguimento dessas gestações, respeitando a história natural da anomalia, a escolha da melhor via de parto e ainda possibilita o atendimento por equipe multidisciplinar composta por obstetras, neonatologistas e cirurgiões pediátricos, a fim de obter o melhor resultado perinatal.

A importância da distinção entre gastrosquise e onfalocele reside no fato de que a última apresenta maior associação com anomalias cromossômicas e/ou outras malformações estruturais, o que modifica a conduta e o aconselhamento no pré-natal.

Diversos estudos recentes têm mostrado aumento na incidência de gastrosquise $^{(1,9)}$, Loane et al. analisam os registros de 15 países europeus e relatam incidência de 0,54/10.000 NV no período de 1980-84, já no período entre 2000-2002 a incidência era de $2,12 / 10.000 \mathrm{NV}^{(10)}$. Observa-se também tendência a ocorrer em comunidades fechadas, sugerindo uma exposição a fatores teratogênicos comuns entre os indivíduos acometidos ${ }^{(11)}$. A gastrosquise acomete mais frequentemente gestantes jovens, especialmente abaixo de 20 anos, e as diversas investigações demonstram enfaticamente que sua etiologia é multifatorial ${ }^{(12)}$. Portanto, são poucas as evidências de correlação com uma única causa genética e muitas são as evidências da ação de fatores ambientais teratogênicos associados ao estilo de vida dessas gestantes, em conjunto ou não com fatores genéticos ainda desconhecidos ${ }^{(13)}$.

A gastrosquise é uma malformação congênita que requer tratamento cirúrgico, imediatamente após o nascimento e apresenta riscos de morbidade e mortalidade tanto antenatal como pós-natal. Porém, se até 1970 a mortalidade das crianças com gastrosquise excedia 50\%, na atualidade, apresenta melhora no prognóstico neonatal com elevada taxa de sobrevida, aproximadamente $90 \%$, para os recém-nascidos acometidos ${ }^{(14-16)}$. Essa melhoria nas taxas de morbimortalidade se deve aos avanços na medicina fetal no acompanhamento destas gestações, às melhorias dos recursos de terapia intensiva neonatal, ao advento da nutrição parenteral, domínio das técnicas de ventilação mecânica de neonatos e ao 
aprimoramento das técnicas cirúrgicas e a introdução de próteses de silos sintéticos, a partir de 1968, para uso nos grandes defeitos da parede abdominal ${ }^{(17)}$.

Apesar disso, a morbimortalidade ainda se faz presente e parte dos pacientes evolui com complexo curso pós-natal. As principais complicações pós-natais desses RN não são devidas ao defeito da parede abdominal propriamente dito e sim à presença de complicações intestinais associadas à gastrosquise como áreas de atresia, volvo, perfuração, infarto, segmentos de necrose ou má-rotação ${ }^{(18,19)}$. A presença dessas patologias compromete o prognóstico neonatal, pois elas complicam o ato intra-operatório, podem levar à necessidade de ressecções intestinais extensas, com demorados períodos de internação, longo período de jejum oral e de uso extenso de nutrição parenteral prolongada (NPP), evolução para síndrome do intestino curto com consequente desidratação e má-absorção ${ }^{(20)}$, necessidade de reintervenções cirúrgicas $^{(21)}$. Ademais, o uso prolongado de NPP pode levar a danos hepáticos ${ }^{(22)}$.

Além dos riscos relacionados ao comprometimento intestinal, a morbimortalidade também está associada a fatores antenatais como: restrição de crescimento fetal $(\mathrm{RCF})$, parto prematuro, recém-nascido $(\mathrm{RN})$ de baixo-peso e baixo escore de Apgar ${ }^{(15,23)}$, assim como elevada taxa de óbito fetal (OF) inesperado $(12,5 \% \text { a } 14,3 \%)^{(19,24)}$.

Também contribuem para a morbidade e mortalidade fatores pós-natais como: presença de malformações intestinais associadas, longos períodos de hospitalização após a cirurgia, deixando os recém-nascidos susceptíveis à sepse de repetição, longo intervalo de tempo até iniciar a dieta via oral no pós-operatório, extenso uso de $\mathrm{NPP}^{(14,15)}$, hipoperistaltismo intestinal, necessidade de eventuais ressecções intestinais, múltiplas laparotomias e síndrome do intestino curto no pósoperatório $^{(16)}$.

Dentre as complicações intestinais, a atresia intestinal está presente em 5 a $15 \%$ dos pacientes com gastrosquise e é considerada indicador de mau prognóstico, já que leva à disfunção gastrointestinal com intolerância à dieta oral. Consequentemente essas crianças fazem uso prolongado de NPP, necessitam de maior tempo de internação hospitalar, evoluem com sepse recorrente devido à 
infecção do catéter venoso central utilizado para NPP, culminando em aumento da mortalidade ${ }^{(16,25-28)}$.

No pós-operatório o íleo prolongado, consequência dos danos causados na parede intestinal das alças exteriorizadas e expostas na vida intrauterina, também contribui para a morbidade ${ }^{(29)}$. Apresentação clínica freqüente, no período pósoperatório, é o prolongado tempo que leva para o início do trânsito intestinal, tornando esses recém-nascidos dependentes de NPP por semanas a meses, enquanto não iniciam a alimentação oral ${ }^{(30)}$, a fim de garantir o seu crescimento e desenvolvimento.

É considerado uso prolongado de NPP período maior/igual a 28 dias pelo "British Intestinal Failure Survey”(31), sendo que 40 a 60\% dessas crianças evoluem com quadro de hepatopatia que inclui esteatose hepática, colestase, colelitíase e fibrose hepática. Podem ainda, em uma minoria dos casos, progredir para cirrose hepática e desenvolver hipertensão portal e insuficiência hepática, sendo essa evolução mais comum em crianças e recém-nascidos do que em adultos usuários de $\mathrm{NPP}^{(32)}$.

Portanto, a morbidade e a mortalidade estão intimamente relacionadas às condições do intestino ao nascimento. Os RN portadores de gastrosquise com complicações intestinais associadas apresentam aumento de $10 \%$ para $28 \%$ na taxa de mortalidade, quando comparados aos casos sem patologias intestinais $\operatorname{associadas}^{(33)}$.

Há muito que se procuram dados antenatais, principalmente achados ultrassonográficos, que possam predizer a presença dessas patologias intestinais, ou que direcionem para o prognóstico neonatal e pós-cirúrgico nesses fetos.

A partir da década de 1980, alguns estudos sugerem que a dilatação das alças intestinais exteriorizadas e/ou intra-abdominais se relaciona com a presença de malformações intestinais ${ }^{(19,34)}$.

Séries observacionais relatam associação da mortalidade perinatal e aumento da morbidade nos fetos com alças intestinais dilatadas na ultrassonografia antenatal. Portanto, a presença de alças intestinais dilatadas pode comprometer o prognóstico fetal $^{(18,35)}$. 
Em estudo retrospectivo de dados longitudinais, foi demonstrada associação direta entre alças intestinais exteriorizadas dilatadas (considerado lúmen da alça $>25$ $\mathrm{mm}$ ) com complicações agudas como sofrimento fetal e óbito fetal, sugerindo necessidade de acompanhamento seriado da vitalidade desses fetos, principalmente, no terceiro trimestre da gestação, a fim de evitar desfechos inesperados ${ }^{(19)}$.

Muitos estudos investigam a associação entre dilatação da alça intestinal exteriorizada com o prognóstico neonatal. Alguns encontram associação ${ }^{(8,35-37)}$ outros, não ${ }^{(38,39)}$. Recente revisão sistemática de literatura demonstra resultados conflitantes e não chega a uma conclusão, pois a definição de dilatação de alça não é padronizada e os grupos populacionais utilizados foram pequenos ${ }^{(21)}$.

Assim, atualmente, a taxa de sucesso dessas gestações é controlada pelos cuidados de vigilância da vitalidade fetal, pelos cuidados perioperatórios e, principalmente, das condições do intestino ao nascimento (pela presença ou não de patologias intestinais associadas).

Apesar de a maioria dos estudos concluir que a dilatação das alças intestinais exteriorizadas e livres no líquido amniótico está associada à piora do prognóstico neonatal e pós-operatório, as maiores dificuldades estão em estabelecer claramente o que constitui dilatação significante e quais valores de corte devem ser usados como referência para direcionar a conduta obstétrica. Essa discussão tem relevante importância, pois há muito se debate qual o momento adequado para a realização do parto e se a presença de dilatação intestinal deveria ser critério para a antecipação do parto, mesmo submetendo-os aos riscos da prematuridade.

O desafio permanece em identificar, no período antenatal, quais fetos evoluem para pior prognóstico. A dilatação das alças intestinais exteriorizadas na ultrassonografia é tradicionalmente considerada fator relacionado a pior prognóstico neonatal, porém ainda não há consenso estabelecido sobre qual melhor valor de corte a ser utilizado. Assim, diante dessa lacuna na literatura e por esse serviço ser Centro de Referência de acompanhamento pré-natal e tratamento pós-natal dos fetos com gastrosquise, o presente estudo se propõe a avaliar a relação entre a dilatação de alças intestinais e o prognóstico fetal e pós-natal nos casos de gastrosquise isolada, 
atendidos no Hospital das Clínicas da Faculdade de Medicina da Universidade de São Paulo (HCFMUSP). 


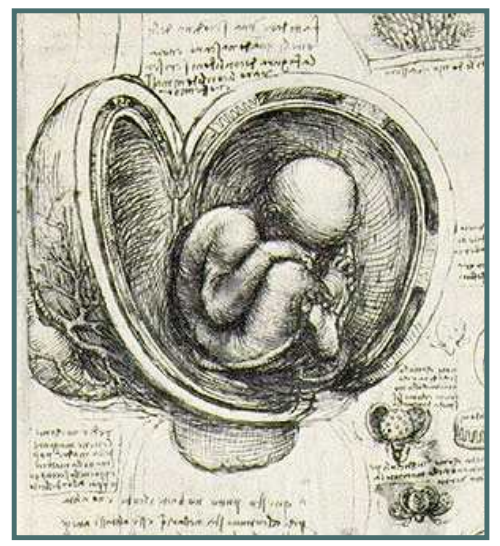




\subsection{DEFINIÇÃO}

Gastrosquise é uma anomalia congênita caracterizada por abertura na parede abdominal anterior, que compromete toda a espessura da parede e usualmente está localizada à direita da inserção do cordão umbilical em $95 \%$ dos $\operatorname{casos}^{(3)}$. Esse defeito de fechamento da parede leva à herniação e exposição do conteúdo abdominal para a cavidade amniótica, e as vísceras herniadas encontram-se livres no líquido amniótico, sem membrana peritoneal recobrindo o conteúdo exteriorizado (Figura 1). Frequentemente, se observa a presença do mesentério e de alças do intestino delgado livres no líquido amniótico e, menos comumente, pode-se encontrar exteriorizado o estômago, cólon, fígado e/ou bexiga ${ }^{(40)}$.

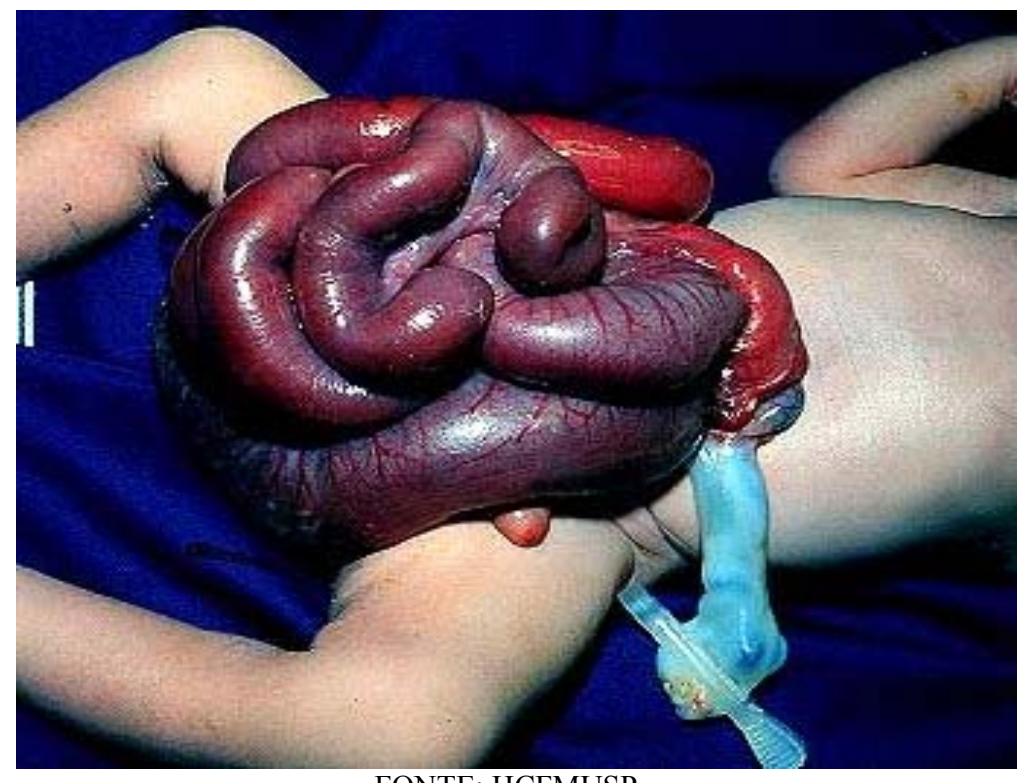

FONTE: HCFMUSP

Figura 1 - Apresentação clínica da gastrosquise em recém-nascido, com conteúdo visceral exteriorizado antes do procedimento cirúrgico corretivo 


\subsection{DADOS HISTÓRICOS}

A origem do nome gastrosquise é feminina, derivada do grego "stomach cleft" que significa literalmente "fenda no estômago" (Gastro: elemento formador de palavras que exprime a idéia de estômago ou de ventre - do grego gastér, trós significa estômago, ventre; - do grego schise significa fenda). No entanto, essa denominação é imprópria já que é a parede abdominal anterior que está fendida e não o estômago. Assim, alguns autores sugerem que o termo mais adequado seria laparosquise ("belly cleft") (33).

A história algumas vezes é incerta quanto às primeiras descrições da patologia. É dado a Calder o crédito por descrever detalhadamente pela primeira vez, em 1733, um caso de gastrosquise ${ }^{\mathrm{I}}$, conforme citado por Bax (1994), no livro Cirurgia do Recém-Nascido ${ }^{(41)}$. Porém, foi apenas, em 1904, que o termo gastrosquise foi proposto por Ballantyne II, apud Bax, a fim de denominar todos os defeitos da parede abdominal, com exceção da hérnia de cordão umbilical fisiológica ${ }^{(41)}$.

Em 1940, Bernstein descreve a gastrosquise corretamente e a distinguiu da onfalocele pela completa ausência de saco herniário e presença de cordão umbilical intacto ${ }^{\text {III }}$ conforme citado por Nyhus ${ }^{(42)}$.

Três anos depois, Watkins (1943) relata o primeiro caso de correção cirúrgica bem sucedida de gastrosquise, pela técnica de fechamento primário da parede abdominal $^{\mathrm{IV}}$, conforme citação do autor Fonkalsrud, no livro Hérnia ${ }^{(42)}$.

Dez anos mais tarde, Moore e Stokes propõem um sistema de classificação para diferenciar os defeitos da parede abdominal e redefinem o termo gastrosquise,

\footnotetext{
${ }^{\text {I }}$ Calder J. Two examples of children with preternatural conformation of the guts. Medical essays and observations. Medical Society of Edimburgh. 1733; 1(1): 203.

${ }^{\text {II }}$ Ballantyne, JW. Manual de Patologia e Higiene Antenatal. Edimburgo. 1904.

III Bernstein, P. Gastroschisis: a rare teratological condition in the newborn. Arch Pediatr. 1940;57:503.

IV Watkins, DE. Gastroschisis. Virginia Med Month. 1943;78:42.
} 
restringindo-o apenas aos defeitos ventrais da parede abdominal sem a presença de um saco recobrindo-os, diferenciando-a da onfalocele ${ }^{(43)}$.

Assim, embora tenha sido bem descrita, desde 1733, só foi claramente e oficialmente diferenciada dos outros defeitos de parede em 1953, dois séculos depois.

Em 2007, foi publicada a $10^{\mathrm{a}}$ versão do "International Classification of Diseases", no qual a gastrosquise foi oficialmente diferenciada da onfalocele como defeitos distintos em suas manifestações clínicas, tendo códigos diferentes a partir de então ${ }^{(44)}$.

\subsection{EMBRIOGÊNESE DA PAREDE ABDOMINAL E FORMAÇÃO DOS DEFEITOS DE FECHAMENTO DA PAREDE ABDOMINAL}

Entre a $4^{\mathrm{a}}$ e $5^{\mathrm{a}}$ semana de desenvolvimento, o pólo embrionário emite discos mesenquimais em quatro direções: cefálica, caudal, lateral direita e lateral esquerda. Cada disco converge em direção ao sítio do umbilicus, obliterando o celoma extraembrionário e formando o canal pleuroperitoneal, o qual é dividido em cavidade pleural e cavidade peritoneal pelo septo transverso ou diafragma (Figura 2). Os discos laterais formam a porção lateral da parede abdominal e a cefálica e a caudal formam o epigástrio e hipogástrio, respectivamente. $\mathrm{O}$ rápido desenvolvimento do intestino e do fígado ocorre ao mesmo tempo, e por essa razão, durante a $6^{\mathrm{a}}$ semana de desenvolvimento, a cavidade abdominal se torna temporariamente pequena demais para acomodar todo o seu conteúdo, levando à protrusão do intestino para dentro do celoma extraembrionário residual na base do cordão umbilical ${ }^{(45)}$ (Figura 3). Essa herniação temporária é chamada de hérnia fisiológica do intestino e é evidente à ultrassonografia realizada entre a $9^{\mathrm{a}}$ e a $11^{\mathrm{a}}$ semana de gestação. A redução dessa hérnia ocorre aproximadamente até a $12^{\mathrm{a}}$ semana, além do que deste período a herniação intestinal não é mais considerada como fisiológica ${ }^{(46)}$. 

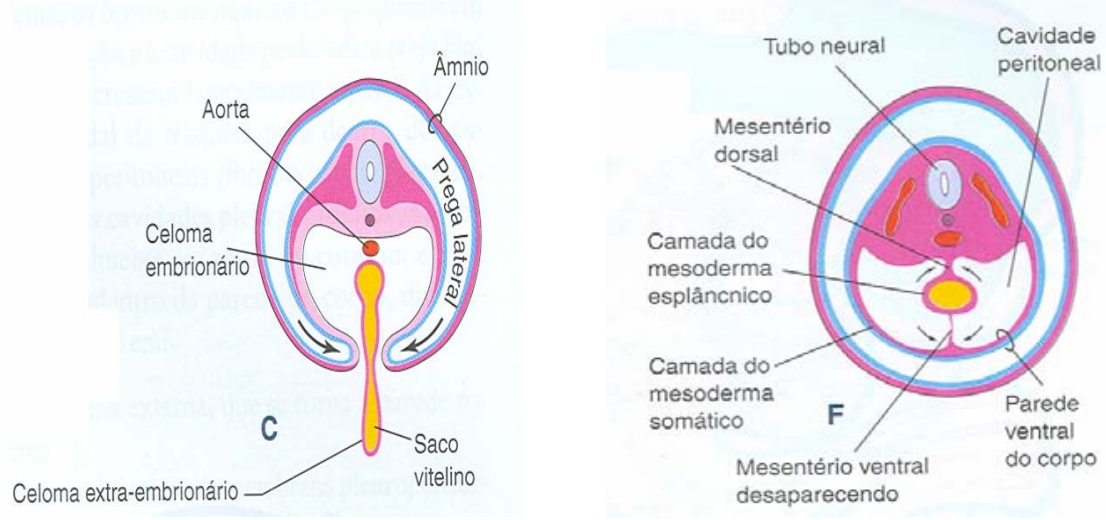

FONTE: Modificado de Moore \& Persaud, 2008 $8^{(47)}$

Figura 2 - Corte transverso do embrião mostrando a migração dos folhetos laterais em direção ao celoma extra-embrionário, obliterando-o

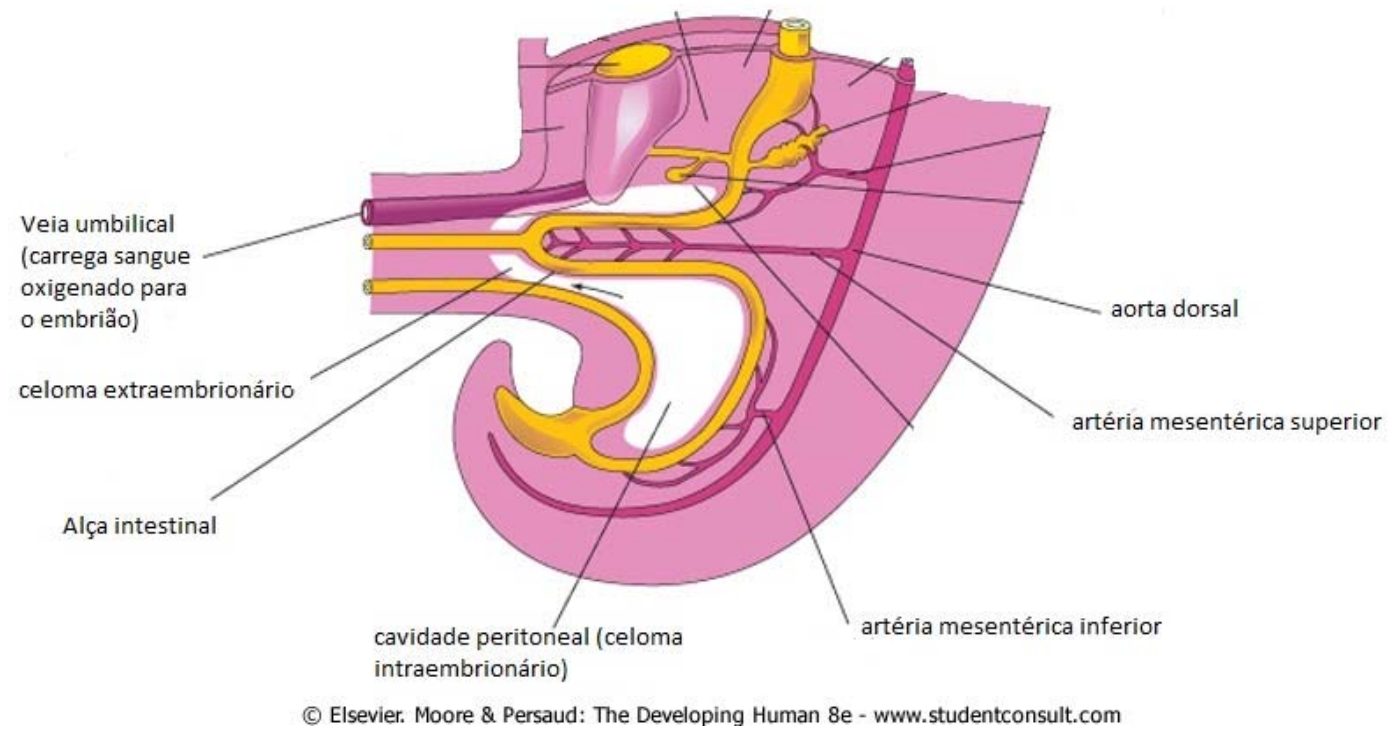

FONTE: Modificado de Moore \& Persaud, 2008 47 )

Figura 3 - $\quad$ Corte médio da metade caudal do embrião no final da $5^{\mathrm{a}}$ semana. A seta indica a comunicação da cavidade peritoneal com o celoma extraembrionário. Herniação fisiológica temporária do intestino em direção ao celoma extraembrionário na porção inicial do cordão umbilical 
Se o folheto lateral não completar todo o seu trajeto para encontrar a linha mediana, o resultado será o desenvolvimento da onfalocele. Se o intestino falhar em retornar à cavidade peritoneal, o recém-nascido apresentará hérnia de cordão umbilical. Como a patogenia da gastrosquise permanece desconhecida, algumas teorias foram propostas.

Inicialmente, o embrião humano possui a veia umbilical direita e esquerda. A veia umbilical direita involui entre o $28^{\circ}$ e $32^{\circ}$ dias pós-concepção e as veias toracoepigástrica e cardinal caudal assumem a sua função. Paralelamente, as artérias onfalomesentéricas (AOM) são um par e funcionam como um plexo de vasos na vida embrionária incipiente, originárias da aorta dorsal. A AOM esquerda involui e a direita persiste como artéria mesentérica superior proximal. A porção distal da AOM direita então passará fora do anel umbilical ao longo e ao lado do intestino, enquanto este permanece herniado fisiologicamente até a $12^{\mathrm{a}}$ semana de gestação ${ }^{(48)}$.

As teorias descritas relacionadas à gastrosquise são:

\section{1- Anomalias da veia umbilical direita ou da artéria onfalomesentérica: o} defeito surgiria no local da involução da veia umbilical direita, pois a debilidade da membrana umbilical no local da reabsorção da veia umbilical direita pode evoluir para uma hérnia, e no caso, de ruptura da membrana, após o infarto dessa região o intestino herniaria por meio da parede abdominal necrosada em direção à cavidade amniótica (Figura 4). Tanto a involução precoce da veia umbilical direita (raramente a esquerda) como qualquer interrupção no fluxo sanguíneo da AOM direita poderiam levar a esse tipo de lesão ${ }^{(49)}$. A involução prematura da veia umbilical direita (antes da circulação colateral estar estabelecida) pode levar à isquemia, resultando em defeitos ectodérmicos e mesodérmicos. Já a interrupção no fluxo distal da AOM direita pode também resultar em isquemia paraumbilical à direita, levando ao defeito clássico paramediano da gastrosquise $^{(49)}$. Tal acidente vascular comprometeria toda a extensão da parede. A teoria é apoiada pela observação de que a gastrosquise, na maioria dos casos, ocorre no lado direito do cordão umbilical.

Além disso, a isquemia da AOM superior parece estar relacionada com a atresia jejunal, frequentemente, associada à gastrosquise ${ }^{(48)}$. Isso leva ao questionamento 
se as atresias intestinais são lesões secundárias ao comprometimento vascular ou ao estrangulamento do intestino no anel herniário como já proposto ${ }^{(50)}$.
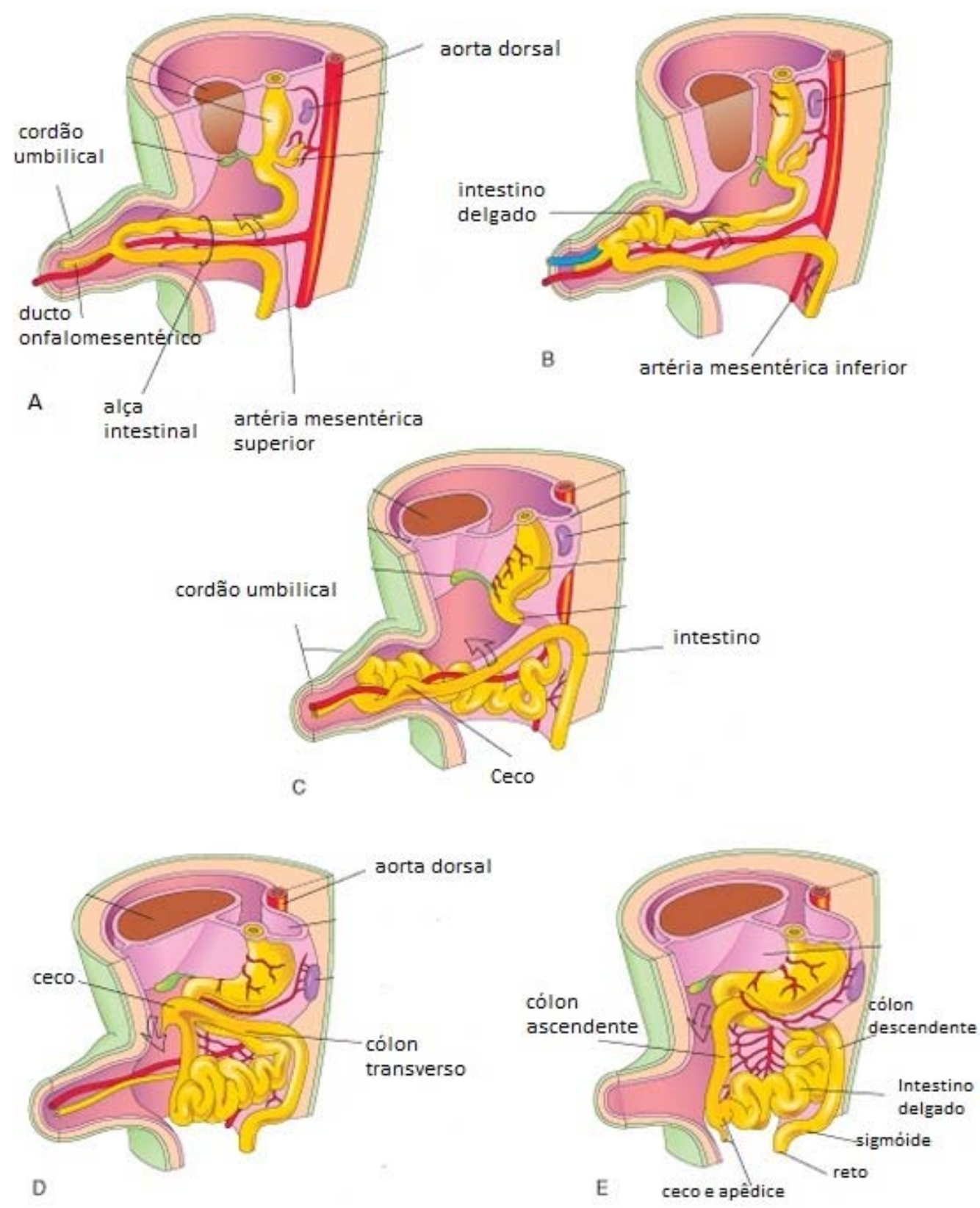

(C) Elsevier. Moore \& Persaud: The Developing Human $8 \mathrm{e}$ - www.studentconsult.com FONTE: Modificado de Moore \& Persaud, 2008 ${ }^{(47)}$

Figura 4 - Corte longitudinal do embrião mostrando artéria mesentérica superior, que faz parte do pedículo vascular e acompanha o intestino herniado, e a veia umbilical $(\mathrm{A}, \mathrm{B}, \mathrm{C})$. Retorno do intestino para a cavidade abdominal $(\mathrm{D}, \mathrm{E})$ 
2- Rotura da artéria vitelínica: essa artéria faz parte do pedículo vitelínico que comunica o intestino médio com o saco vitelínico, carrega sangue do embrião para o saco vitelínico. Uma interrupção anômala ou incipiente em seu fluxo pode levar à subsequente dano na parede corporal e herniação intestinal ${ }^{(47)}$ (Figura5).

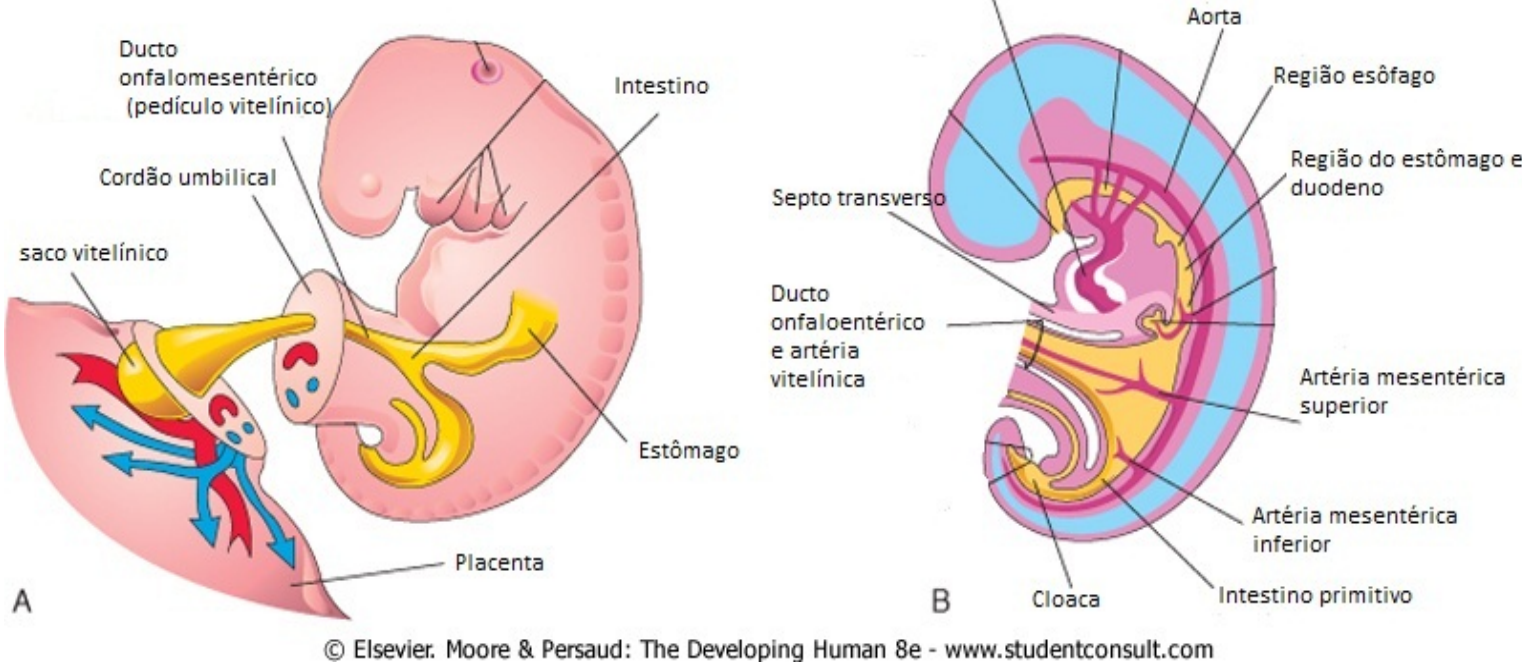

FONTE: Modificado de Moore \& Persaud, 2008 $8^{(47)}$

Figura 5 - Corte mediano do embrião na $4^{\mathrm{a}}$ semana mostrando o sistema digestório e sua vascularização, como a artéria vitelínica (B). O intestino primitivo é um tubo longo que se estende por todo o comprimento do embrião e se comunica com o saco vitelínico pelo pedículo vitelínico (A)

3- Rotura intrauterina de hérnia fisiológica do cordão umbilical ou de uma pequena onfalocele: a herniação que ocorre enquanto o intestino ocupa a cavidade celômica extraembrionária, entre a $5^{\mathrm{a}}$ e a $10^{\mathrm{a}}$ semana do desenvolvimento, leva à formação de uma fraca área na base do cordão umbilical, devido à regressão da veia umbilical na $6^{\mathrm{a}}$ semana de gestação nesse local. Shaw ${ }^{(50)}$ foi o primeiro a propor que a gastrosquise seria resultado da rotura intraútero dessa membrana amniótica, na base da hérnia fisiológica do cordão umbilical, poderia acontecer precocemente após o desenvolvimento do músculo abdominal e dobramento interno da parede abdominal, mas antes do fechamento completo do anel umbilical, entre a $5^{\mathrm{a}}$ e a $10^{\mathrm{a}}$ semana de gestação ou até mesmo 
depois disso, mais tardiamente, naqueles casos em que houve falha no fechamento normal do anel umbilical. Essa teoria é apoiada pela observação de que a maioria dos defeitos ocorre no lado direito do cordão umbilical, além de que, segundo esse mesmo autor, o cordão umbilical não estaria adequadamente formado nesses fetos ${ }^{(50)}$. Essa hipótese também é fortalecida tanto pela associação com a não rotação intestinal, que acontece nesses casos, como por relato de caso de gastrosquise identificada apenas na $34^{\mathrm{a}}$ semana de gestação em feto que sete semanas antes tinha diagnóstico ultrassonográfico de hérnia umbilical. Tanto o intestino grosso como o delgado sofrem herniação e a quantidade de intestino eviscerado é variável, pode ser extensa porque o intestino ainda não sofreu rotação e fixação dos mesentérios completamente ${ }^{(51)}$.

4- Rotura da somatopleura paraumbilical: segundo De Vries, a gastrosquise resulta de ruptura da somatopleura paraumbilical (lateral) ao cordão umbilical, mas não representa uma onfalocele $\operatorname{rota}^{\mathrm{I}}$, conforme citado por Nyhus no livro Hérnia $^{(42)}$.

5- Evento teratogênico: Duhamel (1963), apud Nyhus ${ }^{(42)}$, sugere que a ação de agentes teratogênicos, no estágio inicial da gestação ( $8^{\mathrm{a}}$ semana), poderia impedir a diferenciação do mesênquima que forma as bordas da somatopleura, daí o defeito estar adjacente à cicatriz umbilical ${ }^{\mathrm{II}}$. Porém, a falha dessa teoria está na ausência de defeito da musculatura dos retos abdominais ${ }^{(2)}$.

\footnotetext{
${ }^{\text {I }}$ De Vries, PA. The pathogenesis of gastroschisis and omphalocele. J Pediatr Surg. 1980;15:245.

${ }^{\text {II }}$ Duhamel, B. Embriology of exomphalos and allied malformations. Arch Dis Child. 1963; 38: 138.
} 


\subsection{INCIDÊNCIA DA GASTROSQUISE}

A incidência de gastrosquise descrita na literatura é variável de acordo com a região geográfica estudada (Tabela 1) e com a idade materna ${ }^{(52)}$.

Tabela 1 - Estudos epidemiológicos com incidência de gastrosquise

\begin{tabular}{|c|c|c|c|}
\hline Autor/ Ano & Região Geográfica & Período do estudo & $\begin{array}{l}\text { Prevalência média } \\
\text { de gastrosquise }\end{array}$ \\
\hline Rankin, J/1999 & Norte da Inglaterra & 1986-1996 & $2,98 / 10.000 \mathrm{NV}$ \\
\hline Nazer, J/2001 $1^{(54)}$ & Chile & 1982-1997 & $1,24 / 14.000 \mathrm{NV}$ \\
\hline Canfield, MA/2006 $6^{(55)}$ & EUA & $1999-2011$ & $3,3 / 10.000 \mathrm{NV}$ \\
\hline Loane $M / 2007^{(10)}$ & Europa & $1980-2002$ & $1,62 / 10.000 \mathrm{NV}$ \\
\hline Fillingham, A/2008 & Norte da Inglaterra & $1997-2006$ & $4,28 / 10.000 \mathrm{NV}$ \\
\hline ECLAMC $/ 2008^{(57)}$ & América do Sul & 2006 & $1,43 / 10.000 \mathrm{NV}$ \\
\hline Mac Bird T/2009* (58) & EUA & $1997-2003$ & $4,28 / 10.000 \mathrm{NV}$ \\
\hline Benjamin,BG/2009 $9^{(59)}$ & Texas & $1993-2003$ & $4,18 / 10.000 \mathrm{NV}$ \\
\hline Whitehall, JS/2010 ${ }^{(60)}$ & Austrália & $1988-2007$ & $3,2 / 10.000 \mathrm{NV}$ \\
\hline $\mathrm{Xu}, \mathrm{LL} / 2011^{(61)}$ & China & $1996-2007$ & $2,54 / 10.000 \mathrm{NV}$ \\
\hline
\end{tabular}

NOTA: $\left({ }^{*}\right)=$ Arkansas, Califórnia, Carolina do Norte, Georgia, Iowa, Massachusetts, Nova York, Nova Jersey, Texas e Vermont

Em estudo de meta-análise (2000), avaliando 18 artigos publicados no período de duas décadas, a prevalência média de gastrosquise foi de 1,36/10.000 NV (variando de 0,4 a 3,01), número esse que sobe para 1,95/10.000, quando se inclui os abortamentos e cai para 1,06/10.000, quando apenas os nativivos são considerados ${ }^{(2)}$.

O órgão Estudio Colaborativo Latino Americano de Malformaciones Congénitas (ECLAMC) foi criado em 1967 e pertence à Organização Mundial de Saúde. É um programa de investigação clínica e realiza estudos epidemiológicos das anomalias congênitas nos hospitais dos países latino-americanos; atuando no Brasil, em conjunto com o Instituto Oswaldo Cruz, no Rio de Janeiro. Em estudo realizado por esse órgão, no período entre 1995 a 2008, os autores observaram que, no Brasil, ocorreram: 517.842 nascimentos (510.402 NV e 7.440 natimortos), 21.557 
malformações congênitas (20.455 malformações congênitas em NV e 1.102 malformações congênitas em natimortos). A incidência de gastrosquise, no Brasil, no período de 1995-2008, foi de 7,5/10.000 $\mathrm{NV}^{(62)}$.

A variação da incidência, relatada pelos diferentes estudos, pode ser devido ao aumento da prevalência desse defeito, nas últimas três décadas, por razões ainda não esclarecidas. Diversos autores referem esse aumento tanto nos países desenvolvidos como naqueles em desenvolvimento ${ }^{(1,63,64)}$, como nas Américas do Norte, Central e Sul, Austrália, Japão e Europa ${ }^{(9,10,65-67)}$, com exceção da Itália ${ }^{(68)}$. Maiores aumentos de incidência são descritos no México (de 1,44 para 5,11/10.000 NV - 1980 a 2003), oeste da Austrália (de 1,53 para 4,30/10.000 NV - 1980 a 2003), Paris (de 0,18 para 3,44/10.000 NV - 1981 a 2003), América do Sul (de 0,04 para 2,92/10.000 NV - 1974 a 2003) e Noruega (de 1,34 para 2,74/10.000 NV - 1974 a $2003)^{(68)}$.

Loane et al. utilizam os registros da EUROCAT (European surveillance of congenital anomalies) e analisam 936 casos de gastrosquise, referentes a nascimentos do período entre 1980 e 2002, envolvendo 15 países europeus e observam aumento na incidência da referida malformação em todas as idades maternas, de 0,54/10.000 NV entre os anos de 1980 e 1984, para 2,12/10.000 NV, entre 2000 e $2002^{(10)}$. Apesar de o maior número de casos acometer a população jovem, especialmente abaixo de 20 anos, o fenômeno de aumento de incidência não está restrito a essa faixa etária, abrange todas as idades maternas em todos os tempos (10).

Rankin et al. estudam a prevalência de gastrosquise, no Norte da Inglaterra, entre 1986 e 1996, relatam aumento na incidência de casos de 1,48/10.000 NV, em 1986, para 5,29/10.000 NV, em $1996^{(53)}$. Semelhante estudo realizado no Norte da Califórnia, EUA, identifica pico de incidência de 4,49/10.000 NV, no ano de $2000^{(69)}$.

Similarmente, o banco de dados do "California Birth Defects Monitoring Program” mostra aumento de três vezes na prevalência de gastrosquise entre os anos de 1987 e 2003 , nesse estado americano ${ }^{(63)}$. 
Revisão detalhada da incidência de gastrosquise e onfalocele executada pelo "National Congenital Malformation Notification Scheme", na Inglaterra e no País de Gales, entre 1987 e 1993, observa que a incidência de gastrosquise dobrou nos primeiros cinco anos do estudo, com maior frequência encontrada de 1,35/10.000 NV em $1991^{(1)}$.

Fillingham e Rankin revisam os nascimentos registrados entre 1997 e 2006 da base de dados do Norte da Inglaterra ("Northern Congenital Abnormality Survey") e observam aumento da prevalência de gastrosquise de 3,04/10.000 NV, em 1997, para 4,62/10.000 NV, em 2006. A taxa mais baixa foi observada em $2000(2,69 / 10.000$ $\mathrm{NV})$ e a mais alta em $2004(6,41 / 10.000 \mathrm{NV})^{(56)}$.

A incidência dessa anomalia apresenta variação de acordo com a localização geográfica no mesmo continente ${ }^{(52)}$. Estudo populacional encontra prevalência de 4,48 casos de gastrosquise por 10.000 NV em Mainz, Alemanha, comparado com 0,31/10.000 NV na Toscana, Itália. Os autores referem maiores incidências em Paris (França), Mainz (Alemanha), Finlândia, País de Gales e Trent (Reino Unido), comparado aos que margeiam o Mediterrâneo como Espanha, Itália e Sul de Portugal $^{(10)}$.

$\mathrm{Na}$ China se mostra mais comuns nas áreas rurais que nas urbanas ${ }^{(61)}$.

Os estudos demonstram que diferenças de incidência não acontecem apenas entre países diferentes, mas também entre diferentes regiões de um mesmo país ${ }^{(70)}$, por exemplo, é mais frequente na região norte do Reino Unido (1,55/10.000 NV) que na sudeste $(0,72 / 10.000 \mathrm{NV})^{(1)}$.

A gastrosquise apresenta distribuição semelhante entre os sexos ${ }^{(1,28,68)}$ e é considerada a malformação congênita cirúrgica mais comum ${ }^{(53)}$.

Em relação à etnia, a caucasiana é relatada como fator de risco ${ }^{(28)}$. Mães brancas $^{(71)}$ e as de origem hispânica ${ }^{(13,55)}$ apresentam maior risco de acometimento em relação às mães negras ou afroamericanas. Mães brancas não-hispânicas e hispânicas nascidas nos EUA apresentam maior taxa de acometimento que as mães negras e hispânicas estrangeiras ${ }^{(63)}$. 
$\mathrm{Na}$ Austrália, a incidência também se mostra variável entre as raças, sendo maior entre as mães aborígenes ou indígenas $(6,6 / 10.000 \mathrm{NV})$ que nas brancas $(2,6$ por $10.000 \mathrm{NV}$ ). Acredita-se que a razão para essa maior incidência, no grupo indígena, esteja relacionada à desvantagem socioeconômica desse grupo ${ }^{(60)}$. O baixo nível socioeconômico foi associado à gastrosquise anteriormente ${ }^{(72)}$.

\subsection{ASPECTOS EPIDEMIOLÓGICOS DA GASTROSQUISE}

Os estudos têm consistentemente associado gastrosquise a mulheres jovens, especialmente abaixo de $20 \operatorname{anos}^{(13,56,64,73)}$. Na Austrália, a incidência de gastrosquise entre mulheres abaixo de 20 anos é de 12,1/10.000 NV, para aquelas entre 20-24 anos é de 6,3/10.000 NV e de 1,7/10.000 NV para o grupo com idade materna entre 24-29 $\operatorname{anos}^{(60)}$.

No Reino Unido, a incidência de gastrosquise em mulheres com idade entre 30 e 34 anos é de 0,26/10.000 NV, já naquelas abaixo de 20 anos é de 4,71/10.000 $\mathrm{NV}^{(2)}$. Estudo semelhante realizado na região norte no mesmo país em 2008, encontra a maior incidência em mulheres abaixo de 20 anos $(18,6 / 10.000 \mathrm{NV})$ e a menor nas com mais de 30 anos $(0,66 / 10.000 \mathrm{NV})^{(56)}$.

Durante os anos de 1995-2002, nos registros de 25 países europeus, a prevalência de gastrosquise em mulheres abaixo de 20 anos é de 7 vezes a prevalência entre as mães entre 25-29 anos. Nesse mesmo período, gestantes com idade entre 20-24 anos tinham chance duas vezes maior de ter feto acometido que aquelas entre 25-29 anos. A maioria dos RNs (58\%) desse período nasceram de mães com menos de 25 anos de idade ${ }^{(10)}$.

Estudo populacional realizado na China encontra incidência de 11,43 vezes maior em mulheres abaixo de 20 anos do que naquelas entre 30 e $34 \operatorname{anos}^{(61)}$.

Mais de $60 \%$ dos casos de gastrosquise são de gestantes com idade materna abaixo dos 20 anos e mais de $50 \%$ primigestas ${ }^{(29)}$. Primigestas são referidas como fatores de risco por alguns autores, enquanto nas multíparas o risco é menor ${ }^{(74,75)}$. 
Estudo recente (2011) realizado no estado de Washington, durante o período de 1987-2006, encontra diferença significante para gastrosquise em mães jovens $(<25$ anos) [Risco Relativo $(\mathrm{RR})=8,02$; intervalo de confiança (IC) $95 \%=5,3$ $12,1]$ e em mulheres tabagistas $(\mathrm{RR}=1,58 \text {; IC 95\% }=1,19-2,09)^{(71)}$.

A associação de gastrosquise com idade materna jovem parece estar relacionada com estilo de vida, fatores de exposição ambiental e/ou fatores biológicos. Os fatores de risco para gastrosquise incluem: baixo nível socioeconômico $^{(2,76,77)}$, tabagismo, uso de aspirina e drogas ilícitas durante o período perigestacional e na gestação, dieta materna inadequada e baixo índice de massa corpórea ${ }^{(78-81)}$. Entretanto, fatores de confusão com outros agentes teratogênicos também podem estar presentes nos estudos ${ }^{(2)}$.

Medicamentos (ácido acetilsalicílico) e drogas ilícitas com propriedades vasoconstritoras (cocaína, anfetamina e "ecstasy"), quando utilizadas no período peri-concepcional ou durante o primeiro trimestre da gestação, podem levar a acidente vascular, ainda no período embrionário, resultando em interrupção precoce da artéria onfalomesentérica, que vasculariza a parede abdominal ${ }^{(82)}$. Apesar de associados com aumento na incidência de gastrosquise, nenhum deles foi confirmado como a causa isolada, sendo considerados fatores de risco, tais como: ácido acetilsalicílico, descongestionantes nasais, anticoncepcional oral ${ }^{(83)}$, drogas ilícitas como a maconha, cocaína, anfetamina e "ecstasy"(74,76), principalmente quando o uso é combinado ${ }^{(82)}$. O consumo de álcool em altas doses e tabaco também parecem estar associados com esse defeito da parede abdominal, pois o álcool pode atravessar a barreira placentária e afetar a circulação umbilical ${ }^{(84)}$. O fumo também atua causando vasoconstrição e vasoespasmo placentário, levando a efeitos deletérios na circulação fetoplacentária $^{(74,78,79)}$. Os resultados apresentados na literatura ainda são controversos, já que nem todos os autores observam associação entre eles ${ }^{(74)}$.

Richardson et al. (2011) utilizam dados do National Birth Defects Prevention Study (grande estudo caso-controle multicêntrico com centrais locadas em 10 estados norte-americanos) dos nascimentos ocorridos entre 1997-2005 (6622 controles e 1768 recém-nascidos com malformações congênitas, sendo destes, 720 casos de gastrosquise) e revelam associação estatisticamente significante entre consumo 
periconcepcional de álcool ( $1^{\circ}$ mês antes da gestação até o $3^{\circ}$ mês de gestação) e gastrosquise $\left[\mathrm{OR}\left(\right.\right.$ Odds ratio) $=1,40 ;$ IC 95\%: 1, 17-1,67] ${ }^{(85)}$.

Forrester et al., ao prepararem os dados anuais para o "Hawaii Birth Defects Program" (registro populacional do estado do Hawaí), observam aumento no uso de drogas ilícitas no período pré-natal nos partos ocorridos entre 1986 e 2002. Os autores comparam o uso de drogas ilícitas com a incidência de gastrosquise e observam que o uso de maconha, durante o período pré-gestacional e gestacional, é significativamente maior nos casos de gastrosquise que na população geral. Porém, o uso de cocaína e anfetamina não difere significativamente da população geral ${ }^{(86)}$. Recente metanálise (2010) refere seis estudos que confirmam uso de drogas ilícitas (incluindo maconha, cocaína e metanfetamina), durante a gestação, como fator de risco significante para gastrosquise ${ }^{(13)}$.

Werler et al., em estudo caso-controle, comparam o uso de drogas vasoativas, no primeiro trimestre da gestação, em 76 casos de gastrosquise com 2142 controles (com outras malformações maiores) e encontram risco significantemente elevado para o uso de pseudoefedrina de 3,2 (IC 95\% $=1,3-7,7)^{(84)}$. Riscos relativos para analgésicos / antitérmicos e outros descongestionantes foram encontrados: salicilatos 1,6 (0,9-2,7), acetaminofem 1,7 (1,0-2,9), ibuprofeno $1,3 \quad(0,4-3,7) \quad$ e fenilpropanolamina de $1,5(0,4-5,4)$. Os autores não encontram risco elevado para o uso de anti-histamínicos, antibióticos, espermicida e anticoncepcional oral ${ }^{(84)}$.

Os mesmos autores analisam os dados coletados do programa do "Boston University Birth Defects” de 76 casos de gastrosquise e 2581 casos com outras malformações congênitas (1976-1990). Análise multivariada mostra aumento do risco para gastrosquise diretamente proporcional ao consumo de álcool. Não encontram aumento do risco para gastrosquise com: tabagismo, consumo de café, gestação não planejada, 12 anos ou menos de educação, antecedente obstétrico de dois ou mais partos, sangramento vaginal, náuseas e vômitos, resfriados ou outras infecções, história prévia de abortamento eletivo ou espontâneo ${ }^{(74)}$.

Torfs et al. avaliam os riscos associados ao uso de medicamentos e exposição ocupacional ou por "hobby" no primeiro trimestre da gestação, comparam 110 casos de gastrosquise com 220 controles sem defeitos congênitos. Encontram diferença 
significativa para o contato, ocupacional ou por "hobby", com níveis elevados de solventes [odds ratio $(\mathrm{OR})=3,8$; IC $95 \%=1,6-9,2$ ] e corantes $(\mathrm{OR}=2,3$; IC 95\% $=$ 1,3-4,0). Exposição periconcepcional aos raios-X também se mostrou associado à gastrosquise ( $\mathrm{OR}=2,5$; IC 95\% = 1,2-5,5). Quanto aos medicamentos, observam risco elevado para duas drogas fortemente inibidoras da ciclooxigenase, a aspirina $(\mathrm{OR}=4,7 ; \mathrm{IC} 95 \%=1,2-18,1)$ e o ibuprofeno $(\mathrm{OR}=4,0 ; \mathrm{IC} 95 \%=1,0-16,0)$, mas não para o acetoaminofem, um fraco inibidor da ciclooxigenase. Quanto aos descongestionantes nasais, mostram risco elevado a pseudoefedrina $(\mathrm{OR}=2,1$; IC $95 \%=0,8-5,5)$, a fenilpropanolamina $(\mathrm{OR}=10,0 ;$ IC $95 \%=1,2-85,6)$ e a efedrina $(\mathrm{OR}=2,4 ;$ IC $95 \%=1,0-5,4)$. Antibióticos, antieméticos, sulfonamidas e contraceptivos orais não aumentam o risco para gastrosquise ${ }^{(80)}$.

Outras características em comum encontradas entre as jovens mães dos RNs acometidos são: baixo nível socioeconômico, baixo índice de massa corporal (IMC) e consumo de álcool durante a gestação ${ }^{(87)}$. Acredita-se que essas associações devemse ao estilo de vida que caracteriza a população jovem (como hábito de fumar, uso de drogas ilícitas como a maconha, o baixo IMC, ingestão de álcool em excesso e infecções urinárias de repetição) ${ }^{(58,82,83,87,88)}$. Metanálise observa que os estudos apresentam dados conflitantes referentes a tabagismo e consumo de álcool, durante a gestação, o que dificulta a classificação desses hábitos de vida como fatores de $\operatorname{risco}^{(13)}$.

Baseado em levantamento populacional do "California Birth Defects Monitoring Program”, Torfs et al. analisam 110 mães cujos fetos eram portadores de gastrosquise e 220 mães de fetos normais, sendo que as idades maternas foram pareadas entre os grupos. Análise univariada mostra associação significante com o nível educacional da mãe, estado civil irregular (não-casada ou instável), renda anual familiar, história de tabagismo da mãe da gestante, ausência materna ou paterna durante fase inicial da adolescência da gestante, mais de um abortamento eletivo, curto intervalo de tempo entre menarca e primeira gestação, irmãos de pais diferentes e uso de drogas "recreativas" (como cocaína, anfetamina, maconha e LSD), álcool ou cigarro durante o primeiro trimestre de gestação. A associação com gastrosquise se mostrou mais forte quando a gestante era usuária de mais de uma droga (cocaína, anfetamina e maconha) do que o uso isolado e também se ambos eram usuários, 
gestante e pai. Análise logística e condicional multivariada mostrou OR significante (IC 95\%) para: renda familiar anual $<\$ 10.000[\mathrm{OR}=4,34(1,54-12,22)]$ ou $\$ 10.000$ - \$49.999 [OR = 3,93 (1,43-10,80)]; ausência de pai e mãe durante adolescência [OR $=3,11(1,14-8,46)]$; e uso de drogas ilícitas pela gestante [OR = 2,21 (1,21-4,03)], pelo pai do concepto $[\mathrm{OR}=1,66(1,02-2,69)]$, ou ambos $\left[\mathrm{OR}=3,05(1,48-6,28)^{(77)}\right.$.

O baixo IMC, baixo ganho de peso durante a gestação e/ou nutrição inadequada estão associados com a gastrosquise fetal, enquanto a obesidade materna parece ter papel protetor, bem como a ingestão de vitaminas suplementares parece diminuir o risco dessa anomalia, pois têm papel na imaturidade biológica ${ }^{(13)}$.

Torfs et al. (1998) procuram relação entre estado nutricional materno e gastrosquise em 55 gestantes com fetos portadores de gastrosquise e 182 controles. A avaliação do estado nutricional pré-gestacional foi realizada por questionários alimentares e rastreou 38 nutrientes identificados como mais associados à gastrosquise. Análise univariada evidenciou aumento no risco para dietas pobres em $\alpha$-caroteno $(\mathrm{OR}=4,6$; IC 95\% $=2,2-9,5)$, beta-caroteno $(\mathrm{OR}=3,1 ; \mathrm{IC} 95 \%=1,6-$ 6,0); aminoácidos essenciais como glutationa ( $\mathrm{OR}=3,5$; IC 95\% = 1,7-7,2); vitamina $\mathrm{C}(\mathrm{OR}=2,2 ; \mathrm{IC} 95 \%=1,5-7,8)$; vitamina $\mathrm{E}(\mathrm{OR}=2,3 ; \mathrm{IC} 95 \%=1,2-4,4)$; minerais, fibras e grupo frutas-vegetais $(\mathrm{OR}=3,1$; IC $95 \%=1,5-6,2)$. Análise multivariada com os vários nutrientes mostrou maior associação com gastrosquise e pequena quantidade de $\alpha$-caroteno na dieta $(\mathrm{OR}=4,3$; IC 95\% $=1,9-9,8)$, pequena quantidade de glutationa ( $\mathrm{OR}=3,3$; IC $95 \%=1,4-7,6)$, e altas concentrações de nitrosaminas $(\mathrm{OR}=2,6 \text {; IC } 95 \%=1,3-5,4)^{(89)}$.

Apesar de a gastrosquise ser considerada evento esporádico, alguns autores descrevem recorrência familiar ${ }^{(90,91)}$. Em estudo populacional da Califórnia (1987), os autores observam que seis $(4,7 \%)$ de 127 famílias relatam mais de um filho acometido e referem risco de recorrência de $3,5 \%{ }^{(92)}$.

Hwang e Koussef encontram três casos familiares entre 121 avaliados, que corresponde a risco de recorrência de $2,4 \%{ }^{(9)}$. Semelhante taxa de recorrência $(2,4 \%)$ foi encontrada em recente estudo de Kohl et al. (2010), baseado no registro populacional de nascimentos “Mainz Model” e, em revisão sistemática de literatura, 
os autores alertam para a forte tendência da literatura investigativa em subestimar a taxa de recorrência ${ }^{(93)}$.

Apesar de a etiologia da gastrosquise ser incerta, acredita-se que está relacionada aos fatores ambientais, ao meio social e ao estilo de vida, sendo que os fatores genéticos ainda estão em discussão, como o primeiro gene candidato envolvido (BPM-1) $)^{(3)}$. Assim, não necessariamente precisa haver uma causa genética para explicar o envolvimento familiar, já que os membros familiares geralmente partilham de condição socioeconômica semelhante e convivem no mesmo meioambiente, ou pelo menos semelhante. A solução das diferenças de prevalência entre as diferentes raças e diferentes regiões geográficas pode estar nesses aspectos ${ }^{(93)}$.

\subsection{DIAGNÓSTICO ULTRASSONOGRÁFICO DA GASTROSQUISE}

Ao exame ultrassonográfico, é possível visualizar o defeito de fechamento da parede abdominal, com uma abertura, na maioria das vezes, pequena (aproximadamente $<2-3 \mathrm{~cm}$ ), localizada geralmente ao lado direito do cordão umbilical $^{(41,94)}$. Por meio dessa abertura, visualiza-se protrusão dos órgãos abdominais, mais frequentemente, uma quantidade variável de alças intestinais e menos frequentemente, se identifica parte do estômago e/ou do fígado exteriorizados $^{(41)}$ (Figura 6). As alças livres no líquido amniótico podem ter as suas paredes edemaciadas e o lúmen dilatado. 


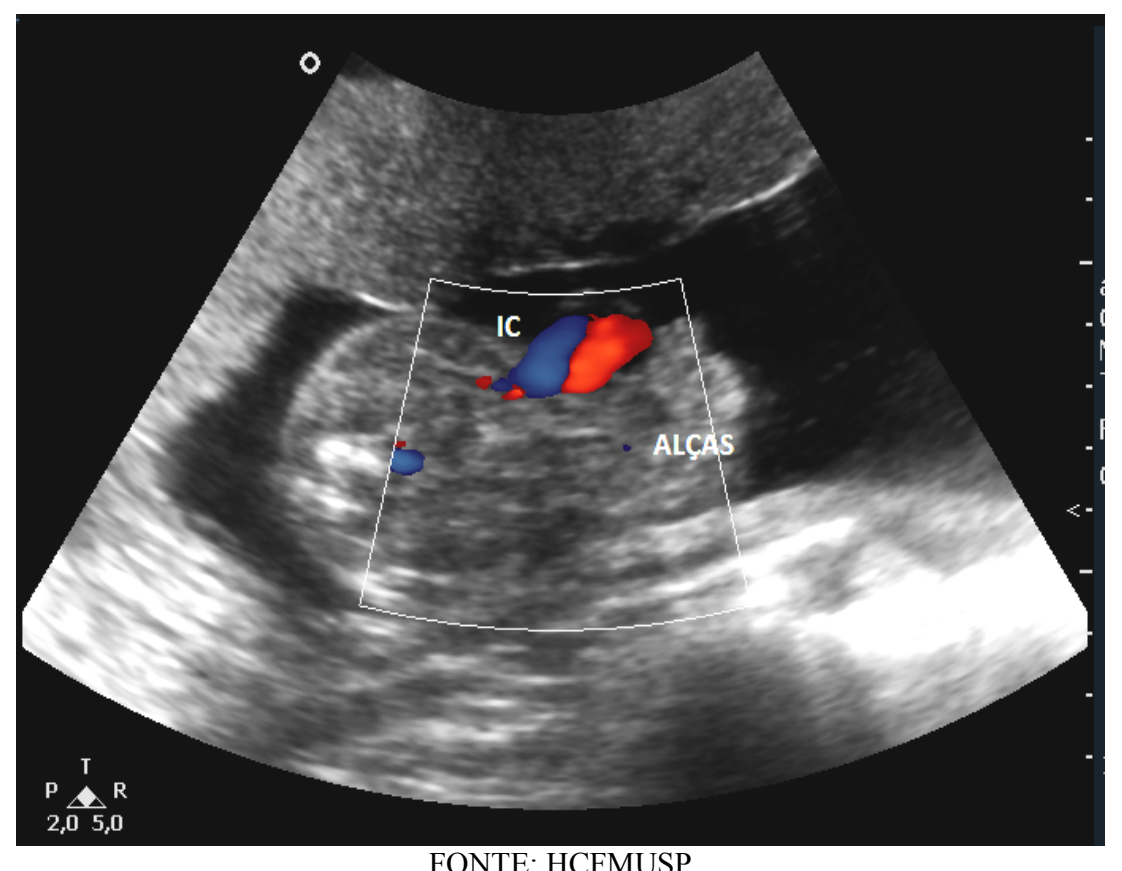

Figura 6 - Aspecto ultrassonográfico de gastrosquise no segundo trimestre de gestação, abertura na parede abdominal localizada à direita da inserção do cordão umbilical (IC). Alças intestinais herniadas pela abertura sem membrana peritoneal recobrindo-as

A figura 7 mostra imagem ultrassonográfica de feto sem gastrosquise, com parede abdominal íntegra e o cordão umbilical nela inserido.

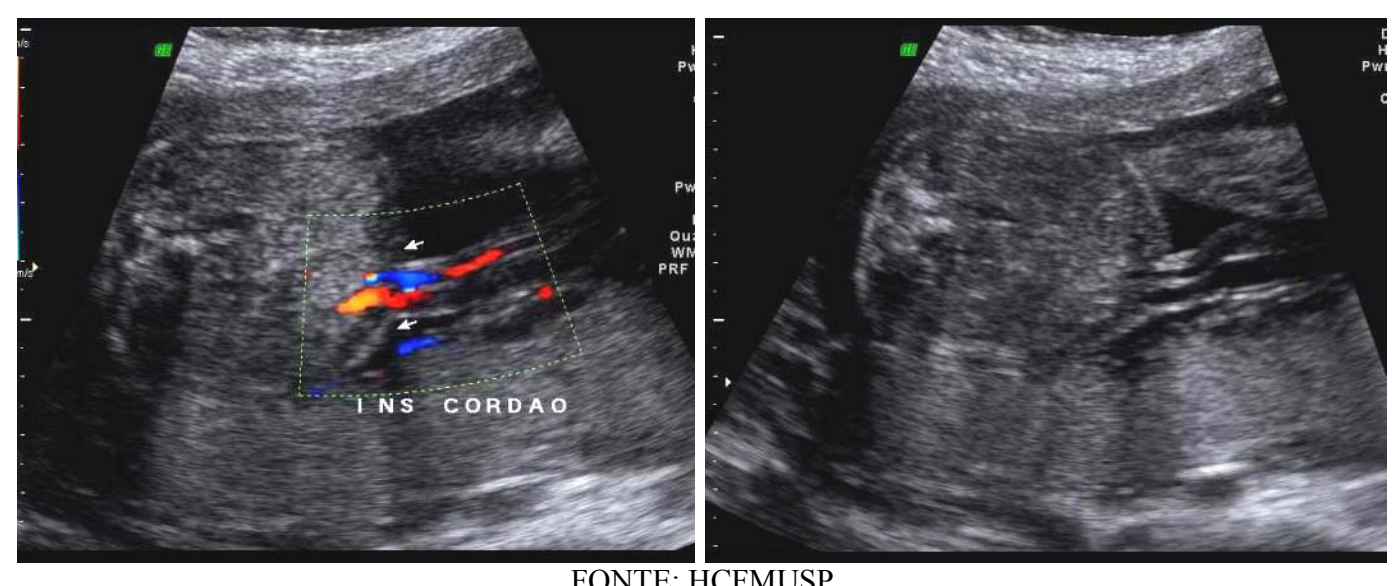

Figura 7 - Imagem ultrassonográfica da parede abdominal íntegra e o cordão umbilical nela inserido, com (à esquerda) e sem (à direita) o Doppler colorido, em feto de 22 semanas sem defeito de fechamento da parede abdominal 
Os diagnósticos diferenciais de gastrosquise incluem os outros defeitos da parede abdominal como: onfalocele, extrofia de cloaca e extrofia de bexiga. Outras síndromes que também podem estar associadas aos defeitos de parede incluem síndrome da banda amniótica e pentalogia de Cantrell $^{(95)}$. A identificação correta do defeito da parede abdominal é importante, pois cada uma dessas entidades tem etiologia, fatores de risco, investigações, seguimentos e condutas distintas.

O diagnóstico diferencial entre gastrosquise e onfalocele é possível a partir do primeiro trimestre de gestação ${ }^{(96)}$ (Figura 8).
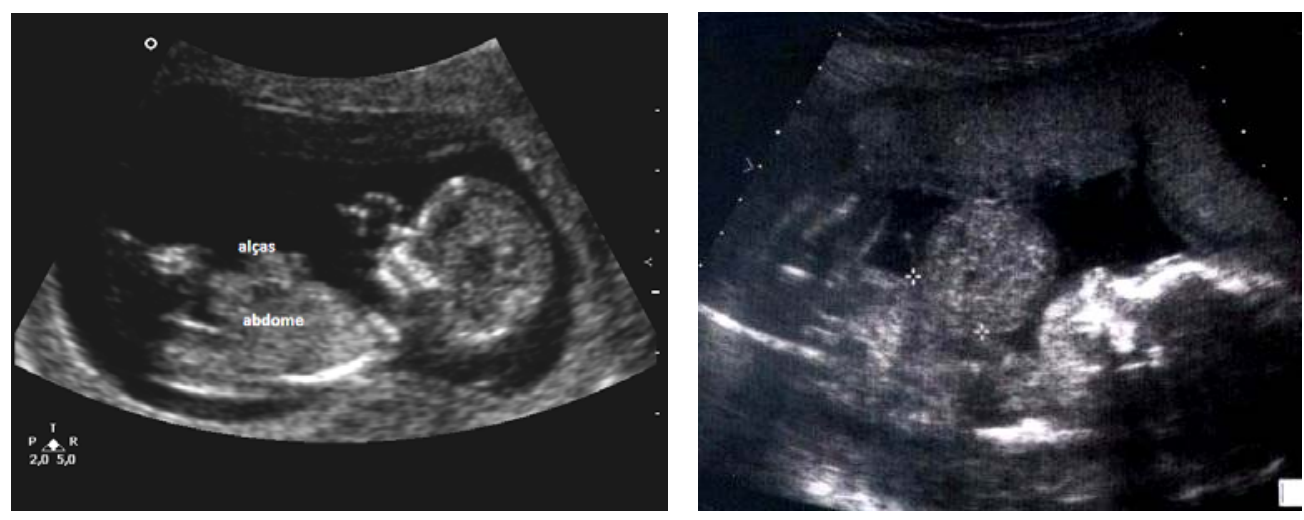

FONTE: À esquerda: HCFMUSP. À direita: http://www.cirujanopediatrico.com.ar/patologia.php?idseccion=65

Figura 8 - À esquerda: imagem sagital de feto portador de gastrosquise demonstrando alças intestinais exteriorizadas livres no líquido amniótico através da parede abdominal, sem membrana peritoneal recobrindo-as. À direita: corte transverso de abdome demonstrando conteúdo exteriorizado delimitado por membrana peritoneal característica de onfalocele

A onfalocele é caracterizada por apresentar anel herniário na parede abdominal na base do cordão umbilical, de tamanho variável, por onde protuem as vísceras abdominais. O saco herniário é formado por uma camada interna de peritônio e uma camada externa de âmnio e geléia de Wharton, não há músculos, fáscia ou pele recobrindo esse saco ${ }^{(97)}$. A presença dessa membrana recobrindo o conteúdo herniado distingue a onfalocele tanto da gastrosquise como da hérnia umbilical, que é recoberta por pele normal ${ }^{(98)}$. O cordão umbilical se insere na membrana que recobre a onfalocele, em seu ápice. 
O defeito da parede pode se apresentar de diversos tamanhos e na maioria dos casos contém quantidade variável de alças intestinais de delgado, entretanto fígado, bexiga, baço, estômago, útero e ovários também podem estar presentes. Quanto maior o defeito da parede abdominal, pior o prognóstico. Comparativamente na gastrosquise o defeito é relativamente pequeno e está localizado à direita do cordão umbilical, o qual está em sua posição normal na parede abdominal. Este é um importante detalhe anatômico que diferencias estas duas entidades, além disso, na gastrosquise não há o saco herniário recobrindo as vísceras exteriorizadas, as quais estão expostas ao nascimento ${ }^{(17)}$.

A Figura 9 mostra e compara o aspecto clínico entre onfalocele e gastrosquise ao nascimento.
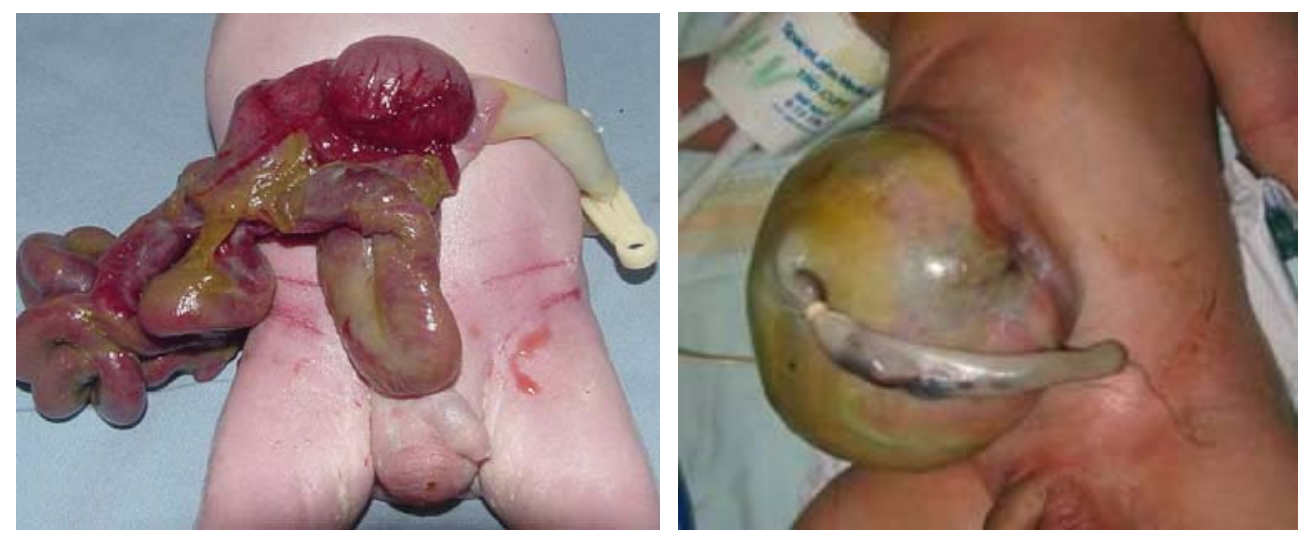

FONTE: À esquerda: HCFMUSP. À direita: http://www.cirujanopediatrico.com.ar/patologia.php?idseccion=65

Figura 9 - À esquerda, recém-nascido com gastrosquise, com conteúdo exteriorizado livre e cordão umbilical inserido na parede abdominal e à direita da abertura. À direita, apresentação clínica de onfalocele em recém-nascido, com saco herniário recobrindo conteúdo exteriorizado e cordão umbilical inserido no ápice do saco

Onfalocele pode ser um defeito isolado, mas frequentemente está associada a outras malformações estruturais e/ou faz parte de anomalias cromossômicas ou genéticas. Múltiplas anomalias estruturais são identificadas em $67-88 \%$ dos fetos com onfalocele e em 30 a $40 \%$ dos casos são percebidas anormalidades 
cromossômicas (incluindo trissomia do 13, 18 e 21) e também anormalidades cromossômicas sexuais como síndrome de Turner, Klinefelter e triploidias ${ }^{(99)}$, implicando alta taxa de mortalidade ${ }^{(98)}$.

Já a gastrosquise frequentemente é isolada, apenas 5 a $27 \%$ dos casos apresentam malformações estruturais associadas ${ }^{(1,100)}$ e bom prognóstico de sobrevida, após reparação cirúrgica ${ }^{(100)}$.

A acurácia do exame ultrassonográfico de rotina no diagnóstico de defeitos de parede abdominal é de 60-90\%. Assim, os casos de gastrosquise foram diferenciados corretamente de onfalocele em 79-95\% dos $\operatorname{casos}^{(101,102)}$. Taxa de $100 \%$ de diagnóstico diferencial foi obtida por Bahlmann et al., os quais avaliam 58 fetos com diagnóstico de defeitos de parede abdominal e diferenciam corretamente todos os casos de onfalocele e gastrosquise pela ultrassonografia no primeiro trimestre da gestação $^{(96)}$.

\subsection{ANOMALIAS ASSOCIADAS À GASTROSQUISE}

A frequência de malformações congênitas estruturais associadas à gastrosquise varia de 5 a $27 \%{ }^{(100)}$. Em estudo multicêntrico envolvendo 3.322 casos de gastrosquise, os autores encontram 14\% de associação com defeitos maiores, com poucos casos de síndromes reconhecidas ${ }^{(103)}$. Esse mesmo estudo também sugere que casos de trissomias ou de anomalias congênitas múltiplas não-sindrômicas estão mais associados à idade materna avançada ${ }^{(103)}$. Stoll et al. apresentam taxa semelhante $(16,6 \%)$ de associação com malformações estruturais, principalmente, as musculoesqueléticas, cardíacas, urogenitais e do sistema nervoso central ${ }^{(100)}$.

Jones, em 2006, considera como principais síndromes associadas à gastrosquise as displasias esqueléticas, artrogripose, craniosinostose e dismorfismos inespecíficos $^{(99)}$.

Recente estudo (2011) realizado na Maternidade do hospital Necker EnfantsMalades, em Paris, identifica 14 (13\%) casos com anomalias congênitas associadas 
em 108 fetos com gastrosquise, sendo que o diagnóstico pré-natal foi realizado em 5 $(35,7 \%)$ e pós-natal em $9(64,3 \%)$. As anomalias associadas encontradas foram: artrogripose $(n=3)$, defeito de membros superiores $(n=2)$, craniosinostose $(n=1)$, divertículo de Meckel $(n=1)$, hidronefrose bilateral $(n=1)$ e atresia intestinal $(n=$ 6). A taxa de sobrevida no grupo da gastrosquise isolada foi de $91,5 \%$, e no grupo com anomalias associadas, de 78,6\% $(p>0,05)$. O grupo com anomalias associadas teve significativamente maior tempo de internação na unidade de terapia intensiva neonatal $(p=0,04)^{(104)}$.

Moore (1977) descreve 2 a 5\% de defeitos cardíacos em associação com gastrosquise $^{(48)}$, porém Hwang et al., em estudo mais recente, em revisão de 18 anos e com maior casuística, observam incidência de $12 \%$ de cardiopatia associada à gastrosquise $(14 / 121)^{(9)}$.

A prevalência de anormalidades cromossômicas em fetos com gastrosquise isolada não é maior do que o risco basal na população geral ${ }^{(103)}$. Raramente há associação com anormalidades cromossômicas nesses pacientes ${ }^{(28,103,105)}$. Estudo multicêntrico, com 24 bases internacionais de registros de defeitos ao nascimento, encontra 1,2\% (41/3322) de síndromes cromossômicas entre os casos de gastrosquise, incluindo tanto os isolados como aqueles com outras malformações estruturais associadas. As anormalidades mais frequentes foram: trissomia do 18 (15 casos), trissomia do 13 (14 casos), anormalidades cromossômicas sexuais (4 casos) e

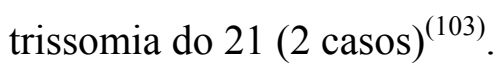

Em largo estudo, originário da base de registro populacional California Birth Defects Monitoring Program, dos 2.894 pacientes com síndrome de Down registrados entre os anos de 1983 e 1993, nenhum apresentou gastrosquise ${ }^{(106)}$. Stoll et al. observam um caso de síndrome de Down (1,7\%) em 60 pacientes com gastrosquise nascidos entre 1979 - 2003, em estudo realizado em 11 maternidades francesas $^{(100)}$.

Nos registros da EUROCAT, considerando todos os casos de nascidos vivos, de óbito fetal após 20 semanas e as interrupções entre 1980-1990, 3\% dos casos de gastrosquise apresentam anomalia cromossômica associada (Trissomia do 13, 18 ou 
21), entretanto, a definição de gastrosquise utilizada incluía outros defeitos da parede abdominal $^{(70)}$.

Paidas et al., em 128 casos de gastrosquise, observam um caso de trissomia do cromossomo $18^{(107)}$. Em outros estudos, totalizando 63 casos de gastrosquise, os autores não encontram anomalia cromossômica associada ${ }^{(108-111)}$.

Embora as malformações estruturais extraintestinais sejam raras na apresentação clínica da gastrosquise, as anomalias gastrointestinais são frequentes em 20 a $40 \%$ dos $\operatorname{casos}^{(107)}$. Dentre as anomalias gastrointestinais que podem estar associadas à gastrosquise podem ser citadas: má-rotação intestinal, atresia intestinal, volvo, estenoses e infartos. Atresia intestinal está presente em 5-15\% dos casos de gastrosquise, pode acometer tanto o intestino delgado como o intestino grosso, e está associada com alta taxa de mortalidade ${ }^{(112,113)}$.

As alterações intestinais, quando presentes, representam grande impacto, pois aumentam a taxa de mortalidade para $28 \%$ comparado, com a taxa de sobrevida de aproximadamente, $100 \%$ nos fetos sem patologias intestinais associadas ${ }^{(33)}$. Ainda, levam à intolerância à dieta oral com período de jejum prolongado, consequente longo tempo de uso de NPP, prolongado período de internação hospitalar, sepse recorrente e mortalidade ${ }^{(16,25-28,112-114)}$.

\subsection{EVOLUÇÃO ANTENATAL E PÓS-NATAL}

As altas taxas de morbidade e mortalidade, observadas tanto antes como após o nascimento, são devidas principalmente a: restrição do crescimento fetal, parto prétermo, recém-nascido de baixo-peso e baixo escore de Apgar ${ }^{(15,23)}$, presença de malformações intestinais associadas, longos períodos de hospitalização após a cirurgia, uso prolongado de NPP e tempo longo para iniciar a dieta via oral no pósoperatório $^{(14,15)}$. As condições do intestino ao nascimento, hipoperistaltismo intestinal, necessidade de eventuais ressecções intestinais, múltiplas laparotomias e 
síndrome do intestino curto também contribuem muito para aumentar a taxa de óbito neonatal $^{(16)}$.

A morbidade é alta e imprevisível, e embora os óbitos neonatais sejam incomuns, a maioria dos óbitos resulta das consequências do longo período de internação hospitalar, como sepse, perda intestinal importante e complicações, a longo prazo, da síndrome do intestino curto ${ }^{(115)}$.

Atualmente, a taxa de sobrevida é de, aproximadamente, $90 \%{ }^{(14-16)}$. Avaliação retrospectiva dos defeitos da parede abdominal, realizada na população de Londres, confirma esse achado. De 42 casos com diagnóstico antenatal de gastrosquise, a maioria $(90 \%)$ sobreviveu até o nascimento, com mortalidade neonatal de $11 \%{ }^{(116)}$.

Henrich et al. avaliam, retrospectivamente, 40 casos de gastrosquise e encontram idade gestacional média do nascimento de 36 semanas e 2 dias ${ }^{(117)}$. Tan et al. revisam 539 casos de gastrosquise notificados entre 1987 e 1993, e observam a idade gestacional média ao nascimento de 37,0 (35 - 38) semanas ${ }^{(1)}$. Os autores de metanálise encontram idade gestacional média ao parto de 36,8 semanas, nos casos de gastrosquise sem atresia intestinal, e de 36 semanas nos casos com atresia ${ }^{(33)}$.

Restrição do crescimento fetal e baixo peso ao nascimento são desfechos comuns. Ocorrem em um a dois terços dessas gestações, dependendo do critério utilizado (peso abaixo do percentil 3 para a idade gestacional ou abaixo do percentil $10)^{(15,118)}$. A incidência de restrição do crescimento relatada na literatura é em média de 24 a $67 \%$ dos $\operatorname{casos}^{(18,119-121)}$ e a sua presença aumenta o risco de resultados adversos neonatais ${ }^{(115)}$

Os autores, de estudo retrospectivo, revisam 66 casos de gastrosquise, de 1998 a 2006, e encontram $38 \%$ de recém-nascidos abaixo do percentil $3^{(15)}$. Pouco mais da metade (61\%) dos recém-nascidos com gastrosquise apresentam RCF, comprovada ao nascimento ${ }^{(122)}$. Em estudo realizado na Inglaterra, entre $1987 \mathrm{e}$ 1993, os autores descrevem um terço de recém-nascidos abaixo do percentil 5 ao nascimento $^{(1)}$. Vários estudos relatam peso médio ao nascimento de aproximadamente $2400 \mathrm{~g}^{(18,121,122)}$.

O tipo de restrição do crescimento fetal, nesses casos, é simétrico e de aparecimento precoce ${ }^{(118)}$, geralmente a partir do segundo trimestre de 
gestação $^{(118,121)}$. É demonstrado que não apenas a circunferência abdominal é pequena, devido à herniação de parte do conteúdo abdominal, mas todos os parâmetros biométricos (circunferência craniana, diâmetro biparietal, diâmetro occipito-frontal, comprimento do fêmur e úmero) podem estar abaixo do esperado para a idade gestacional. A deficiência do crescimento fetal pode estar associada à perda de proteína e líquidos pelo intestino exposto ${ }^{(123)}$.

As gestações com gastrosquise apresentam altas taxas de óbito fetal inesperado no terceiro trimestre da gestação ${ }^{(119,120,122)}$, média descrita na literatura de $12,5 \%$ a $14,3 \%{ }^{(19,24,122)}$.

Oligoâmnio, líquido amniótico abaixo do limite na normalidade, é a alteração de líquido amniótico mais comum nos fetos com gastrosquise, descrito em 20 a $25 \%$ dos $\operatorname{casos}^{(120)}$. A presença do oligoâmnio acarreta aumento da concentração de mecônio e de urina fetal no líquido amniótico. Tais componentes encontram-se fisiologicamente presentes na cavidade amniótica, porém quando em alta concentração podem ser os responsáveis pelo efeito deletério do líquido amniótico sobre o intestino exteriorizado ${ }^{(124,125)}$.

Polihidrâmnio, líquido amniótico acima do limite na normalidade, está presente em cerca de $15 \%$ dos $\operatorname{casos}^{(120)}$, particularmente naqueles fetos cuja motilidade intestinal está diminuída ou que apresentam obstrução intestinal devido a alguma malformação estrutural intestinal associada ${ }^{(119)}$.

\subsection{AVALIAÇÃO ULTRASSONOGRÁFICA DAS ALÇAS INTESTINAIS EXTERIORIZADAS}

O aspecto ultrassonográfico antenatal das alças intestinais (Figuras 10 e 11), exteriorizadas e intra-abdominais, é avaliado há mais de duas décadas na tentativa de encontrar correlação com o prognóstico antenatal, pós-natal e pós-cirúrgico ${ }^{(35)}$. Vários estudos clínicos em animais foram realizados, investigando o dano intestinal na gastrosquise durante a gestação ${ }^{(35,36)}$. 


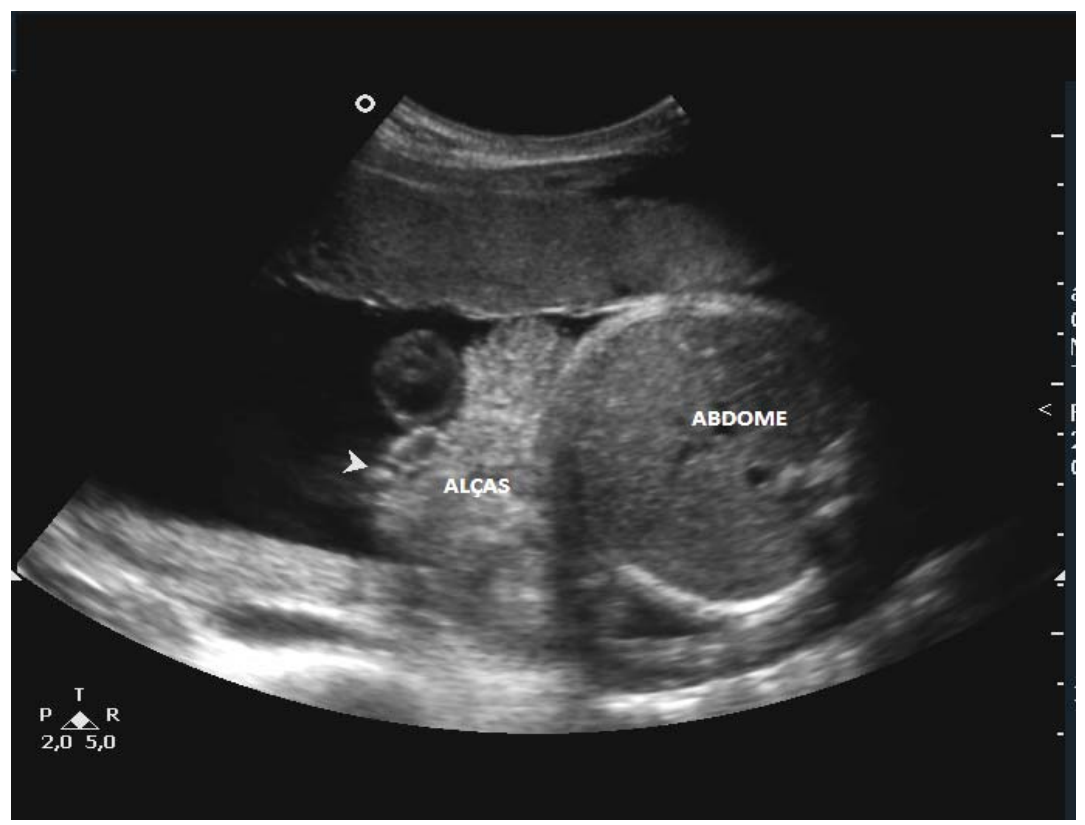

FONTE: HCFMUSP

Figura 10 - Corte transverso do abdome demonstrando aspecto ultrassonográfico das alças intestinais em feto com gastrosquise. Alças exteriorizadas no líquido amniótico sem sinais sugestivos de dilatação do lúmen (seta)

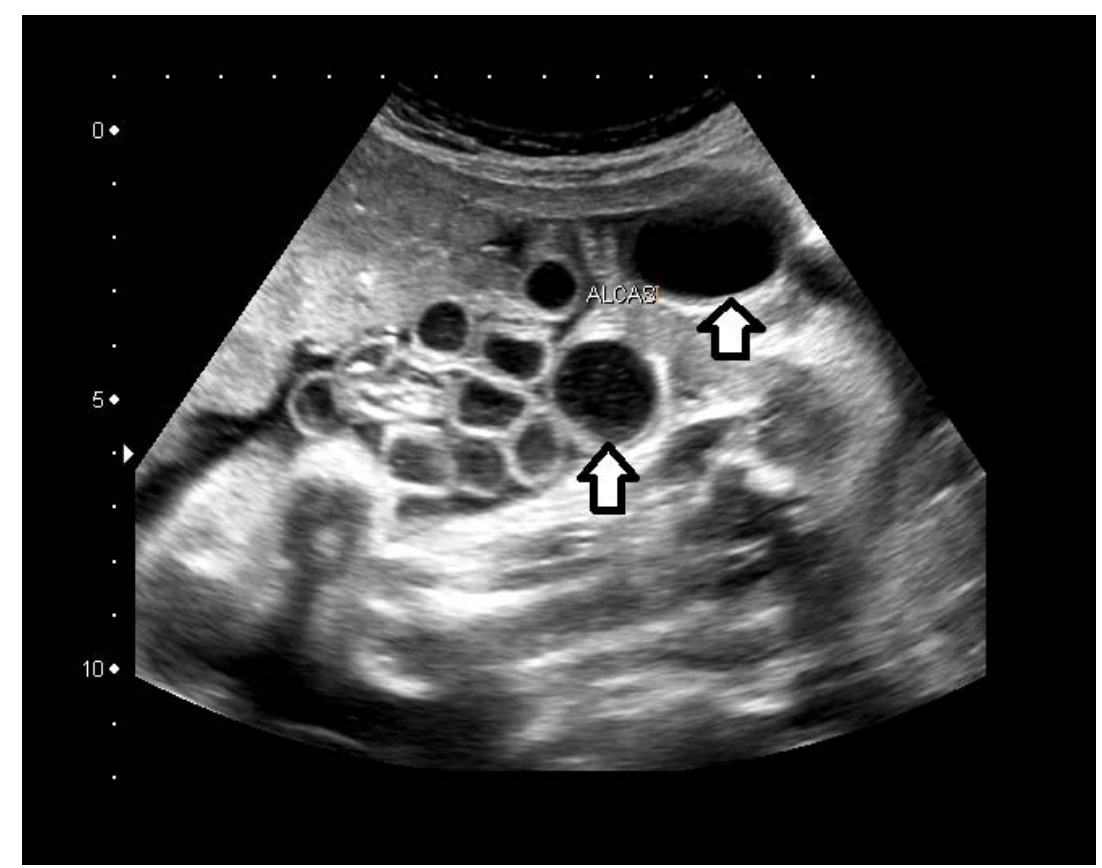

FONTE: HCFMUSP

Figura 11 - Imagem ultrassonográfica de alças intestinais exteriorizadas com aspecto sugestivo de dilatação do lúmen (setas) 
Bond et al. (1988) foram os primeiros a relacionar o aspecto da alça na ultrassonografia com o prognóstico neonatal. Esses autores reavaliam os dados armazenados das gestações com diagnóstico de defeito da parede abdominal ocorridos entre 1982 a 1986. São identificados onze fetos com diagnóstico antenatal de gastrosquise, quatro deles com alças intestinais dilatadas e paredes espessadas na ultrassonografia. Os autores encontram forte associação desses sinais ecográficos com lesão intestinal mais grave e pior prognóstico neonatal. Observam que, na ausência desses dois sinais ecográficos, os casos apresentam mudanças intestinais mais brandas ao nascimento e evoluem com curso pós-operatório benigno, sem morbidade ou mortalidade ${ }^{(35)}$.

Posteriormente, Lenke et al. (1990) descrevem cinco casos de gastrosquise diagnosticados antes do nascimento, tendo sido os primeiros a estabelecer um valor de corte como referência para o lúmen da alça aferida (normal $<10 \mathrm{~mm}$ ). Encontram relação entre dilatação intestinal antes do nascimento com o prognóstico neonatal e dano intestinal grave. Observam que alguns recém-nascidos com dano intestinal ao nascimento não apresentam dilatação em suas alças na ultrassonografia antenatal ${ }^{(126)}$.

No mesmo ano, Sipes et al. (1990) também relatam dois casos de gastrosquise e concluem que a dilatação intestinal antenatal não necessariamente reflete lesão intestinal ou pior prognóstico neonatal ${ }^{(39)}$.

Em 1993, Langer et al. realizam estudo em dois centros perinatais e avaliam casos com diagnóstico pré-natal de gastrosquise (14 casos entre 1986-1990; 16, entre 1990 e 1991). Seis casos foram excluídos restando 24 no grupo de estudo. Parede da alça intestinal espessada $>3,0 \mathrm{~mm}$ esteve associada com maior tempo para iniciar a dieta oral, mas a diferença não foi estatisticamente significante. Entretanto, mostrou associação significante quando o diâmetro da alça intestinal foi $>17 \mathrm{~mm}$. Fetos com diâmetro da alça $\geq 18 \mathrm{~mm}$ tiveram maior período de íleo prolongado do que aqueles sem dilatação (média de dias para iniciar a dieta oral $36,3 \pm 6$ vs $22,3 \pm 5$ dias; $P=$ 0,04). Necessitou-se de ressecção intestinal em 5/12 (42\%) dos RNs que apresentavam máximo diâmetro $\geq 18 \mathrm{~mm}$, comparado com $1 / 12(8 \%)$ que tinham diâmetro máximo de até $17 \mathrm{~mm}(p=0,03)$. Quatro dos RNs que necessitaram de ressecção intestinal apresentavam atresia, um tinha volvo e o outro, atresia ileal 
progressiva. Fechamento da parede abdominal em dois estágios foi necessário em $3 / 12$ (25\%) pacientes com diâmetro máximo de $18 \mathrm{~mm}$ ou mais versus, 4/12 (33\%) diâmetro máximo de até $17 \mathrm{~mm}$, mas a diferença não foi estatisticamente significativa $^{(36)}$.

No ano seguinte, Babcook et al. (1994) realizam coorte retrospectiva de 24 fetos, com última avaliação ultrassonográfica realizada entre 0 e 3,6 semanas antes do parto (média 0,9 semanas). Nove entre 24 casos (38\%) tiveram complicações intestinais (incluindo 2 óbitos neonatais), e essas complicações ocorreram em 7/12 que tinham o maior diâmetro transverso da alça intestinal $>11 \mathrm{~mm}(p=0,05)$. Com valor de corte $>11 \mathrm{~mm}$, a sensibilidade é de $78 \%$; a especificidade, de $66 \%$; o valor preditivo positivo, de $71 \%$; e o valor preditivo negativo, de $88 \%$, em predizer complicações intestinais pós-natais. Não observam relação estatisticamente significativa entre parede da alça intestinal espessada e as complicações pós-natais intestinais. Com taxa de sobrevida de $92 \%(22 / 24)$, os dois óbitos neonatais foram tardios, após longo período de hospitalização e devido a graves complicações intestinais ${ }^{(37)}$.

Pryde et al. (1994) analisam 23 casos de gastrosquise em duas avaliações. Em uma delas usam como critério de dilatação intestinal o maior diâmetro da alça aferido $>10 \mathrm{~mm}$ e, na outra, o maior diâmetro de $17 \mathrm{~mm}$. Os grupos foram comparados e as variáveis neonatais analisadas foram de curto prazo (tipo de cirurgia, complicações pós-cirúrgicas a curto prazo, como necrose e necessidade de reintervenção cirúrgica por obstrução, tempo de internação hospitalar, dias de uso de NPP e tempo para iniciar dieta oral) e de longo prazo (tolerância alimentar, ganho de peso pós-natal adequado, desenvolvimento cognitivo, uso indefinido de NPP e internação prolongada). Quando usado o critério de $10 \mathrm{~mm}$, não houve diferença estatística entre os grupos em nenhuma variável analisada em relação ao prognóstico. No grupo do valor de corte $>17 \mathrm{~mm}$, houve mais complicações a curto prazo (44\% versus $14 \% ; p<0,05)$ e menor proporção de complicações a longo prazo ( $45 \%$ versus $86 \%$; $p<0,05)$. O critério de $10 \mathrm{~mm}$ apresentou sensibilidade de 85,7\% (6/7) e especificidade de $37,5 \%$ (6/16), com valor preditivo positivo de $37,5 \%$ e valor preditivo negativo de $85,7 \%$. O critério de $17 \mathrm{~mm}$ apresentou sensibilidade de $71,4 \%$ 
(5/7) e especificidade de 75\% (12/16), com valor preditivo positivo de 55,5\% e valor preditivo negativo de $85,7 \%$ na predição das variáveis analisadas ${ }^{(8)}$.

Adra et al. (1996) analisam, retrospectivamente, 47 casos de gastrosquise, durante o período de 1986 a 1994, em Miami, Florida. Os autores correlacionam o aspecto ultrassonográfico do intestino delgado fetal com o prognóstico pós-natal e, consideram como dilatação intestinal o diâmetro da maior alça exteriorizada $>10$ mm na última ultrassonografia antes do parto. Dos 47 casos, cinco são excluídos na análise [três $(6,4 \%)$ abortamentos e dois $(4,3 \%)$ casos de óbito fetal], dos 42 restantes, 27 casos tiveram diagnóstico e acompanhamento pré-natal e 15 foram identificados como gastrosquise ao nascimento. Os fetos (12/27) com evidência de dilatação intestinal (>10 mm) apresentam edema intestinal significante intraoperatório $(66,7 \%$ vs $26,7 \%, p=0,038)$, maior tempo cirúrgico (média 131,1 $\pm 48,6$ minutos vs 95,3 $\pm 25,0$ minutos, $p=0,031)$ e desenvolvimento de complicações no pós-operatório ( $p=0,037)$, como sepse, síndrome do intestino curto, obstrução do intestino delgado, reabordagem cirúrgica para ressecções intestinais e enterocolite necrotizante. Comparado com o grupo sem dilatação intestinal, quatro casos apresentam atresia intestinal. Quando esses casos foram excluídos da análise, a associação entre dilatação intestinal e desenvolvimento de complicações pósoperatórias não foi mais observada $(p=0,162)^{(127)}$.

Alsulyman et al. (1996) revisam 21 casos com diagnóstico pré-natal de gastrosquise, que tiveram acompanhamento no período de 1988 a 1995, no Los Angeles County / University of Southern Califórnia Women's and Children's Hospital. Os pacientes foram divididos em dois grupos baseados na presença ou ausência de dilatação intestinal na ultrassonografia (considerado dilatação o diâmetro da maior alça exteriorizada $>17 \mathrm{~mm}$ ) até uma semana antes do parto. Dos 21 casos, $6(27 \%)$ deles foram pequenos para a idade gestacional. Treze fetos tinham a maior alça intestinal aferida até $17 \mathrm{~mm}$ e 8 tinham dilatação intestinal $>17 \mathrm{~mm}$. Os autores não observam diferença significante entre os grupos em relação ao peso ao nascimento, idade gestacional no parto, tempo de internação hospitalar, tempo de uso de nutrição parenteral prolongada e necessidade de reintervenções cirúrgicas. Três fetos tinham alças intestinais $>47 \mathrm{~mm}$ (entre 47 e $61 \mathrm{~mm}$ ) e nenhum apresentou complicações pós-operatórias. Duas crianças foram submetidas a ressecções 
intestinais, devido à atresia intestinal, e apresentaram significantes complicações no pós-operatório com longo período de hospitalização (75 e 141 dias), tinham a luz da maior alça exteriorizada até $5,0 \mathrm{~mm}^{(38)}$.

Quarenta e cinco casos de gastrosquise, correspondentes ao período de 8,5 anos (1993 a 2001), são avaliados por Japaraj et al. (2003) em Queensland, Austrália. Os fetos são divididos em dois grupos, de acordo com a maior medida da alça intestinal dilatada $(<17 \mathrm{~mm} \mathrm{e} \geq 17 \mathrm{~mm}$ ), a maioria deles $(96 \%)$ com a última ultrassonografia realizada até duas semanas antes do nascimento. Dezenove (42\%) fetos apresentam restrição de crescimento fetal (< percentil 10) e nenhum caso de óbito fetal é observado. Dilatação intestinal $\geq 17 \mathrm{~mm}$ é observada em 19 casos e não há diferença estatisticamente significante entre os grupos em relação a peso ao nascimento, complicações intestinais, múltiplas laparotomias, período de internação hospitalar, intervalo para iniciar dieta via oral, tempo de uso de NPP e taxa de óbito neonatal $(\mathrm{ONN})$. Os autores também dividem os fetos em outros dois grupos de comparação, um com presença de RCF e o outro sem RCF, e também não observam diferença estatisticamente significante entre os grupos e complicações intestinais, necessidade de múltiplas laparotomias e taxa de ONN. A presença de polihidrâmnio é o único parâmetro que mostra associação estatisticamente significativa com o prognóstico neonatal: presença de complicações intestinais $(p=0,003)$, necessidade de múltiplas laparotomias $(p=0,003)$ e ONN $(p=0,02)$. O polihidrâmnio se mostra fortemente associado com graves complicações intestinais, com razão de verossimilhança de $11,7(p=0,001)^{(18)}$.

Nick et al. (2006), em estudo retrospectivo, revisam 58 casos de gastrosquise isolada, sem outras malformações associadas, avaliados entre 1998 e 2004 . Quarenta e oito fetos não mostram dilatação de alça intra-abdominal, na ultrassonografia antenatal, e nenhum deles apresenta atresia intestinal ao nascimento. Os outros 10 casos $(17 \%)$ com dilatação intra-abdominal, no segundo trimestre, apresentavam atresia intestinal ao nascimento $(p<0,0001)$. Análise de regressão logística mostra maior tempo de internação hospitalar $(p=0,0027)$ e maior intervalo de tempo para fechamento definitivo da parede abdominal $(p=0,021)$, no grupo com dilatação intestinal, e, atresia, quando comparado com o grupo sem dilatação e sem atresia. Os autores relatam dois ONN no grupo de estudo: um deles tinha dilatação de alça intra- 
abdominal e o outro apresentava extenso defeito de fechamento que não pode ser corrigido mesmo após várias tentativas. A dilatação das alças intra-abdominais também se mostrou estatisticamente significativa com restrição do crescimento fetal $(P=0,0199)^{(34)}$.

Piper et al. (2006) avaliam 27 casos de gastrosquise, no período de 1999 a 2004, em Boston, EUA. Treze pacientes (48\%) apresentam dilatação intestinal (considerado como dilatação o diâmetro máximo da alça exteriorizada $>6,0 \mathrm{~mm}$ ) e $14(52 \%)$ não apresentam dilatação intestinal na ultrassonografia. Observam diferença estatisticamente significativa entre os grupos em relação ao intervalo de tempo para iniciar a dieta via oral. Os pacientes com dilatação intestinal demoram mais tempo para iniciar a dieta oral $(20,4$ dias $\pm 11,7$ vs 12,5 dias $\pm 4,3 ; P=0,04)$. Os grupos não diferem estatisticamente em relação ao tempo de internação na unidade de terapia intensiva, número de dias de uso de NPP e tempo de internação hospitalar. Os recém-nascidos com dilatação intestinal são menos submetidos a fechamento primário da parede abdominal comparado aos sem dilatação ( $26 \%$ vs $50 \%, P=0,06)$, entretanto não atingiu significância estatística. Cinco RNs (38\%) com dilatação intestinal desenvolvem sintomas tardios de obstrução intestinal, após o fechamento definitivo da parede abdominal. Quatro deles necessitam de reintervenção cirúrgica e nenhum dos cinco teve fechamento primário da parede abdominal. Nenhum dos RNs sem dilatação intestinal necessitou de re-intervenção ou de tratamento para sintomas obstrutivos. Análise de regressão múltipla identifica longa estadia na UTI, idade gestacional tardia no parto e dilatação intestinal antenatal como fatores de risco para desenvolver obstrução intestinal, após o fechamento definitivo da parede abdominal $(p<0,01)^{(128)}$.

Cohen-Overbeek et al. (2007) realizam análise retrospectiva das imagens ultrassonográficas armazenadas do período pré-natal e do prontuário da cirurgia pediátrica de 24 gestações únicas diagnosticadas como gastrosquise, entre 1991 e 2003, no University Medical Centre Rotterdam, na Holanda. O diâmetro da alça intestinal exteriorizada foi aferido de uma parede interna a outra e considerada a máxima dilatação de 10 a $17 \mathrm{~mm}$, mais próxima do parto. Duas gestações foram interrompidas antes da $24^{\mathrm{a}}$ semana e ocorreram 3 OF $(12,5 \%)$. Houve suspeita de atresia intestinal em 3 de 19 casos: em dois deles, devido à herniação do estômago 
concomitante ao intestino dilatado com diâmetro da alça de 11 e $33 \mathrm{~mm}$; no último caso, também complicado com polihidrâmnio associado a alças intra-abdominais dilatadas com peristaltismo visível. O terceiro caso apresentava alça dilatada com diâmetro de $23 \mathrm{~mm}$. Atresia intestinal foi confirmada ao nascimento nos dois primeiros casos. O primeiro evoluiu com sintomas obstrutivos e foi submetido a cirurgias adicionais. $\mathrm{O}$ segundo necessitou de ressecção ampla do intestino devido à extensa área de necrose associada, evoluindo a óbito no dia seguinte ao nascimento. Um RN apresentou atresia intestinal ao nascimento, porém não mostrava dilatação das alças ou polihidrâmnio na ultrassonografia. Dilatação intestinal no terceiro trimestre de gestação foi identificada em 67\% (14/21) dos casos, com média de 18 mm (11 a $33 \mathrm{~mm})$. Um caso de atresia é diagnosticado após o nascimento em cada grupo. A dilatação intestinal pré-natal não se correlaciona com o prognóstico neonatal e a presença de atresia intestinal é considerada o fator prognóstico mais importante para morbidade ${ }^{(24)}$.

Heinig et al. (2008) estudam 14 gestações com diagnóstico de gastrosquise isolada que foram acompanhadas até o momento do parto, no período entre 2001 a 2005, no Departamento de Ginecologia e Obstetrícia da Universidade de Münster, Alemanha. Os autores aferiram o diâmetro máximo da alça intestinal pela medida da face externa da parede da alça até a outra face externa, no eixo curto (transverso) da alça no segmento mais dilatado de intestino exteriorizado. Sete em 14 fetos obtiveram suas medidas determinadas, retrospectivamente, por meio das imagens ultrassonográficas armazenadas, enquanto em outros sete foram obtidas prospectivamente. Análise de regressão logística mostrou forte correlação entre o diâmetro da alça de delgado exteriorizada com o avançar da idade gestacional. Dois casos (14,3\%) evoluíram para OF, ambos apresentavam diâmetro da alça exteriorizada $>25 \mathrm{~mm}$ e nenhum deles apresentava alça intra-abdominal dilatada. Diâmetro da alça intestinal $>25 \mathrm{~mm}$, no $3^{\circ}$ trimestre da gestação, esteve associado com aumento do risco em curto prazo de complicações no período pré-natal, como sofrimento fetal e OF (valor preditivo positivo de 100\%; IC 95\%: 29,2 - 100\% e valor preditivo negativo de 100\%; IC 95\%: 71,5 - 100\%) ${ }^{(19)}$.

A Tabela 2 mostra a comparação entre os diversos estudos que avaliam, pela ultrassonografia antenatal, a relação entre dilatação da alça intestinal exteriorizada, 
nos casos de gastrosquise fetal, com o prognóstico neonatal e a conduta proposta quando tal associação está presente.

Tabela 2 - Revisão dos estudos em gastrosquise fetal que avaliam a associação entre dilatação das alças intestinais exteriorizadas e o prognóstico perinatal

\begin{tabular}{|c|c|c|c|c|c|c|}
\hline ESTUDO & $\begin{array}{c}n \\
\text { (DI) }\end{array}$ & $\begin{array}{c}\text { Dilatação } \\
\text { intestinal } \\
(\mathbf{m m})\end{array}$ & $\begin{array}{l}\text { IG no } \\
\text { parto }\end{array}$ & $\begin{array}{c}\text { Resultado } \\
\text { perinatal }\end{array}$ & $\begin{array}{c}\text { Associação } \\
\text { com } \\
\text { resultados } \\
\text { adversos } \\
\end{array}$ & $\begin{array}{l}\text { Conduta } \\
\text { proposta }\end{array}$ \\
\hline $\begin{array}{l}\text { Lenke et al } \\
(1990)^{(126)}\end{array}$ & $5(114)$ & $>10$ & 35 & $\begin{array}{c}5 \mathrm{NV} \\
1 \mathrm{ONN}\end{array}$ & Talvez & Expectante \\
\hline $\begin{array}{l}\text { Sipes et al } \\
(1990)^{(39)}\end{array}$ & $2(2)$ & $23 / 38$ & 36 & $2 \mathrm{NV}$ & Não & Expectante \\
\hline $\begin{array}{l}\text { Langer et al } \\
(1993)^{(36)}\end{array}$ & $24(12)$ & $>18$ & NR & $24 \mathrm{NV}$ & Sim & $\begin{array}{c}\text { Considerar } \\
\text { parto }\end{array}$ \\
\hline $\begin{array}{l}\text { Babcook et al } \\
\quad(1994)^{(37)}\end{array}$ & $24(12)$ & $>11$ & NR & $\begin{array}{l}24 \mathrm{NV} \\
2 \mathrm{ONN}\end{array}$ & Sim & Expectante \\
\hline $\begin{array}{l}\text { Pryde et al. } \\
(1994)^{(8)}\end{array}$ & $23(9)$ & $>17$ & 36.2 & $\begin{array}{l}23 \mathrm{NV} \\
3 \mathrm{ONN}\end{array}$ & Sim & $\begin{array}{l}\text { Considerar } \\
\text { parto }\end{array}$ \\
\hline $\begin{array}{l}\text { Adra et al } \\
(1996)^{(127)}\end{array}$ & $27(12)$ & $>10$ & 36 & $\begin{array}{l}27 \mathrm{NV} \\
3 \mathrm{ONN}\end{array}$ & Sim & Expectante \\
\hline $\begin{array}{l}\text { Alsulyman et al } \\
\qquad(1996)^{(38)}\end{array}$ & $22(8)$ & $\geq 17$ & 34.3 & $\begin{array}{c}1 \mathrm{IJ} \\
21 \mathrm{NV}\end{array}$ & Não & Expectante \\
\hline $\begin{array}{l}\text { Japaraj et al } \\
(2003)^{(18)}\end{array}$ & $45(19)$ & $>17$ & 35.6 & $\begin{array}{l}45 \mathrm{NV} \\
6 \mathrm{ONN}\end{array}$ & Não & Expectante \\
\hline $\begin{array}{l}\text { Piper e Jaksic } \\
\qquad(2006)^{(128)}\end{array}$ & $27(13)$ & $>6$ & 35.4 & $\begin{array}{l}27 \mathrm{NV} \\
2 \mathrm{ONN}\end{array}$ & Sim & Expectante \\
\hline $\begin{array}{l}\text { Cohen-Overbeek } \\
\text { et al }(2008)^{(24)}\end{array}$ & $24(8)$ & $\geq 17$ & 36.2 & $\begin{array}{c}2 \mathrm{IJ} \\
3 \mathrm{OF} \\
19 \mathrm{NV} \\
1 \mathrm{ONN}\end{array}$ & Não & Expectante \\
\hline $\begin{array}{l}\text { Heinig et al } \\
(2008)^{(19)}\end{array}$ & $14(114)$ & $\geq 25$ & 36 & $\begin{array}{c}2 \mathrm{OF} \\
12 \mathrm{NV}\end{array}$ & Sim & $\begin{array}{c}\text { Considerar } \\
\text { parto }\end{array}$ \\
\hline
\end{tabular}

NOTA: DI = dilatação intestinal; $\mathrm{IG}=$ idade gestacional; $\mathrm{IJ}=$ interrupção judicial; $\mathrm{n}=$ número de casos; $\mathrm{NR}=$ não referido; $\mathrm{NV}=$ nascido vivo; $\mathrm{OF}=$ óbito fetal; $\mathrm{ONN}=$ óbito neonatal 
Esta discussão tem relevante importância, pois há muito se debate o meio de identificar os fetos com gastrosquise que evoluiriam com resultados desfavoráveis, bem como qual o momento ideal para a realização do parto a fim de evitar desfechos adversos. Apesar de a maioria dos estudos ${ }^{(8,19,36,37,127,128)}$ concluir que a dilatação das alças intestinais exteriorizadas, na ultrassonografia antenal, está associada à piora do prognóstico neonatal e do pós-operatório, ainda não há consenso entre todos autores dessa associação ${ }^{(18,24,38,39)}$ bem como do nível de corte a ser considerado como dilatação da alça intestinal exteriorizada na predição do prognóstico perinatal adverso. 


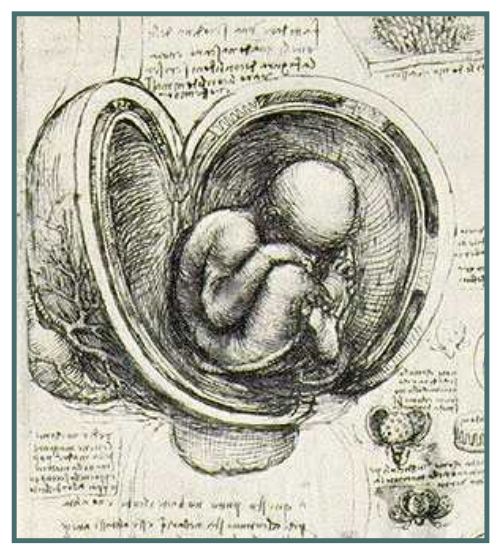


O presente estudo, envolvendo fetos com gastrosquise isolada, tem como objetivo:

\section{Principal:}

- Investigar a predição de resultado perinatal adverso em função da dilatação da alça intestinal exteriorizada.

\section{Secundário:}

- Identificar a melhor medida de corte do diâmetro transverso da alça intestinal exteriorizada na predição de resultados perinatais adversos. 


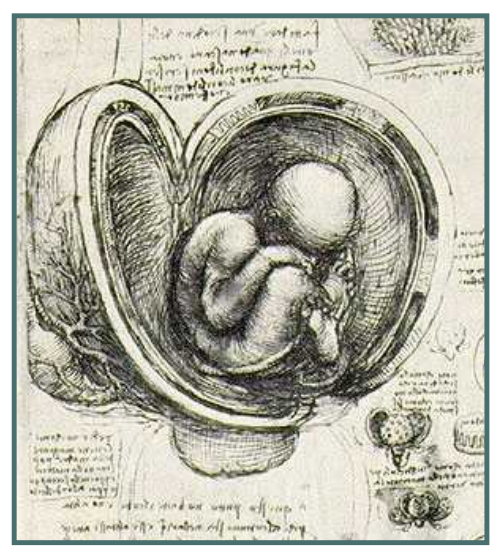




\subsection{DELINEAMENTO DA PESQUISA}

Este é um estudo do tipo coorte retrospectivo.

\section{2 ÉTICA}

O projeto de pesquisa foi aprovado pelo Comitê de Ética do Departamento de Obstetrícia e Ginecologia e pela Comissão de Ética para Análise de Projetos de Pesquisa (CAPPesq) do HCFMUSP em 12/03/2009 (Projeto de pesquisa $n^{\circ} 0007 / 09$ ) (Anexo 1).

Não foi aplicado o Termo de Consentimento Livre e Esclarecido por se tratar de estudo retrospectivo.

\subsection{CASUÍSTICA}

Foram avaliados os prontuários dos casos de gastrosquise fetal acompanhados pelo Setor de Medicina Fetal da Clínica Obstétrica do Hospital das Clínicas da Faculdade de Medicina da Universidade de São Paulo (HCFMUSP), no período de janeiro de 1997 a agosto de 2009. 


\subsection{MÉTODO}

\subsubsection{SELEÇÃO DO GRUPO DE ESTUDO}

\subsubsection{Critérios de Inclusão:}

Fizeram parte dos critérios de inclusão ao estudo:

- Gestação única com feto vivo e com diagnóstico ultrassonográfico de gastrosquise, isolada, tendo sido realizado ou confirmado no Setor de Medicina Fetal da Clínica Obstétrica do HCFMUSP;

- Casos com a medida do diâmetro transverso da maior alça intestinal herniada realizada até três semanas antes do parto;

- Resultados pós-natais conhecidos.

\subsubsection{COLETA DOS DADOS}

A identificação dos casos foi realizada utilizando-se dos sistemas informatizados de dados do setor de Medicina Fetal da Clínica Obstétrica do HCFMUSP. Foram selecionados os casos de gestações únicas com gastrosquise fetal isolada referenciadas e acompanhadas, nesse serviço, no período de janeiro de 1997 a agosto de 2009, que tinham pelo menos um exame ultrassonográfico realizado antes do parto.

As informações relativas ao parto e aos dados pós-natais dos RNs foram obtidas pelo prontuário da paciente no Sistema informatizado da Enfermaria da Clínica Obstétrica do HCFMUSP.

Os dados referentes ao procedimento cirúrgico e ao período de internação no pós-operatório do $\mathrm{RN}$ foram obtidos pelo prontuário do paciente no Departamento de Cirurgia Pediátrica do Instituto da Criança do HCFMUSP.

Também foi realizado contato telefônico ou pessoal para se obter as informações nos casos em que o parto não ocorreu na referida instituição. 


\subsubsection{PROTOCOLO DE ATENDIMENTO DAS GESTANTES COM FETO PORTADOR DE GASTROSQUISE}

\subsubsection{Metodologia do exame ultrassonográfico no seguimento dos casos}

A gestante com diagnóstico pré-natal de gastrosquise fetal foi referenciada a este centro terciário para avaliação especializada. Portanto, exame minucioso da morfologia fetal e ecocardiografia fetal foram realizados para confirmar a anormalidade e investigar a presença de outras malformações associadas.

Os exames foram realizados pelos médicos do Setor de Medicina Fetal do HCFMUSP, sendo a grande maioria pela equipe que acompanha especificamente esse tipo de malformação fetal.

\subsection{Aparelhos utilizados}

Os exames foram realizados pela via transabdominal com transdutor convexo 3,5 MHz, modo B (dinâmico) capacitado com precisão de medida em décimos de milímetros, nos aparelhos disponíveis no Setor de Medicina Fetal da Clínica Obstétrica do HCFMUSP, dentre os quais:

- Corevision, Toshiba (Japão);

- HDI 3000, ATL (EUA);

- Envisor, Philips (Holanda);

- Voluson 730, General Eletrics (Áustria).

\subsection{Diagnóstico de gastrosquise}

Foi considerado diagnóstico de gastrosquise a presença de herniação de vísceras abdominais, por meio de abertura na parede abdominal, no líquido amniótico sem membrana peritoneal recobrindo o conteúdo exteriorizado. No corte transversal do abdome, foi identificada a abertura da parede abdominal e o cordão umbilical com inserção normal e adjacente à abertura. 


\subsection{Avaliação Fetal}

Os fetos diagnosticados com gastrosquise foram acompanhados seriadamente com exame ultrassonográfico e a cada retorno foi avaliado:

- Crescimento fetal: o peso fetal estimado foi calculado pela combinação dos parâmetros ultrassonográficos medida do diâmetro biparietal, circunferências cefálica e abdominal e comprimento do fêmur ${ }^{(129)}$.

- Abertura na parede abdominal: aferida a extensão da abertura do abdome fetal no corte transverso em milímetros. Não foi considerado, nessa aferição, o cordão umbilical, que se encontra justaposto à abertura da parede.

- Conteúdo exteriorizado e medida da alça intestinal exteriorizada: foram identificadas as vísceras abdominais herniadas, bem como seu aspecto. Identificada a alça com maior dilatação e obtido o seu corte transverso. Os calibradores foram posicionados delimitando apenas o lúmen da alça de modo que a medida não incluiu a espessura da parede da alça (medida "internainterna") ${ }^{(18)}$ (Figura 12).

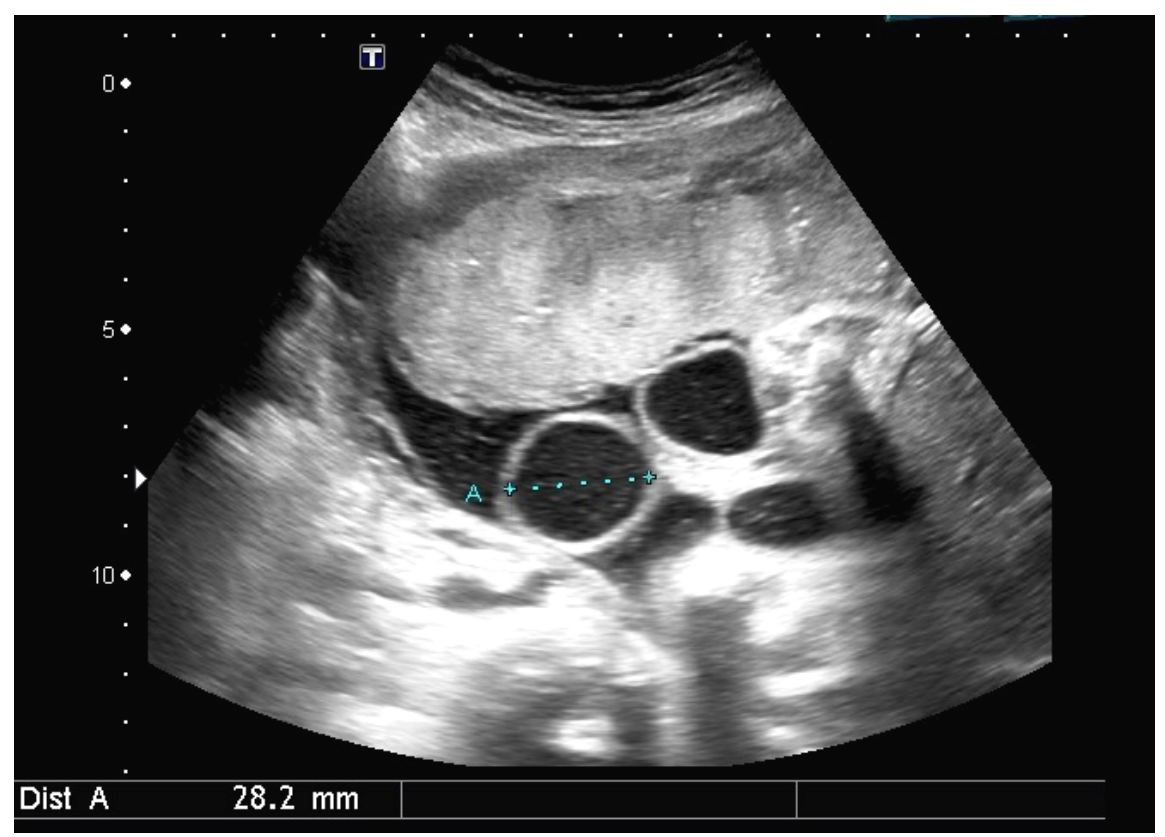

FONTE: HCFMUSP

Figura 12 - Demonstração da técnica para medida do diâmetro da alça intestinal exteriorizada em corte transverso da mesma. Calipers posicionados nas faces internas da alça, delimitando apenas o lúmen $(28,2 \mathrm{~mm})$ 
- Conteúdo intra-abdominal: identificado as vísceras que permanecem intraabdominais, avaliado o aspecto das estruturas e a presença de dilatação do estômago e/ou das alças intestinas intra-abdominais ${ }^{(34)}$ (Figura 13).

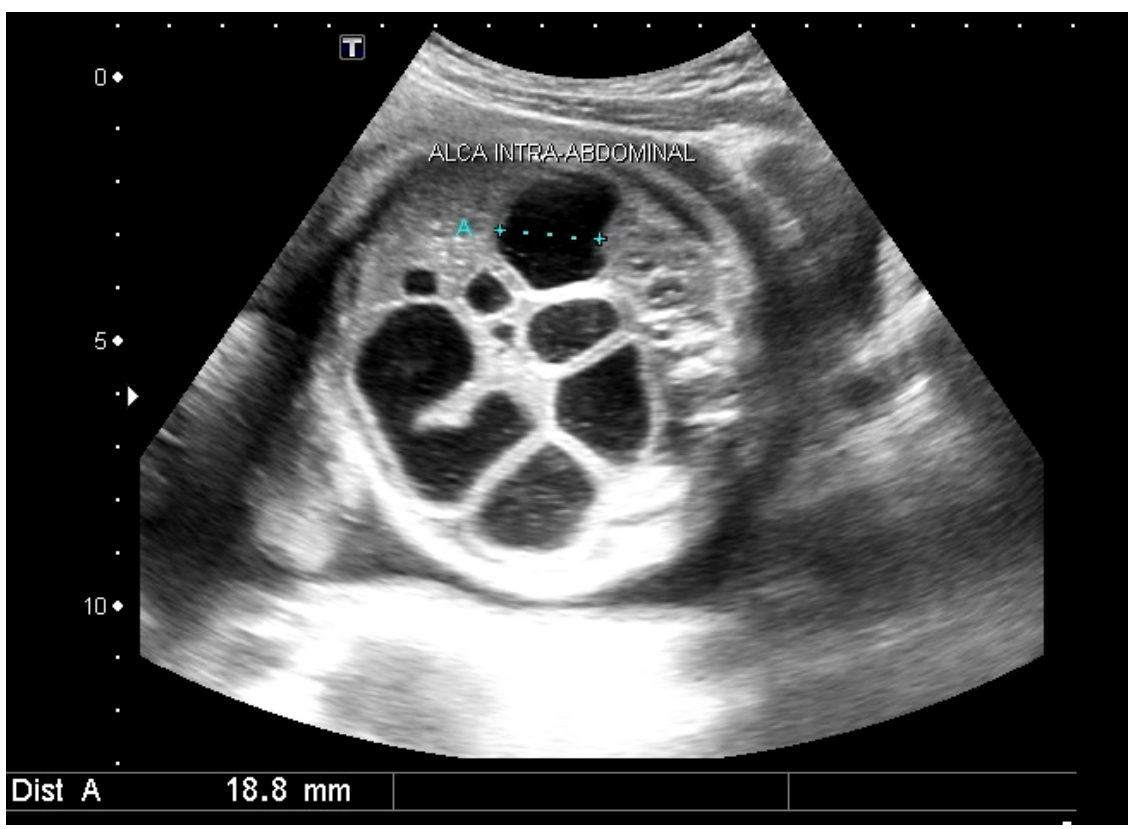

FONTE: HCFMUSP

Figura 13 - Demonstração ultrassonográfica de alças intestinais intra-abdominais dilatadas $(18,8 \mathrm{~mm})$ no terceiro trimestre de gestação, no corte transverso do abdome fetal

- Volume de líquido amniótico: até 27 semanas de gestação o volume de líquido amniótico foi avaliado subjetivamente pela técnica descrita por Philipson et al., sendo considerado oligoidrâmnio: 1) pequena quantidade de líquido amniótico entre as interfaces fetais e a parede uterina; 2) constatação de pequenas partes fetais muito"aglomeradas"; 3) diminuição evidente de líquido amniótico. Os critérios subjetivos que consideram poliidrâmnio incluem: 1) discrepância entre o tamanho do feto e a quantidade de líquido amniótico; 2) bolsões grandes de líquido amniótico; 3) presença de espaços entre o feto e a parede uterina anterior $^{(130)}$. Após 28 semanas, o volume de líquido amniótico foi quantificado por meio do Índice de Líquido Amniótico pela técnica dos quatro quadrantes de Phelan $^{(131)}$. 
- Vitalidade fetal: após 28 semanas de gestação, avalia-se a vitalidade fetal por meio de: 1) perfil biofísico fetal modificado por Miyadahira (1997) ${ }^{(132)}$ que considera os parâmetros: volume do líquido amniótico, movimentos respiratórios fetais, movimentos corpóreos fetais, tônus fetal e cardiotocografia basal; que constitui na modificação do perfil biofísico fetal descrito por Manning et al. em 1980 e reformulado em $1990^{(133)}$ no parâmetro análise da cardiotocografia; 2) dopplervelocimetria da artéria umbilical, na porção próxima à inserção do cordão umbilical na placenta $(\text { de } 3 \text { a } 5 \mathrm{~cm})^{(134)}$.

\subsection{Datação da gestação}

Para a datação da gestação, foi considerada a idade gestacional estimada pela data da última menstruação (DUM), quando esta estava de acordo com a ultrassonografia do $1^{\mathrm{o}}$ trimestre.

Optou-se pela adoção da idade gestacional estimada por meio da ultrassonografia nos seguintes casos:

- DUM incerta / desconhecida;

- Discrepância entre a idade gestacional menstrual e a biometria fetal maior que 7 dias, na avaliação do primeiro trimestre (entre 6 a 14 semanas);

- Discrepância entre a idade gestacional menstrual e a biometria fetal maior que 10 dias, na avaliação do segundo trimestre, em dois exames consecutivos e em intervalos próximos.

O parâmetro ultrassonográfico utilizado para datar a gestação no $1^{\circ}$ trimestre foi o comprimento cabeça-nádega, obtido em imagem sagital estrita do pólo cefálico e tronco fetais em posição neutra ${ }^{(135)}$. No $2^{\circ}$ trimestre de gestação, o parâmetro utilizado foi a medida do diâmetro biparietal do pólo cefálico ${ }^{(136)}$. 


\subsection{Seguimento dos casos}

O pré-natal e o acompanhamento clínico da gestante foram continuados na Unidade Básica de Saúde de origem. O seguimento ultrassonográfico realizado pelo setor de Medicina Fetal da Clínica Obstétrica da FMUSP é descrito a seguir.

O protocolo assistencial incluiu seguimento ultrassonográfico fetal a cada 3-4 semanas até a $30^{\mathrm{a}}$ semana de gestação. Após essa idade gestacional, a avaliação foi feita a cada duas semanas, e, após a $35^{\text {a }}$ semana, por avaliações semanais. As avaliações realizadas foram descritas no item 4.4.3.1.3.

As gestantes foram orientadas quanto à importância do repouso físico e da ingesta hídrica (três litros de água por dia) para manutenção do volume de líquido amniótico $^{(137)}$.

Cesárea eletiva foi geralmente agendada com 37 semanas de gestação. Essa recomendação baseia-se nos maiores índices de óbito fetal no terceiro trimestre da gestação e alteração de vitalidade fetal no final do terceiro trimestre, levando à necessidade de cesárea de urgência nesses últimos casos $(19,24)$. A realização da cesárea permite o planejamento do nascimento, sem sofrimento fetal, e de modo que o recém-nascido receba o atendimento assistencial multidisciplinar, com equipe de cirurgia pediátrica preparada para a correção cirúrgica imediata.

\subsubsection{VARIÁVEIS ANALISADAS NA POPULAÇÃO DO ESTUDO}

\subsubsection{Variáveis maternas - dados demográficos:}

- Idade materna (anos);

- Número de gestações anteriores (primigesta; secundigesta; duas ou mais gestações anteriores);

- Raça (branca; não-branca);

- Antecedentes pessoais (presença/ausência de doenças prévias);

- Tabagismo (sim; não). 


\subsubsection{Variáveis fetais}

- Idade gestacional no primeiro exame realizado na instituição (semanas);

- Valor do diâmetro transverso da maior alça intestinal exteriorizada (expresso em $\mathrm{mm})$;

- Número de ultrassonografias realizadas por gestação;

- Idade gestacional da última ultrassonografia realizada antes do parto (semanas);

- Ocorrência de óbito fetal.

\subsubsection{Recém-nascido}

- Via de parto (cesareana; vaginal);

- Idade Gestacional no dia do parto (semanas);

- Gênero (feminino; masculino);

- $\quad$ Peso ao nascimento (gramas);

- Classificação do recém-nascido segundo a adequação do peso à idade gestacional, pela curva de Alexander et al. (1996) ${ }^{(138)}$ (foram considerados adequados para a idade gestacional aqueles com peso entre os percentis 10 e 90 da curva utilizada; e considerados pequeno para a idade gestacional, aqueles de peso inferior ao $10^{\circ}$ percentil da mesma curva, conforme idade gestacional);

- Índice de Apgar de $1^{\circ}$ minuto $(<7 ; \geq 7)$;

- Índice de Apgar de $5^{\circ}$ minuto $(<7 ; \geq 7)$;

- Índice de Apgar de $10^{\circ}$ minuto $(<7 ; \geq 7)$;

- Condições de Nascimento: nativivo ou natimorto;

- Presença de complicações intestinais associadas: atresia, perfuração, necrose ou volvo;

- Tipo de correção cirúrgica: fechamento primário ou em duas ou mais etapas; 
- Morbidade: Tempo de internação hospitalar, tempo de uso da nutrição parenteral, tempo para iniciar a dieta oral (expresso em dias) e evolução para síndrome do intestino curto (sim ou não);

- Mortalidade: ocorrência de óbito neonatal e sobrevida.

\subsubsection{ANÁLISE ESTATÍSTICA DOS RESULTADOS}

As variáveis categóricas foram descritas pelas frequências absolutas e relativas (contagem e percentual). As variáveis numéricas foram analisadas pela observação do valor mínimo e máximo, e do cálculo de média, mediana e desviopadrão ${ }^{(139)}$.

Foi realizada análise por regressão para verificar a relação entre a medida do diâmetro transverso da alça e a idade gestacional. Para isso, foram utilizadas todas as medidas obtidas até três semanas antes do parto. A medida do diâmetro transverso da alça foi ajustada para a idade gestacional pela divisão do valor observado pelo valor esperado para a respectiva idade gestacional.

As medidas do maior diâmetro transverso da alça intestinal, avaliada até três semanas antes do parto nas 94 gestações, foram utilizadas para o cálculo da predição do resultado adverso da gestação.

A curva Receiver operating characteristic (ROC) foi utilizada para avaliar o melhor valor de corte do diâmetro transverso da alça para a predição de resultado adverso.

Os casos foram agrupados de acordo com o melhor valor de corte da dilatação intestinal identificado, e, comparados, utilizando-se o teste de Mann-Whitney para as variáveis não-paramétricas e os testes qui-quadrado e exato de Fisher para testar as proporções $^{(140)}$.

Os testes foram realizados com nível de significância de 5\%. 


\subsubsection{CARACTERIZAÇÃO DA POPULAÇÃO DO ESTUDO}

Durante o período compreendido entre janeiro de 1997 a agosto de 2009, 174 casos de gastrosquise foram acompanhados no setor de Medicina Fetal da Clínica Obstétrica do HCFMUSP, sendo que 80 casos $(45,9 \%)$ não preencheram os critérios de inclusão estabelecidos ( 2 gestações gemelares, 22 casos com outras malformações associadas, 14 casos com defeito extenso da parede abdominal - compatíveis com Síndrome da Banda Amniótica, 2 casos associados à extrofia vesical, 20 casos sem aferição do diâmetro transverso da alça, 10 casos com a última medida do diâmetro transverso da alça a mais de 3 semanas do parto e em 10 casos não foi obtido o resultado da gestação).

A amostra final foi constituída de 94 gestações de fetos únicos e portadores de gastrosquise isolada, que tiveram a medida do maior DTA até três semanas antes do nascimento e com desfecho da gestação conhecido.

As pacientes foram divididas em dois grupos para comparação:

- Grupo sem resultados adversos: incluiu os casos que evoluíram satisfatoriamente, sem complicações ao nascimento e após a correção cirúrgica;

- Grupo com resultados adversos: foram considerados os casos de óbito fetal, óbito neonatal e/ou presença de complicações intestinais. 


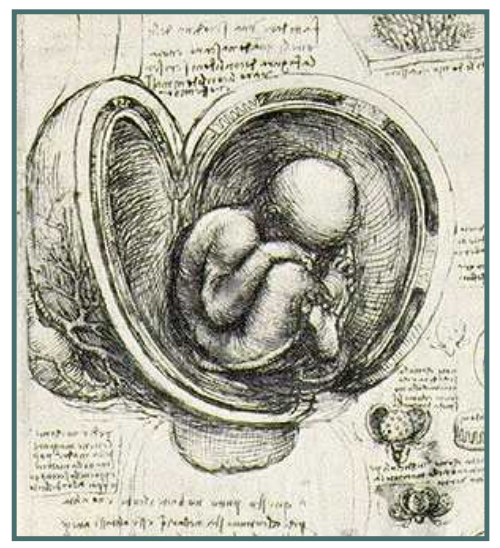


A amostra final foi constituída de 94 gestações de fetos únicos e portadores de gastrosquise isolada, que tiveram a medida do maior diâmetro transverso da alça até três semanas antes do nascimento e com desfecho da gestação conhecido.

\subsection{DESCRIÇÃO DOS DADOS DEMOGRÁFICOS DAS GESTANTES}

A idade materna variou de 15,9 anos (mínimo) a 33,3 anos (máximo), sendo que a média foi de 21,4 $\pm 3,9$ anos e mediana de 20,3 anos.

A Tabela 3 apresenta a distribuição do número de gestações, etnia, hábito de tabagismo e presença de doenças prévias entre as gestantes incluídas no estudo. Foi considerado grupo de etnia não-branca as mulheres de cor parda, cor negra e cor amarela. 
Tabela 3 - Distribuição do número de gestações, etnia, hábito de tabagismo e presença de doenças prévias entre as gestantes de fetos portadores de gastrosquise - HCFMUSP - janeiro de 1997 a agosto de 2009

\begin{tabular}{|c|c|c|}
\hline VARIÁVEL & $\begin{array}{c}\text { FREQUÊNCIA } \\
\text { (n) }\end{array}$ & $\begin{array}{c}\text { PROPORÇÃO } \\
(\%)\end{array}$ \\
\hline \multicolumn{3}{|l|}{ NÚMERO DE GESTAÇÕES } \\
\hline Primigesta & 60 & 63,8 \\
\hline Secundigesta & 13 & 13,8 \\
\hline Duas gestações anteriores ou mais & 12 & 12,8 \\
\hline Ignorado & 9 & 9,6 \\
\hline TOTAL & 94 & 100 \\
\hline \multicolumn{3}{|l|}{ ETNIA } \\
\hline Branca & 54 & 57,4 \\
\hline Não-branca & 39 & 41,5 \\
\hline Ignorado & 1 & 1,1 \\
\hline TOTAL & 94 & 100 \\
\hline \multicolumn{3}{|l|}{ TABAGISMO } \\
\hline Sim & 17 & 18,1 \\
\hline Não & 66 & 70,2 \\
\hline Ignorado & 11 & 11,7 \\
\hline TOTAL & 94 & 100 \\
\hline \multicolumn{3}{|l|}{ DOENÇAS PRÉVIAS } \\
\hline Sim & 9 & 9,6 \\
\hline Não & 73 & 77,6 \\
\hline Ignorado & 12 & 12,8 \\
\hline TOTAL & 94 & 100 \\
\hline
\end{tabular}

NOTA: $\mathrm{n}=$ número de casos

A maioria das mulheres era primigesta $(63,8 \%)$ e de cor branca $(57,4 \%)$.

Aproximadamente $1 / 5(18,1 \%)$ das gestantes eram tabagistas e a maioria delas não apresentava doença prévia associada (77,6\%), tendo sido referidas: hipotireoidismo $(\mathrm{n}=2)$, asma $(\mathrm{n}=1)$, hipertensão arterial crônica $(\mathrm{n}=1)$, crises convulsivas $(\mathrm{n}=1)$, anemia $(\mathrm{n}=1)$, portadora do vírus HPV $(\mathrm{n}=1)$, polipose intestinal $(n=1)$ e gastrite $(n=1)$. 


\subsection{DESCRIÇÃO DAS VARIÁVEIS FETAIS}

A idade gestacional da realização do exame variou de 31,3 a 39,1 semanas (média $=35,6$ semanas; $\mathrm{DP}= \pm 1,6$ semanas $/$ mediana $=35,8$ semanas).

A medida do diâmetro da alça externa oscilou de 9,4 a 44,5 $\mathrm{mm}$ (média = $20,5 \mathrm{~mm} ; \mathrm{DP}= \pm 6,2 \mathrm{~mm} /$ mediana $=19,8 \mathrm{~mm}$ ).

O intervalo médio entre a última medida da alça intestinal e o parto foi de 6,2 dias. A distribuição do tempo decorrido entre a última medida da alça intestinal e o parto está descrita na Tabela 4.

Tabela 4 - Descrição do tempo médio entre a última medida da alça intestinal e o parto nas 94 gestações avaliadas - HCFMUSP - janeiro de 1997 a agosto de 2009

VARIÁVEL

FREQUENNCIA

(n)

$\Delta t$ de tempo entre medida da alça

e parto

$$
\begin{gathered}
0-6 \text { dias } \\
7-13 \text { dias } \\
14-20 \text { dias }
\end{gathered}
$$

TOTAL
49

37

8

94
PROPORÇÃO

(\%)

\footnotetext{
NOTA: $\Delta \mathrm{t}=$ intervalo de tempo; $\mathrm{n}=$ número de casos
} 


\subsection{DESCRIÇÃO DAS VARIÁVEIS DO RECÉM-NASCIDO}

A Tabela 5 descreve a análise das variáveis dos recém-nascidos com gastrosquise em relação ao tipo de parto, gênero dos recém-nascidos, resultado da gestação e sobrevida.

Tabela 5 - Descrição do tipo de parto, gênero, resultado da gestação e sobrevida dos recém-nascidos com gastrosquise - HCFMUSP - janeiro de 1997 a agosto de 2009

\begin{tabular}{lcc}
\hline \multicolumn{1}{c}{ VARIÁVEL } & $\begin{array}{c}\text { FREQUÊNCIA } \\
(\mathbf{n})\end{array}$ & $\begin{array}{c}\text { PROPORÇÃO } \\
(\%)\end{array}$ \\
\hline TIPO DE PARTO & 88 & 93,6 \\
Cesárea & 6 & 6,4 \\
Vaginal & 94 & 100 \\
TOTAL & & \\
GÊNERO RN & 46 & 48,9 \\
Masculino & 48 & 51,1 \\
Feminino & 94 & 100 \\
TOTAL & & \\
RESULTADO DA GESTAÇÃO & 5 & 5,3 \\
Natimorto & 89 & 94,7 \\
Nativivo & 94 & 100 \\
TOTAL & & \\
\hline SOBREVIDA & 54 & 5,6 \\
Óbito neonatal & 89 & 94,4 \\
Vivo & 54 & 100 \\
TOTAL & & \\
\hline
\end{tabular}

NOTA: $\mathrm{n}$ = número de casos; $\mathrm{RN}$ = recém-nascido 
Seis $(6,4 \%)$ partos foram vaginais, sendo $5 / 6(83,4 \%)$ os casos de óbito fetal. O parto vaginal com feto vivo ocorreu em outro serviço, com 35 semanas e 5 dias, peso ao nascimento de 2015 g, com evolução satisfatória no pós-operatório, sem complicações e com alta hospitalar após 30 dias de internação, segundo dados obtidos.

Em relação aos partos cesáreos, sessenta e quatro $(72,7 \%)$ foram indicados por trabalho de parto espontâneo, rotura das membranas ovulares ou alteração do perfil biofísico; 24 (27,3\%) foram cesarianas eletivas.

A idade gestacional do parto das 94 gestações variou de 32,1 a 40,4 semanas (média $=36,5$ semanas; $\mathrm{DP}= \pm 1,4$ semanas $/$ mediana $=37$ semanas).

Três $(3,2 \%)$ partos ocorreram abaixo de 34 semanas devido trabalho de parto prematuro espontâneo.

$\mathrm{O}$ peso do $\mathrm{RN}$ variou de $1220 \mathrm{~g}$ a $3520 \mathrm{~g}$ (média $=2441 \mathrm{~g} \pm \mathrm{DP}=432 \mathrm{~g}$; mediana $=2428 \mathrm{~g})$.

Dezesseis das 94 gestações (17,0\%) apresentaram resultados adversos: 5/94 $(5,3 \%)$ casos de óbito fetal; 5/89 (5,6\%) evoluíram para óbito neonatal e 6/89 (6,7\%) nasceram vivos, apresentaram complicações intestinais e sobreviveram. Quatro óbitos neonatais foram precoces $(<28$ dias de vida) e 1 tardio $(\geq 28$ dias de vida), sendo que dois casos de ONN também apresentavam complicações intestinais. Os 16 casos que fazem parte do grupo com resultados adversos estão descritos na Tabela 6 . 
Tabela 6 - Evolução dos 16 casos de gastrosquise fetal isolada com resultados adversos - HCFMUSP - janeiro de 1997 a agosto de 2009

\begin{tabular}{|c|c|c|c|c|c|c|c|c|}
\hline Caso & Desfecho & $\begin{array}{l}\text { IG no } \\
\text { parto } \\
(\text { sem) }\end{array}$ & $\begin{array}{c}\text { Última } \\
\text { medida } \\
\text { DTA } \\
(\mathrm{mm}) \\
\end{array}$ & $\begin{array}{c}\Delta t \\
\text { até } 0 \\
\text { parto } \\
\text { (dias) } \\
\end{array}$ & $\begin{array}{l}\text { PN (g) e } \\
\text { percentil }\end{array}$ & $\begin{array}{c}\Delta \text { t óbito } \\
\text { (dias) }\end{array}$ & $\begin{array}{l}\text { Complicações } \\
\text { intestinais }\end{array}$ & $\begin{array}{l}\text { Reintervenção } \\
\text { cirúrgica }\end{array}$ \\
\hline 1 & OF & $346 / 7$ & 16,7 & 8 & $\begin{array}{c}2030 \\
(<\mathrm{P} 10)\end{array}$ & - & - & - \\
\hline 2 & OF & $321 / 7$ & 17 & 2 & $\begin{array}{l}1220 \\
(<\mathrm{P} 5)\end{array}$ & - & - & - \\
\hline 3 & OF & $374 / 7$ & 18,7 & 9 & $\begin{array}{c}2850 \\
(\mathrm{P} 10-\mathrm{P} 50)\end{array}$ & - & - & - \\
\hline 4 & OF & $353 / 7$ & 22,5 & 7 & $\begin{array}{l}1870 \\
(<\mathrm{P} 5)\end{array}$ & - & - & - \\
\hline 5 & OF & $365 / 7$ & 35 & 7 & $\begin{array}{l}1800 \\
(<\mathrm{P} 5)\end{array}$ & - & - & - \\
\hline 6 & ONN & $372 / 7$ & 11,6 & 19 & $\begin{array}{l}2300 \\
(<\mathrm{P} 5)\end{array}$ & 2 & - & - \\
\hline 7 & ONN & $355 / 7$ & 16,6 & 0 & $\begin{array}{c}2270 \\
(<\mathrm{P} 10)\end{array}$ & 8 & $\begin{array}{l}\text { perfuração } \\
\text { jejuno }\end{array}$ & Sim \\
\hline 8 & ONN & $374 / 7$ & 20 & 7 & $\begin{array}{l}2425 \\
(<\mathrm{P} 5)\end{array}$ & 2 & J & - \\
\hline 9 & ONN & $364 / 7$ & 20 & 1 & $\begin{array}{c}2420 \\
(<\mathrm{P} 10)\end{array}$ & 2 & - & - \\
\hline 10 & ONN & $325 / 7$ & 25,9 & 10 & $\begin{array}{c}2000 \\
(\mathrm{P} 10-\mathrm{P} 50)\end{array}$ & 109 & $\begin{array}{c}\text { atresia jejuno } \\
+ \text { necrose } \\
\text { extensa }\end{array}$ & Sim \\
\hline 11 & Vivo & $344 / 7$ & 16 & 6 & $\begin{array}{c}2400 \\
(\mathrm{P} 10-\mathrm{P} 50)\end{array}$ & 64 & atresia ceco & Sim \\
\hline 12 & Vivo & $344 / 7$ & 19 & 0 & $\begin{array}{c}2270 \\
(\mathrm{P} 10-\mathrm{P} 50)\end{array}$ & 150 & atresia & Sim \\
\hline 13 & Vivo & $365 / 7$ & 27,5 & 4 & $\begin{array}{c}2520 \\
(\mathrm{P} 10-\mathrm{P} 50)\end{array}$ & 51 & atresia íleo & Sim \\
\hline 14 & Vivo & $345 / 7$ & 28 & 12 & $\begin{array}{c}2460 \\
(\mathrm{P} 10-\mathrm{P} 50)\end{array}$ & 50 & $\begin{array}{c}\text { atresia + } \\
\text { 'vanishing } \\
\text { midgut' }\end{array}$ & Sim \\
\hline 15 & Vivo & $336 / 7$ & 31,4 & 13 & $\begin{array}{c}2000 \\
(\mathrm{P} 10-\mathrm{P} 50)\end{array}$ & 63 & $\begin{array}{c}\text { atresia }+ \\
\text { volvo }\end{array}$ & Sim \\
\hline 16 & Vivo & $352 / 7$ & 32,5 & 1 & $\begin{array}{c}2920 \\
(\mathrm{P} 10-\mathrm{P} 50)\end{array}$ & 31 & necrose íleo & Sim \\
\hline
\end{tabular}

NOTA: $\Delta$ t: intervalo de tempo; DTA: diâmetro transverso da alça intestinal; g: gramas; IG: idade gestacional; OF: óbito fetal; ONN: óbito neonatal; sem: semanas; $\mathrm{P}=$ percentil; $\mathrm{PN}$ : peso ao nascimento; Vanishing midgut: condição que foi diagnosticada como gastrosquise, mas a abertura da parede fecha espontaneamente durante a gestação e as alças intestinais não estão mais herniadas, porém o intestino está compactado em uma massa única de fibrose com diversas malformações intestinais associadas, dentro da cavidade abdominal 


\subsection{COMPARAÇÃO DAS VARIÁVEIS MATERNAS, FETAIS E DO RECÉM-NASCIDO ENTRE OS GRUPOS COM E SEM RESULTADOS PERINATAIS ADVERSOS}

A média da idade materna no grupo com resultados perinatais adversos foi de $21,6 \pm 2,6$ anos e, no grupo sem resultados adversos, foi de $21,3 \pm 4,1$ anos. Não houve diferença estatística em relação à idade materna entre os grupos com e sem resultados adversos $(p=0,761$; teste $\mathrm{t}$ de Student $)$.

As variáveis das avaliações ultrassonográficas fetais estão descritas na Tabela 7 e foram comparadas entre os grupos com e sem resultados perinatais adversos.

Tabela 7 - Comparação das variáveis fetais e do recém-nascido de acordo com os resultados perinatais - HCFMUSP - janeiro de 1997 a agosto de 2009

\begin{tabular}{cccc}
\hline VARIÁVEL & $\begin{array}{c}\text { Grupo com resultados } \\
\text { adversos } \\
(\mathbf{n = 1 6 )}\end{array}$ & $\begin{array}{c}\text { Grupo sem resultados } \\
\text { adversos } \\
(\mathbf{n = 7 8 )}\end{array}$ & $\boldsymbol{p}$ \\
\hline No exames por gestação & $\begin{array}{c}3,08 \pm 0,99 \\
(2,0-5,0)\end{array}$ & $\begin{array}{c}3,12 \pm 1,14 \\
(2,0-6,0)\end{array}$ & 0,964 \\
Idade gestacional da primeira & $29,2 \pm 3,9$ & $29,6 \pm 4,3$ & 0,3229 \\
USG (semanas) & $(23,7-34,7)$ & $(19-37,6)$ & \\
Idade gestacional da última & $34,4 \pm 1,7$ & $35,8 \pm 1,4$ & 0,008 \\
USG (semanas) & $(31,3-36,6)$ & $(32,3-39,1)$ & \\
Diâmetro da alça na última & $22,4 \pm 6,8$ & $20,1 \pm 6,0$ & 0,176 \\
avaliação (mm) & $(11,6-35)$ & $(9,4-44,5)$ & \\
\hline
\end{tabular}

NOTA: Valores expressos em média \pm desvio padrão (intervalo mínimo - máximo) $\mathrm{n}=$ número de casos; $\mathrm{N}^{\mathrm{o}}=$ número; $\mathrm{USG}=$ ultrassonografia; $p=$ nível descritivo de probabilidade $(p<0,05)$ 
Conforme apresentado na Tabela 7 , os grupos diferem em relação à idade gestacional da última ultrassonografia, realizada antes do parto. O grupo com resultados adversos apresenta idade gestacional, na última ultrassonografia, significativamente menor quando comparado ao grupo sem resultado adverso (teste $t$ de Student; $p=0,008)$.

Os grupos não diferem em relação ao número de exames realizados (teste de Mann-Whitney; $p=0,964)$ e não apresentam diferença significativa em relação à média da idade gestacional da primeira ultrassonografia (teste $\mathrm{t}$ de Student; $p=0,329)$.

A Tabela 8 apresenta as variáveis do recém-nascido em relação à: via de parto, idade gestacional e peso ao nascer, adequação do peso e escore de Apgar ao nascimento. As variáveis foram comparadas entre os grupos com e sem resultados perinatais adversos. A variável adequação de peso ao nascimento foi baseada na curva de Alexander et al. ${ }^{(138)}$. Considerou-se escore de Apgar $<7$ como critério de gravidade para pior prognóstico perinatal. 
Tabela 8 - Descrição das variáveis do recém-nascido com gastrosquise isolada segundo os grupos de resultados perinatais adversos - HCFMUSP janeiro de 1997 a agosto de 2009

\begin{tabular}{|c|c|c|c|}
\hline VARIÁVEL & $\begin{array}{c}\text { Grupo com resultados } \\
\text { adversos } \\
(\mathbf{n}=16)\end{array}$ & $\begin{array}{c}\text { Grupo sem resultados } \\
\text { adversos } \\
(\mathbf{n}=78)\end{array}$ & $p$ \\
\hline & $\begin{array}{l}\text { Média } \pm \text { DP } \\
\text { (mín - máx) }\end{array}$ & $\begin{array}{l}\text { Média } \pm \text { DP } \\
\text { (mín - máx) }\end{array}$ & $p$ \\
\hline $\begin{array}{c}\text { Idade gestacional no parto } \\
\text { (semanas) }\end{array}$ & $\begin{array}{c}35,6 \pm 2,0 \\
(32,1-40,4)\end{array}$ & $\begin{array}{c}36,7 \pm 1,2 \\
(34,1-39,6)\end{array}$ & 0,054 \\
\hline \multirow[t]{2}{*}{ Peso RN (g) } & $\begin{array}{c}2235 \pm 415 \\
(1220-2920)\end{array}$ & $\begin{array}{c}2484 \pm 425 \\
(1555-3520)\end{array}$ & 0,035 \\
\hline & n (proporção) & n (proporção) & $p$ \\
\hline Parto Cesárea & $11(68,8 \%)$ & $77(98,7 \%)$ & $<0,001$ \\
\hline \multicolumn{4}{|l|}{$\begin{array}{c}\text { Adequação do peso ao } \\
\text { nascimento }\end{array}$} \\
\hline AIG (entre p10 e p90) & $8(50 \%)$ & $35(44,9 \%)$ & 0,708 \\
\hline PIG $(<$ percentil10) & $8(50 \%)$ & $43(55,1 \%)$ & 0,708 \\
\hline \multicolumn{4}{|l|}{$\begin{array}{c}\text { APGAR }(<7) \\
\left(n^{0} \text { de casos) }\right.\end{array}$} \\
\hline $1^{\mathrm{o}}$ minuto & $1(10,0 \%)$ & $17(33,0 \%)$ & 0,682 \\
\hline $5^{\circ}$ minuto & $0(0,0 \%)$ & $3(4,0 \%)$ & 1 \\
\hline $10^{\circ}$ minuto & $0(0,0 \%)$ & $0(0,0 \%)$ & - \\
\hline
\end{tabular}

NOTA: $\mathrm{AIG}=$ adequado para a idade gestacional, $\mathrm{DP}=$ desvio padrão; $($ mín - máx $)=$ intervalo mínimo e máximo; $\mathrm{n}=$ número de casos; $p=$ nível descritivo de probabilidade $(p<0,05) ; \mathrm{PIG}=$ pequeno para a idade gestacional; proporção = porcentagem; $\mathrm{RN}=$ recém-nascido

Observa-se que os grupos diferem em relação ao tipo de parto (teste exato de Fisher; $p<0,001$ ), com porcentagem significativamente maior de cesárea no grupo sem resultados perinatais adversos.

Os grupos diferem em relação ao peso ao nascimento. $\mathrm{O}$ grupo com resultado adverso apresenta peso ao nascimento significativamente menor quando comparado ao grupo sem resultado adverso (teste t de Student; $p=0,035$ ).

Não houve diferença estatisticamente significativa entre os grupos em relação à classificação do peso ao nascimento pela curva de Alexander (teste qui-quadrado; $p$ $=0,708$ ) e em relação ao escore de Apgar (teste exato de Fisher). 


\subsection{CORRELAÇÃO ENTRE IDADE GESTACIONAL E O DIÂMETRO TRANSVERSO DA ALÇA INTESTINAL AO LONGO DA GESTAÇÃO}

Nas 94 gestações avaliadas foram realizados 253 exames de ultrassonografia (média: 2,7 por paciente). O Gráfico 1 mostra a distribuição do diâmetro transverso da alça externa (DTA) aferido para a idade gestacional por ocasião da medida.

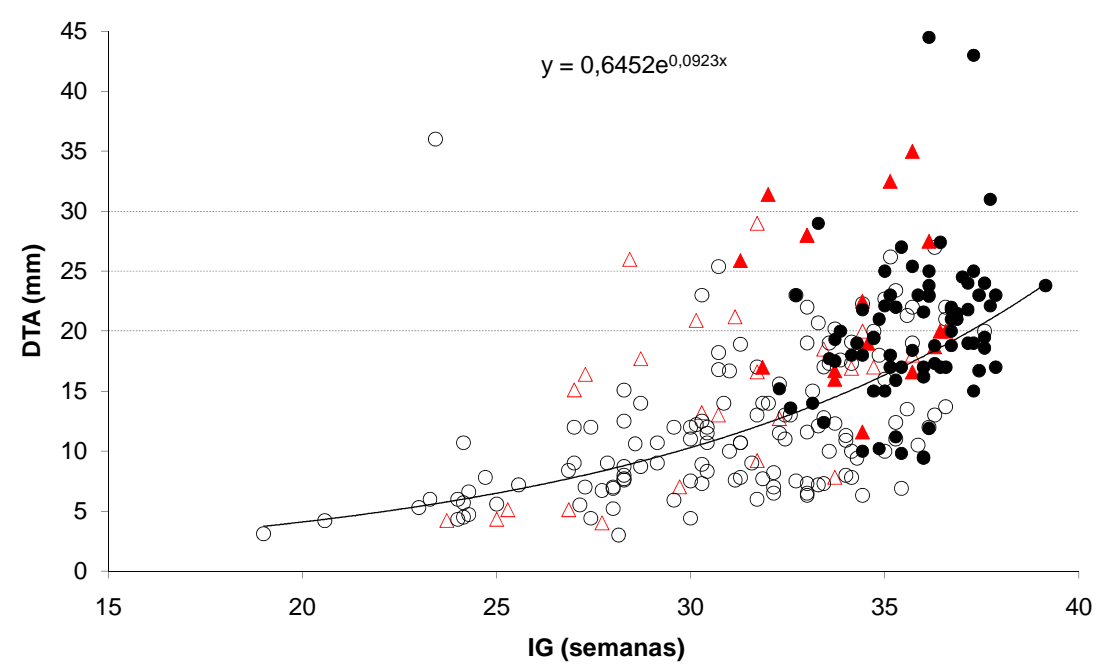

Gráfico 1 - Distribuição do maior diâmetro transverso da alça exteriorizada identificado durante o exame ultrassonográfico, em 94 casos de gastrosquise fetal isolada (253 medidas) - HCFMUSP - janeiro de 1997 a agosto de 2009 - NOTA: DTA = diâmetro transverso da alça; IG = idade gestacional; $\bigcirc=$ pacientes sem resultados adversos $(n=78) ; \bigcirc=$ última medida do DTA antes do parto no grupo sem resultados adversos; $\Delta=$ paciente com resultados adversos $(\mathrm{n}=16) ; \boldsymbol{\Delta}=$ última medida do DTA antes do parto no grupo com resultados adversos; $\boldsymbol{-}=$ Regressão simples DTA $=\left(0,6452 \times \exp ^{(0,0923 \times \text { IG })}\right)$

Foi observada correlação significativa entre o diâmetro transverso da alça intestinal exteriorizada e a idade gestacional $(r=+0,69 ; p<0,001)$. 
Foi possível derivar a função para determinação do DTA esperado para cada idade gestacional:

$$
E=\left(0,645^{*} \exp ^{\left(0,0923^{*} \mathrm{IG}\right)}\right),
$$

onde $\mathrm{E}=$ Diâmetro transverso esperado da alça externa (em milímetros) e IG $=$ idade gestacional (em semanas).

Com base nessa função, o DTA estimado para a idade gestacional nesse grupo de 94 gestações variou de 11,6 a 23,9 mm (média $=17,4 \mathrm{~mm} \pm \mathrm{DP}=2,4 \mathrm{~mm} /$ mediana $=17,5 \mathrm{~mm})$.

\subsection{OBTENÇÃO DO MELHOR VALOR DE CORTE NA PREDIÇÃO DOS RESULTADOS ADVERSOS PERINATAIS}

Para a obtenção de uma medida prognóstica com maior discriminação para os resultados adversos perinatais, foram selecionadas medidas de corte do DTA $(\geq 10$, $15,20,25,0$ e $30,0 \mathrm{~mm}$ ) obtidas até três semanas antes do parto.

Além disso, foi estudado o quociente entre a medida da alça observada $(\mathrm{O})$ e

a medida estimada $\left(E=0,645^{*} \exp ^{\left(0,0923^{*} \mathrm{IG}\right)}\right)$, obtendo-se, assim, uma nova variável (DTA O/E), isto é, um valor da razão DTA O/E para cada idade gestacional. A razão DTA O/E variou de $=0,5$ a 2,5 (média $=1,2 \pm \mathrm{DP}=0,4 /$ mediana $=1,1)$.

Inicialmente foi feita comparação entre os grupos com e sem resultados adversos perinatais em relação ao DTA obtido (O) na USG, com o DTA esperado (E) para aquela idade gestacional (calculada pela formula da IG) e a razão entre essas medidas $(\mathrm{O} / \mathrm{E})$, conforme descrito na Tabela 9. 
Tabela 9 - Valores descritivos do diâmetro transverso da alça obtido e esperado para a idade gestacional, e a relação entre essas medidas, segundo os grupos de resultados - HCFMUSP - janeiro de 1997 a agosto de 2009

\begin{tabular}{lccc}
\hline VARIÁVEL & $\begin{array}{c}\text { Grupo com resultados } \\
\text { adversos } \\
(\mathbf{n = 1 6 )}\end{array}$ & $\begin{array}{c}\text { Grupo sem resultados } \\
\text { adversos } \\
(\mathbf{n}=\mathbf{7 8})\end{array}$ & $\boldsymbol{p}$ \\
\hline Alça no USG (O) & $22,4 \pm 6,8$ & $20,1 \pm 6,0$ & 0,176 \\
Alça calculada (E) & $15,7 \pm 2,4$ & $17,7 \pm 2,3$ & 0,002 \\
Razão O/E & $1,5 \pm 0,5$ & $1,1 \pm 0,3$ & 0,03 \\
\hline
\end{tabular}

NOTA: Valores expressos em média e desvio padrão

$\mathrm{E}=$ esperado; $\mathrm{O}=$ observado; $\mathrm{USG}=$ ultrassonografia

$p=$ nível descritivo de probabilidade do teste $\mathrm{t}$ de Student $(p<0,05)$

Pelos dados apresentados na Tabela 9 observa-se que os grupos diferem em relação às medidas da alça calculadas para a idade gestacional (E) e na razão entre as medidas (DTA O/E).

Com o intuito de buscar a melhor medida prognóstica dos resultados perinatais adversos, foi comparada a razão DTA O/E (obtida para cada idade gestacional) e as diferentes medidas do DTA ( $\geq 10,15,20,25,0$ e 30,0 mm) obtidas pela ultrassonografia.

Calculou-se, por meio da curva ROC (Curva Receiver operating characteristic), o melhor nível de corte de DTA e da razão DTA O/E para predição de resultados perinatais adversos (Gráficos 2 e 3). 


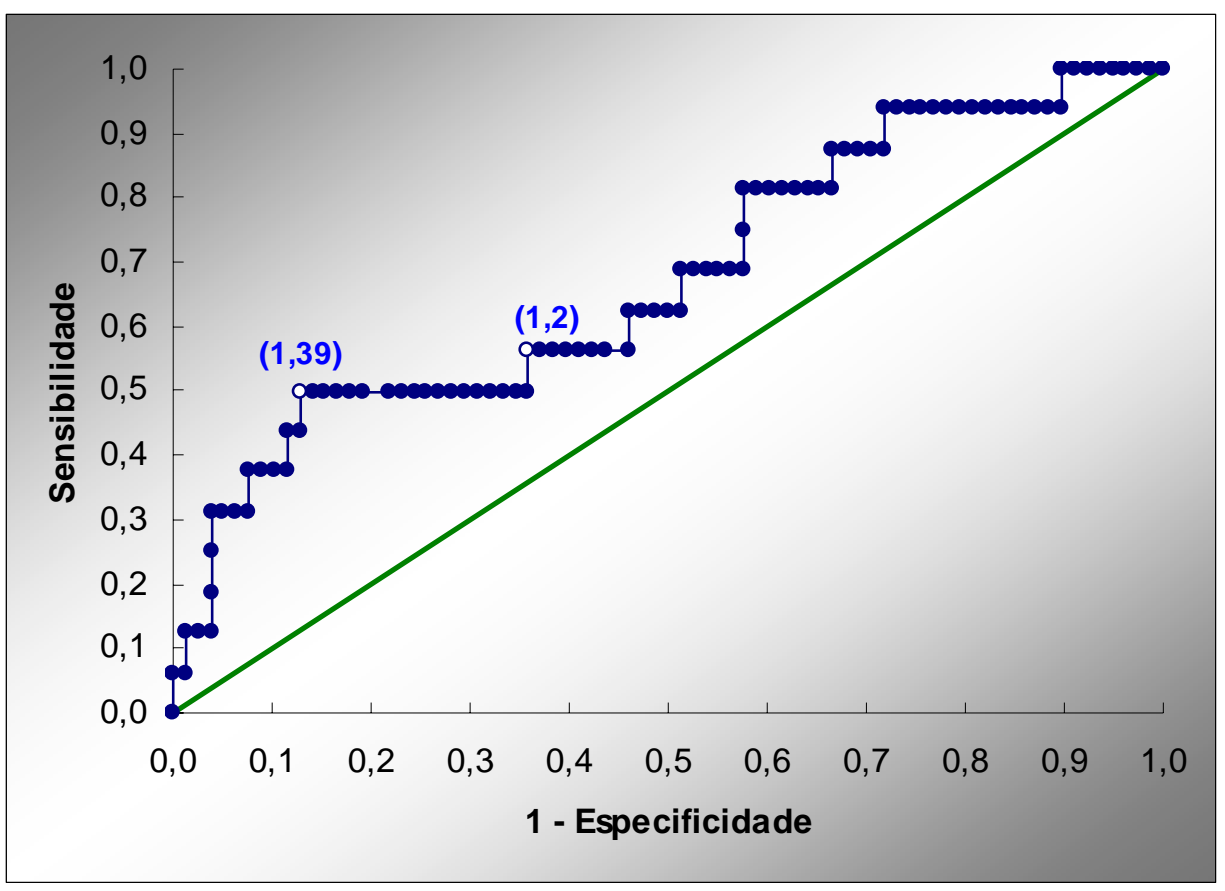

Gráfico 2 - Curva ROC para predição de resultados adversos em 94 gestações com gastrosquise fetal isolada, de acordo com valores de observado/esperado do maior diâmetro transverso da alça (área sob a curva $=0,67$ ) HCFMUSP - janeiro de 1997 a agosto de 2009

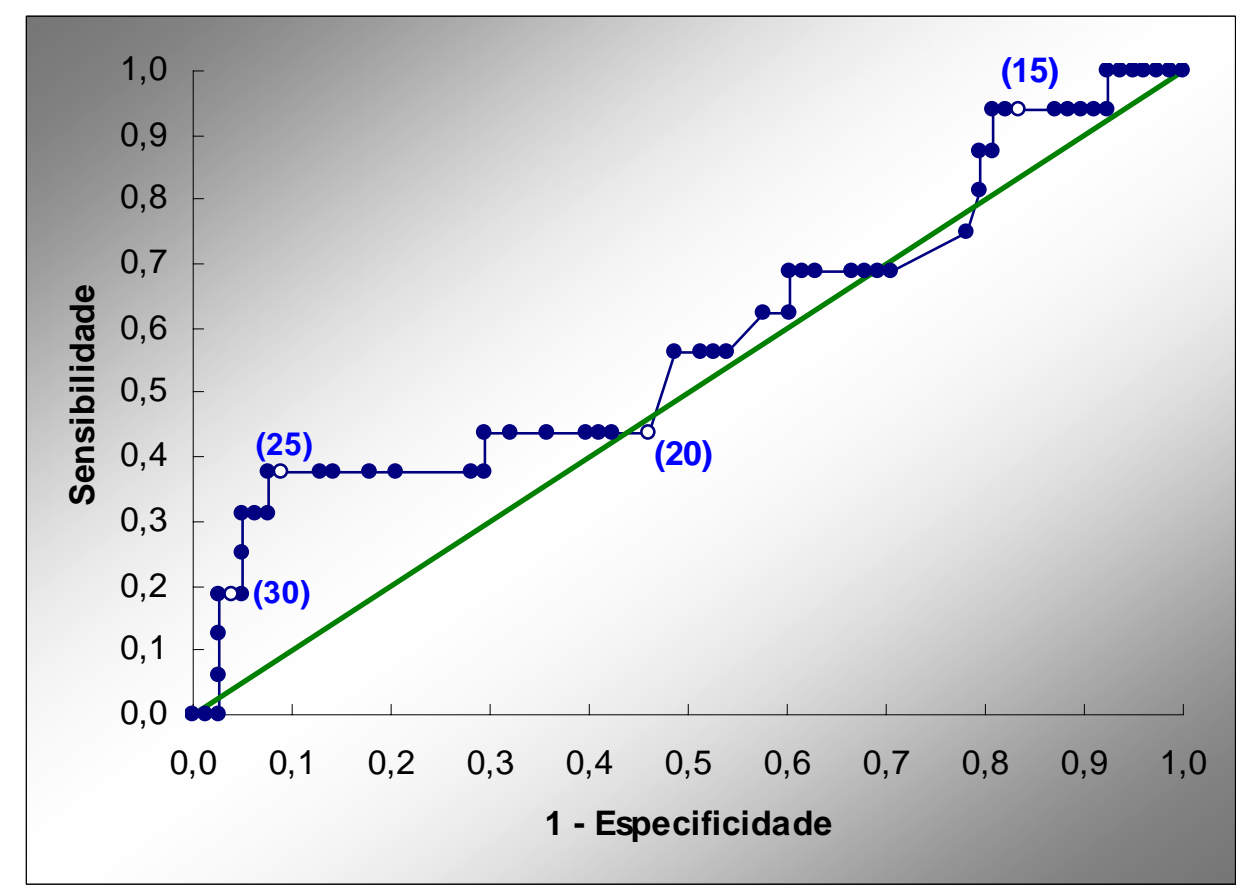

Gráfico 3 - Curva ROC para predição de resultados adversos em 94 gestações com gastrosquise fetal isolada, de acordo com valores do maior diâmetro transverso da alça observados até três semanas antes do parto (área sob a curva $=0,58)-$ HCFMUSP - janeiro de 1997 a agosto de 2009 
Pela análise da área sob a curva das duas curvas ROC obtidas (Gráfico 2: área sob a curva $R O C$ para os valores de $\mathrm{O} / \mathrm{E}$ é de 0,67 ; Gráfico 3: área sob a curva para os valores observados de DTA é de 0,58 ), nota-se que a curva com a razão DTA O/E apresenta pequena vantagem sobre a curva da medida da alça externa (DTA).

Pode-se comparar os valores de sensibilidade, especificidade, valores preditivos positivo e negativo, falsos positivo e negativo e a acurácia na predição de resultados adversos, de acordo com os valores de corte analisados do maior DTA, medido até três semanas antes do parto, e os valores de DTA O/E (pontos de sensibilidade e 1- especificidade apresentados nos gráficos das curvas ROC construídas), conforme descrito na Tabela 10. 
Tabela 10 - Predição de resultado adverso na gestação de acordo com maior medida do diâmetro transverso da alça aferido até 3 semanas antes do parto - HCFMUSP - janeiro de 1997 a agosto de 2009

\begin{tabular}{|c|c|c|c|c|c|c|c|c|}
\hline & & $\begin{array}{c}\text { Sensibilidade } \\
(\%)\end{array}$ & $\begin{array}{c}\text { Especificidade } \\
(\%)\end{array}$ & $\begin{array}{l}\text { VPP } \\
(\%)\end{array}$ & $\begin{array}{l}\text { VPN } \\
(\%)\end{array}$ & $\begin{array}{c}\text { Falso } \\
\text { positivo } \\
(\%)\end{array}$ & $\begin{array}{c}\text { Falso } \\
\text { negativo } \\
(\%)\end{array}$ & $\begin{array}{c}\text { Acurácia } \\
(\%)\end{array}$ \\
\hline \multirow[t]{4}{*}{$\begin{array}{c}\text { DTA } \\
\mathbf{m m}\end{array}$} & Resultados adversos & $15 / 16(93,8)$ & $10 / 78(12,8)$ & $15 / 83(18,1)$ & $10 / 11(90,9)$ & $68 / 83(81,9)$ & $1 / 11(9,1)$ & $25 / 94(26,6)$ \\
\hline & $\mathrm{OF}$ & $5 / 5(100)$ & $11 / 89(12,4)$ & $5 / 83(6,0)$ & $11 / 11(100)$ & $78 / 83(94,0)$ & $0 / 11(0,0)$ & $16 / 94(17)$ \\
\hline & ONN & $4 / 5(80)$ & $10 / 89(11,2)$ & $4 / 83(4,8)$ & $10 / 11(90,9)$ & $79 / 83(95,2)$ & $1 / 11(9,1)$ & $14 / 94(14,9)$ \\
\hline & Complicações intestinais & $8 / 8(100)$ & $11 / 86(12,8)$ & $8 / 83(9,6)$ & $11 / 11(100)$ & $75 / 83(90,4)$ & $0 / 11(0,0)$ & $19 / 94(20,2)$ \\
\hline \multirow[t]{4}{*}{$\begin{array}{c}\text { DTA } \geq 20 \\
\text { mm }\end{array}$} & Resultados adversos & $9 / 16(56,3)$ & $40 / 78(51,3)$ & $9 / 47(19,2)$ & $40 / 47(85,1)$ & $38 / 47(80,8)$ & $7 / 47(14,9)$ & $49 / 94(52,1)$ \\
\hline & $\mathrm{OF}$ & $2 / 5(40,0)$ & $44 / 89(49,4)$ & $2 / 47(4,3)$ & $44 / 47(93,6)$ & $45 / 47(95,7)$ & $3 / 47(6,4)$ & $46 / 94(48,9)$ \\
\hline & ONN & $3 / 5(60,0)$ & $45 / 89(50,6)$ & $3 / 47(6,4)$ & $45 / 47(95,7)$ & $44 / 47(93,6)$ & $2 / 47(4,3)$ & $48 / 94(51,1)$ \\
\hline & Complicações intestinais & $5 / 8(62,5)$ & $44 / 86(51,2)$ & $5 / 47(10,6)$ & $44 / 47(93,6)$ & $42 / 47(89,4)$ & $3 / 47(6,4)$ & $49 / 94(52,1)$ \\
\hline \multirow[t]{4}{*}{$\begin{array}{c}\text { DTA } \geq 25 \\
\text { mm }\end{array}$} & Resultados adversos & $6 / 16(37,5)$ & $68 / 78(87,2)$ & $6 / 16(37,5)$ & $68 / 78(87,2)$ & $10 / 16(62,5)$ & $10 / 78(12,8)$ & $74 / 94(78,7)$ \\
\hline & OF & $1 / 5(20,0)$ & $74 / 89(83,1)$ & $1 / 16(6,3)$ & $74 / 78(94,9)$ & $15 / 16(93,8)$ & $4 / 78(5,1)$ & $75 / 94(79,8)$ \\
\hline & ONN & $1 / 5(20,0)$ & $74 / 89(83,1)$ & $1 / 16(6,3)$ & $74 / 78(94,9)$ & $15 / 16(93,8)$ & $4 / 78(5,1)$ & $75 / 94(79,8)$ \\
\hline & Complicações intestinais & $5 / 8(62,5)$ & $75 / 86(87,2)$ & $5 / 16(31,3)$ & $75 / 78(96,2)$ & $11 / 16(68,8)$ & $3 / 78(3,8)$ & $80 / 94(85,1)$ \\
\hline
\end{tabular}


Tabela 10 - Predição de resultado adverso na gestação de acordo com maior medida do diâmetro transverso da alça aferido até 3 semanas antes do parto - HCFMUSP - janeiro de 1997 a agosto de 2009 (conclusão)

\begin{tabular}{|c|c|c|c|c|c|c|c|c|}
\hline & & $\begin{array}{c}\text { Sensibilidade } \\
(\%)\end{array}$ & $\begin{array}{c}\text { Especificidade } \\
(\%)\end{array}$ & $\begin{array}{l}\text { VPP } \\
(\%)\end{array}$ & $\begin{array}{l}\text { VPN } \\
(\%)\end{array}$ & $\begin{array}{c}\text { Falso } \\
\text { positivo } \\
(\%) \\
\end{array}$ & $\begin{array}{c}\text { Falso } \\
\text { negativo } \\
(\%) \\
\end{array}$ & $\begin{array}{c}\text { Acurácia } \\
\qquad \%)\end{array}$ \\
\hline \multirow[t]{4}{*}{$\begin{array}{c}\text { DTA } \geq 30 \\
\mathbf{m m}\end{array}$} & Resultados adversos & $3 / 16(18,8)$ & $75 / 78(96,2)$ & $3 / 6(50,0)$ & $75 / 88(85,2)$ & $3 / 6(50,0)$ & $13 / 88(14,8)$ & $78 / 94(83,0)$ \\
\hline & $\mathrm{OF}$ & $1 / 5(20,0)$ & $84 / 89(94,4)$ & $1 / 6(16,7)$ & $84 / 88(95,5)$ & $5 / 6(83,3)$ & $4 / 88(4,5)$ & $85 / 94(90,4)$ \\
\hline & ONN & $0 / 5$ & $83 / 89(93,3)$ & $0 / 6$ & $83 / 88(94,3)$ & $6 / 6(100,0)$ & $5 / 88(5,7)$ & $83 / 94(88,3)$ \\
\hline & Complicações intestinais & $2 / 8(25,0)$ & $82 / 86(95,3)$ & $2 / 6(33,3)$ & $82 / 88(93,2)$ & $4 / 6(66,7)$ & $6 / 88(6,8)$ & $84 / 94(89,4)$ \\
\hline \multirow[t]{4}{*}{$\begin{array}{l}\text { DTA O/E } \\
\geq 1,39 \mathrm{~mm}\end{array}$} & Resultados adversos & $8 / 16(50,0)$ & $67 / 78(85,9)$ & $8 / 19(42,1)$ & $67 / 75(89,3)$ & $11 / 19(57,9)$ & $8 / 75(10,7)$ & $75 / 94(79,8)$ \\
\hline & $\mathrm{OF}$ & $3 / 5(60,0)$ & $73 / 89(82,0)$ & $3 / 19(15,8)$ & $73 / 75(97,3)$ & $16 / 19(84,2)$ & $2 / 75(2,7)$ & $76 / 94(80,9)$ \\
\hline & ONN & $1 / 5(20,0)$ & $71 / 89(79,8)$ & $1 / 19(5,3)$ & $71 / 75(94,7)$ & $18 / 19(94,7)$ & $4 / 75(5,3)$ & $72 / 94(76,6)$ \\
\hline & Complicações intestinais & $5 / 8(62,5)$ & $72 / 86(83,7)$ & $5 / 19(26,3)$ & $72 / 75(96,0)$ & $14 / 19(73,7)$ & $3 / 75(4,0)$ & $77 / 94(81,9)$ \\
\hline
\end{tabular}

NOTA: DTA: diâmetro transverso da alça; $\mathrm{O} / \mathrm{E}=$ observado/esperado; $\mathrm{OF}=$ óbito fetal; $\mathrm{ONN}=$ óbito neonatal; $\mathrm{VPN}=$ valor preditivo negativo; $\mathrm{VPP}=$ valor preditivo positivo 
Observa-se, pela Tabela 10, que os índices que apresentam melhor equilíbrio entre todos os parâmetros para a predição de resultados adversos é a razão $\mathrm{O} / \mathrm{E} \geq$ 1,39 (área sob a curva de 0,67). O valor de DTA $\geq 25 \mathrm{~mm}$ apresenta desempenho semelhante a aqueles encontrados pela razão (DTA $\mathrm{O} / \mathrm{E} \geq 1,39$ ). Opta-se pelo valor do DTA $\geq 25 \mathrm{~mm}$ ao invés da razão (DTA O/E), na predição de resultados adversos, pois apresenta melhor reprodutibilidade na prática clínica diária.

Considerando todos os exames de ultrassonografia realizados após a $30^{\mathrm{a}}$ semana, $8(50 \%)$ casos entre os 16 que apresentaram alguma complicação pós-natal possuíam pelo menos um exame ultrassonográfico que mostrava DTA $\geq 25 \mathrm{~mm}$, enquanto no grupo normal esse achado esteve presente em 11/78 (14\%).

Três entre $16(18,8 \%)$ apresentavam pelo menos um exame ultrassonográfico com DTA $\geq 30 \mathrm{~mm}$, e, no grupo normal, $3 / 78(3,8 \%)$.

A Tabela 11 resume a evolução da gestação e o prognóstico neonatal das 94 gestações avaliadas divididas em dois grupos: aquelas com DTA $<25 \mathrm{~mm}$ e aquelas com DTA $\geq 25 \mathrm{~mm}$. 
Tabela 11 - Comparação das variáveis dos recém-nascidos com gastrosquise no grupo geral, no grupo com dilatação intestinal $\geq 25 \mathrm{~mm}$ e no grupo com dilatação intestinal $<25 \mathrm{~mm}$ - HCFMUSP - janeiro de 1997 a agosto de 2009

\begin{tabular}{|c|c|c|c|c|}
\hline & $\begin{array}{l}\text { População } \\
\text { do estudo }\end{array}$ & DTA $<25 \mathrm{~mm}$ & DTA $\geq 25 \mathrm{~mm}$ & $p$ \\
\hline Número de casos & 94 & 78 & 16 & \\
\hline $\begin{array}{l}\text { Idade gestacional no parto (sem) } \\
\text { M (DP) }\end{array}$ & $36,5(1,4)$ & $36,3(1,4)$ & $36,0(1,4)$ & 0,14 \\
\hline $\begin{array}{l}\text { Peso nascimento (g) } \\
\text { M (DP) }\end{array}$ & $2441(432)$ & $2462(425)$ & $2514(471)$ & 0,54 \\
\hline $\begin{array}{c}\text { Óbito fetal } \\
\text { n }(\%)\end{array}$ & $5(5,3)$ & $4(5,1)$ & $1(6,3)$ & $>0,99$ \\
\hline $\begin{array}{l}\text { Óbito neonatal } \\
\mathrm{n}(\%)\end{array}$ & $5(5,3)$ & $4(5,1)$ & $1(6,3)$ & $>0,99$ \\
\hline $\begin{array}{l}\text { Fechamento primário } \\
\mathrm{n}(\%)\end{array}$ & $72(76,6)$ & $64(82,1)$ & $8(50,0)$ & 0,01 \\
\hline $\begin{array}{l}\text { Silo } \\
\mathrm{n}(\%)\end{array}$ & $4(4,3)$ & $4(5,1)$ & - & $>0,99$ \\
\hline $\begin{array}{c}\text { Complicação intestinal } \\
\mathrm{n}(\%)\end{array}$ & $8(8,5)$ & $3(3,8)$ & $5(31,3)$ & 0,003 \\
\hline $\begin{array}{l}\text { Atresia } \\
\mathrm{n}(\%)\end{array}$ & $6(6,4)$ & $2(2,6)$ & $4(25,0)$ & 0,007 \\
\hline $\begin{array}{l}\text { Volvo } \\
\mathrm{n}(\%)\end{array}$ & $1(1,1)$ & - & $1(6,3)$ & 0,17 \\
\hline $\begin{array}{l}\text { Necrose } \\
\mathrm{n}(\%)\end{array}$ & $2(2,1)$ & - & $2(12,5)$ & 0,03 \\
\hline $\begin{array}{l}\text { Perfuração } \\
\text { n (\%) }\end{array}$ & $1(1,1)$ & $1(1,3)$ & - & $>0,99$ \\
\hline $\begin{array}{l}\text { Síndrome do intestino curto } \\
\mathrm{n}(\%)\end{array}$ & $1(1,1)$ & - & $1(6,3)$ & 0,17 \\
\hline $\begin{array}{l}\text { Tempo para iniciar dieta oral (dias) } \\
\text { M (DP) }\end{array}$ & $19,5(10,8)$ & $18,2(9,9)$ & $25,7(12,8)$ & 0,02 \\
\hline $\begin{array}{c}\text { Tempo de internação hospitalar } \\
\text { (dias) } \\
\text { M (DP) }\end{array}$ & $34,9(22,0)$ & $33,3(22,3)$ & $42,4(19,7)$ & 0,04 \\
\hline
\end{tabular}

NOTA: DP = desvio padrão, DTA = diâmetro transverso da alça intestinal; $\mathrm{g}=$ gramas, $\mathrm{M}=$ média, $\mathrm{n}$ $=$ número de casos, $p=$ nível descritivo de probabilidade $(p<0,05)$, sem $=$ semanas, $\%=$ percentual 
Pela Tabela 11, observa-se que o grupo com DTA $\geq 25 \mathrm{~mm}$ até três semanas antes do parto apresentou significativamente mais complicações intestinais (como atresia e necrose), menor taxa de fechamento primário da parede abdominal, maior tempo de internação hospitalar e de uso de nutrição parenteral prolongada. Não houve diferença estatística entre os grupos em relação à ocorrência de óbito fetal e neonatal. 


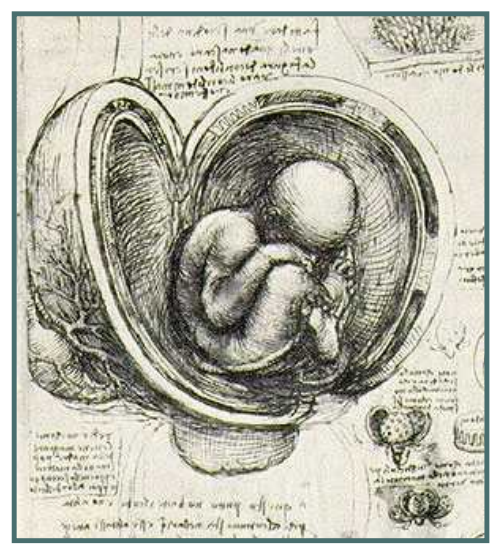


A gastrosquise é uma malformação congênita de correção cirúrgica com bom prognóstico, cuja etiologia ainda permanece desconhecida. As gestações com gastrosquise fetal são consideradas de alto-risco por apresentar risco elevado de sofrimento fetal, óbito fetal, tendência à prematuridade e baixo peso ao nascimento (122)

A prevalência dessa entidade tem aumentado dramaticamente, como demonstra o International Clearinghouse for Birth Defects em 14/25 registros mundiais $^{(68)}$, principalmente na Ásia, Austrália, oeste europeu e EUA ${ }^{(53,65,69)}$.

Vários são os aspectos dessa malformação que ainda necessitam de esclarecimentos como: etiopatogenia, fatores de risco e fatores prognósticos. Dessa forma, o presente estudo, apesar de retrospectivo, é o que apresenta a maior casuística na avaliação da relação entre dilatação das alças intestinais exteriorizadas e o prognóstico perinatal.

A idade materna jovem tem sido demonstrada como consistente fator de risco para gastrosquise, nos últimos 20 anos, porém ainda não é possível esclarecer sua contribuição independente na etiopatogenia dessa malformação ${ }^{(10)}$. Em concordância com outros estudos ${ }^{(1,18,38,122,127,141)}$, na presente casuística, a idade materna média foi de $21,4 \pm 3,9$ anos e mais da metade das gestantes eram primigestas $(63,8 \%)$.

A raça caucasiana é relatada como fator de risco ${ }^{(28)}$. Já foi demonstrado maior acometimento em mães brancas e de origem hispânica do que em mulheres negras ou afroamericanas $^{(13,55,71)}$. Também observamos maior prevalência $(57,4 \%)$ dessa etnia nos casos estudados.

Em apenas 18,1\% das gestantes, o tabagismo foi referido. Em outros estudos, esse porcentual variou de 47 a $48 \%^{(79,122)}$. Apesar de nossa taxa de tabagistas ser inferior ao referido por outros estudos realizados em outros países, corrobora com a taxa de mulheres jovens tabagistas do Brasil, na faixa etária semelhante a do nosso estudo. Segundo informação do Instituto Nacional do Câncer (INCA), órgão governamental brasileiro $^{(142)}$, atualmente a prevalência de fumantes do sexo feminino 
entre 18 a 24 anos é de 12,4\% e, em idade escolar (5 a 17 anos), de 9 a $24 \%$. Ademais, nossa porcentagem de tabagismo pode estar subestimada, já que se trata de estudo retrospectivo e essa informação não constava no prontuário institucional em $11,7 \%$ dos casos.

Apesar da necessidade de correção cirúrgica imediatamente ao nascimento, a maioria das crianças com gastrosquise apresenta bom prognóstico com taxas de sobrevida descritas de $90 \%-100 \%{ }^{(143)}$. Entretanto, algumas delas apresentam alto risco de desenvolver inúmeras complicações pós-natais como: evolução com íleo prolongado, risco de obstrução intestinal mecânica ${ }^{(30)}$ e evolução para síndrome do intestino curto devido a extensas ressecções intestinais ${ }^{(112)}$. Além disso, podem evoluir com significante morbidade devido ao longo período de hospitalização póscirúrgico $^{(114)}$, susceptibilidade a infecções, uso prolongado de nutrição parenteral com consequente risco de toxicidade hepática e de sepse por infecção pelo catéter venoso central e, por final, à alta taxa de mortalidade ${ }^{(112)}$.

Muitos estudos ${ }^{(8,35,36)}$ têm investigado critérios ultrassonográficos sugestivos de dano intestinal, na esperança de identificar quais fetos se beneficiariam da antecipação do parto a fim de evitar a progressão da deterioração intestinal. Daí, a importância de monitorar o aspecto do intestino exteriorizado, antes mesmo do nascimento.

Em gestações sem complicações ou anomalias estruturais, o diâmetro da alça de intestino delgado e de cólon aumenta com o avançar da gestação. O lúmen da alça de intestino delgado raramente excede $10 \mathrm{~mm}$ de diâmetro, e o diâmetro do cólon fetal dificilmente excede $23 \mathrm{~mm}^{(144)}$. O mesmo processo dinâmico de desenvolvimento tem sido descrito para o intestino herniado nas gestações com gastrosquise $^{(145)}$.

Nossos resultados confirmam os estudos anteriores ${ }^{(19,34,145)}$ de que há correlação positiva entre o diâmetro da alça intestinal e a idade gestacional. Por essa razão, a definição de dilatação intestinal deveria diferir ao longo da gestação. $\mathrm{Na}$ literatura, não há curva bem estabelecida de medida da alça intestinal exteriorizada para cada idade gestacional e nossa série também não continha valor de alça observado para cada idade gestacional, pois nossa análise preditiva foi baseada no 
diâmetro observado da alça intestinal exteriorizada até três semanas antes do parto e em idade gestacional média de 36 semanas. Criamos, então, a razão entre os valores observado e o esperado (DTA O/E) para idade gestacional (pela função $\mathrm{E}=$ $0,645^{*} \exp ^{\left(0,0923^{*} \mathrm{IG}\right)}$, onde IG = idade gestacional). Portanto, visto que o DTA mostra mudanças ao longo da gestação, a análise também foi ajustada para essa variação.

Nossos resultados mostraram que o melhor valor de corte na predição de resultados adversos nessas gestações foi o DTA observado/esperado de 1,39 em qualquer idade gestacional. Entretanto, valores preditivos semelhantes foram observados para DTA $\geq 25 \mathrm{~mm}$ em qualquer idade gestacional. A aferição da medida intestinal é de fácil realização e interpretação na prática clínica.

A definição de dilatação intestinal encontrada nos estudos prévios varia entre 6 a $25 \mathrm{~mm}$ entre 34 e 36 semanas (Tabela 2). Apesar de a maioria dos estudos considerar $\leq 17 \mathrm{~mm}$ como o limite da normalidade, nossa análise mostrou que o maior DTA $\geq 15, \geq 20, \geq 25$ e $\geq 30 \mathrm{~mm}$ é encontrado em $87,46,13$ e 4\%, respectivamente, das gestações com resultados favoráveis. Além disso, o DTA $\geq 25$ $\mathrm{mm}$ apresenta valores de sensibilidade de $38 \%$, valor preditivo positivo de $38 \%$ e valor preditivo negativo de $87 \%$, na predição de resultados adversos nas gestações com gastrosquise. Já com a medida de DTA $\geq 30 \mathrm{~mm}$, o valor de sensibilidade é de $19 \%$, valor preditivo positivo de $50 \%$ e valor preditivo negativo de $85 \%$ (Tabela 10 ).

A dilatação intestinal, definida como $\geq 25 \mathrm{~mm}$, esteve associada à baixa taxa de fechamento primário da parede abdominal, maior tempo de uso de NPP e de internação hospitalar (Tabela 11). Possivelmente a dilatação intestinal reflita piores níveis de dano intestinal.

Gastrosquise fetal associou-se a complicações intestinais adicionais (necrose, perfuração, atresia e volvo) em oito casos (8,5\%) e a dilatação intestinal esteve presente em cinco deles. O grupo com dilatação intestinal $(\geq 25 \mathrm{~mm})$ apresentou significativamente mais complicações intestinais do que o grupo sem dilatação $(p=0,003)$. Esse achado é concordante com resultados de Babcook et al., que consideram valor de dilatação intestinal $>10 \mathrm{~mm}^{(37)}$. Discordante a esse resultado, Japaraj et al. apresentam taxas maiores (26\%) de RN com complicações intestinais $^{(18)}$. Porém, esses autores não observam associação significante entre 
dilatação intestinal > $17 \mathrm{~mm}$ com complicações intestinais, conclusão semelhante já havia sido descrita anteriormente, com critério de dilatação intestinal de $\geq 17 \mathrm{~mm}^{(38)}$ e $>20 \mathrm{~mm}^{(39)}$.

Diferentemente do encontrado por outros estudos, observamos que apenas $17 \%$ dos casos possuíam dilatação intestinal, definida como $\geq 25 \mathrm{~mm}$. Tal diferença pode ser decorrente de valores menores de dilatação intestinal considerados em outros estudos, o que possibilita a maior seleção de casos, porém com maior taxa de falso-positivo. Ao considerar valor de corte de $10 \mathrm{~mm}$, Mears et al. encontram 84\% de pacientes com dilatação intestinal antenatal ${ }^{(146)}$ e Lenke et al., $60 \%{ }^{(126)}$. Autores que consideram o valor de corte de $17 \mathrm{~mm}$, como Japaraj et al., encontram 42\% de pacientes com dilatação intestinal ${ }^{(18)}$ e Cohen-Overbeek et al. observam $67 \%$ no terceiro trimestre ${ }^{(24)}$.

A dificuldade no estabelecimento de um valor de corte da dilatação intestinal, entre os diferentes estudos anteriores, tem origem na falta de padronização do método de mensuração, pois a medida pode ser realizada: na alça de intestino delgado ou na alça de intestino grosso, no diâmetro da luz intestinal (sem incluir a espessura da sua parede - “inner-to-inner”) ou incluindo a espessura da parede (“outer-outer”). Além disso, mesmo quando profissionais experientes utilizam os mesmos métodos específicos e predefinidos para medir a dilatação intestinal, pode haver discrepância de até $5 \mathrm{~mm}$, entre as medidas dos diferentes examinadores, em mais de $20 \%$ das aferições ${ }^{(36)}$. Babcook et al. demonstram alta incidência de complicações intestinais nos casos com dilatação de alça de intestino delgado $>11 \mathrm{~mm}$, porém também observam que as medidas diferem mais de $2 \mathrm{~mm}$ entre os examinadores, em $58 \%$ dos $\operatorname{casos}^{(37)}$. Ainda, alguns autores consideram que a medida ultrassonográfica da alça intestinal é um processo dinâmico, sujeito à variação interobservador e intraobservador, com dificuldades na identificação da maior alça exteriorizada e acurácia na medida a cada avaliação ${ }^{(127)}$.

Para reduzir esses vieses, utilizamos a técnica descrita por Japaraj et al. ${ }^{(18)}$. Ademais, o nível de corte por nós utilizado de $25 \mathrm{~mm}$ implica menor índice de falsopositivo, considerando-se margem de erro de 2-5 mm nas aferições do diâmetro da alça externa. 
Apesar de a dilatação das alças intestinais exteriorizadas ( $\geq 25 \mathrm{~mm}$ ), no terceiro trimestre da gestação, ter sido observada em metade dos casos que resultaram em óbito fetal, óbito neonatal ou naqueles com complicações intestinais, não foi significativamente preditiva para a ocorrência dos referidos óbitos.

Semelhante resultado foi relatado por outros autores, como Adra et al., que consideram como dilatação intestinal $\geq 10 \mathrm{~mm}^{(127)}$ e Babcook et al. que usaram valor de corte de $11 \mathrm{~mm}^{(37)}$. Para ambos, a dilatação intestinal não esteve associada significativamente com óbito fetal, e sim com desenvolvimento de alguma complicação no pós-operatório. Já, Heinig et al. ${ }^{(19)}$ associam dilatação intestinal $>25$ $\mathrm{mm}$, no terceiro trimestre da gestação, com alto risco de complicações antenatais, a curto prazo, como sofrimento fetal e óbito fetal. Os autores observam 14,3\% de óbito fetal e ambos os casos apresentavam dilatação intestinal $>25 \mathrm{~mm}$.

Obtivemos taxa de óbito fetal de 5,3\%, em concordância com outros como: Brantberg et al. $(1,6 \%)^{(122)}$, Mears et al. $(5,0 \%)^{(146)}$ e Adra et al $(6,4 \%)^{(127)}$. Esses autores também realizam rigoroso acompanhamento da vitalidade fetal, semelhante ao realizado em nosso serviço. Nossos dados sugerem que a realização seriada da vitalidade fetal pode contribuir para diminuir as taxas de sofrimento fetal e de óbito fetal nas gestações complicadas com gastrosquise.

Entretanto, a literatura também reporta taxa de óbito fetal mais elevada, variando de $12,5 \%$ a $14,3 \%{ }^{(18,19,24,119)}$. Essa diferença pode ser devido ao rigoroso e seriado acompanhamento da vitalidade fetal no grupo avaliado e também à exclusão de grande número de casos que não contemplavam os critérios de inclusão como: gemelares, outras malformações estruturais associadas, ausência da medida do DTA, última medida do DTA maior que três semanas antes do parto ou perda de acompanhamento.

Para Cohen-Overbeek et al., uma das maiores contribuições do diagnóstico e seguimento antenatal de gastrosquise pode ser a prevenção de óbito fetal inesperado $^{(24)}$. Como a maioria dos casos de óbito fetal ocorre no terceiro trimestre da gestação, propõe-se vigilância do bem-estar fetal com perfil biofísico e dopplerfluxometria da artéria umbilical ao longo do seguimento no terceiro trimestre ${ }^{(119,122)}$. Poucos autores discordam dessa conduta. Japaraj et al. não 
recomendam intenso controle da vitalidade com cardiotocografia, exceto na evidência de restrição do crescimento fetal e/ou Dopplervelocimetria anormal da artéria umbilical, uma vez que, em 45 casos, os autores não observam nenhum óbito fetal $^{(18)}$.

A idade gestacional média do parto foi $36,5 \pm 1,4$ semanas, o que é comparável a outros estudos ${ }^{(21,119,127,128)}$, que varia de 35,6 semanas a 37,1 semanas $(18,19,116,122,146)$. Alsulyman et al. reportam idade gestacional média do parto pouco menor (34,3 semanas) em 23 gestações avaliadas ${ }^{(38)}$ o que corrobora os achados de Piper et al. (35,4 semanas) em 27 recém-nascidos com gastrosquise ${ }^{(128)}$.

A idade gestacional ao nascimento não diferiu significativamente na comparação entre os grupos com DTA $<25 \mathrm{~mm}$ e $\geq 25 \mathrm{~mm}$. Alsulyman et al. ${ }^{(38)}$ também não encontram diferença estatística para a idade gestacional do parto, ao utilizar valor de corte para dilatação intestinal de $17 \mathrm{~mm}$, bem como Piper et al. ${ }^{(128)}$ ao considerar valor de corte $\geq 6 \mathrm{~mm}$.

O peso médio ao nascimento foi de 2441 ( $\pm 432 \mathrm{~g})$, semelhante ao apresentado na literatura, entre 2435 e $2612 \mathrm{~g}^{(19,116,122,127)}$. Também não houve diferença significativa entre o peso dos recém-nascidos com alça intestinal $<25 \mathrm{~mm}$ e $\geq 25 \mathrm{~mm}$. Nossos dados vão de encontro aos de Japaraj et al. e Alsulyman et al. que utilizam valor de dilatação intestinal $>17 \mathrm{~mm}^{(18,38)}$, e de Piper et al. ${ }^{(128)}$ que consideram valor de corte $\geq 6 \mathrm{~mm}$.

A maioria (54,3\%) dos recém-nascidos apresentou peso ao nascimento abaixo do percentil 10 de Alexander, o que confirma os estudos anteriores ${ }^{(105,119,122,147,148)}$. Crawford et al. observam $67 \%$ de recém-nascidos pequenos para a idade gestacional $^{(119)}$, e Towers e Carr, em meta-análise, referem $38 \%$ de recém-nascidos abaixo do percentil $10^{(120)}$.

Alguns autores referem maior taxa de complicações em crianças pequenas para a idade gestacional, como sepse ${ }^{(149)}$ e parto cesárea por sofrimento fetal ${ }^{(150)}$. Brantberg et al. observam que $1 / 4$ das crianças que evoluíram para óbito neonatal eram PIG ao nascimento ${ }^{(122)}$. Na presente série, os óbitos neonatais foram mais frequentes no grupo PIG (11,7\%) em relação ao grupo com peso AIG (7,0\%). Já a 
maioria dos casos de sepse $(25,6 \%)$ ocorreu mais no grupo de $\mathrm{RN}$ com peso adequado ao nascimento em relação ao grupo PIG (15,7\%).

Nem todas as pesquisas observam pior prognóstico nos recém-nascidos com gastrosquise e pequenos para a idade gestacional $^{(19,116,119,148)}$, como Japaraj et al. que não encontram correlação significativa entre resultados adversos pós-natais (complicações intestinais, necessidade de múltiplas laparotomias e óbito neonatal) nos pequenos para a idade gestacional ${ }^{(18)}$.

$\mathrm{Na}$ presente amostra, quatro dos cinco casos que evoluíram para óbito fetal apresentavam restrição do crescimento fetal (Tabela 7), incluindo um caso com dilatação intestinal (35 mm). Porém, maiores casuísticas são necessárias para avaliar o real valor preditivo da combinação entre dilatação intestinal e restrição do crescimento intraútero.

Não observamos diferença significativa entre os grupos (DTA $\geq 25 \mathrm{~mm}$ e $<25 \mathrm{~mm}$ ) em relação à ocorrência de óbito neonatal, ou seja, a dilatação da alça intestinal não foi preditora de óbito neonatal. Estudos prévios ${ }^{(18,141,146)}$ também não encontram correlação entre dilatação de alças intestinais em fetos com gastrosquise e óbito neonatal. A taxa de óbito neonatal foi de 5,6\%, semelhante à descrita por estudos anteriores, variando de $4,3 \%^{(127)}$ a $6,7 \%{ }^{(122)}$. Porém, taxas maiores de até $11,2 \%^{(116)}$ a $13 \%{ }^{(18)}$ são referidas.

Os cinco casos de óbito neonatal ocorridos foram após a primeira correção cirúrgica, sendo que dois deles apresentavam complicações intestinais (um com perfuração intestinal e o outro com atresia associada a áreas de necrose) e somente um deles apresentava dilatação intestinal $(25,9 \mathrm{~mm})$.

No presente estudo, o tempo médio de uso de NPP $(19,5 \pm 10,8$ dias $)$ foi menor que o encontrado por outros estudos, variável de 30,2 dias $^{(127)}$ a 30,9 dias $^{(122)}$. Isso porque, rotineiramente, a nutrição parenteral prolongada é suspensa no momento em que a criança tolera totalmente a dieta oral, sem nenhum tipo de intercorrência (como vômitos de estase, distensão abdominal, diminuição da peristalse ou parada de eliminação de flatos).

Quando se compara os grupos (DTA $\geq 25 \mathrm{~mm} \mathrm{e}<25 \mathrm{~mm}$ ), nota-se diferença significativa em relação ao tempo de uso de NPP, sendo que o grupo com dilatação 
intestinal necessitou de mais dias de NPP em relação àquele sem dilatação intestinal. Essa constatação vai de encontro ao observado por Langer et al. ${ }^{(36)}$ e por Pryde et al. ${ }^{(8)}$ em que dilatação intestinal $\geq 18 \mathrm{~mm}$ esteve associada a maior tempo de uso de NPP.

Na avaliação dos estudos prévios, observa-se que quanto menor o nível de corte considerado como dilatação intestinal, menor associação com NPP. Não observam diferença significativa de maior tempo de uso de NPP nos casos com dilatação intestinal os autores: Piper et al. com valor de corte $\geq 6 \mathrm{~mm}^{(128)}$, Adra et al. com valor $\geq 10 \mathrm{~mm}^{(127)}$, Japaraj et al. e Alsulyman et al., ao considerar valor de corte $>17 \mathrm{~mm}^{(18,38)}$. Babcook et al. também não encontram associação significativa entre dilatação intestinal ( $\geq 10 \mathrm{~mm}$ ) com maior tempo de uso de NPP, porém observam correlação com outras complicações neonatais, como maior necessidade de ressecção intestinal $^{(37)}$.

Mears et al. relatam que o número de dias necessitados de NPP estava correlacionado com a dilatação precoce das alças, mas não com um valor de dilatação, e que os casos com complicações intestinais careceram de mais dias de $\mathrm{NPP}^{(146)}$. Outras pesquisas já haviam associado a ocorrência de complicações intestinais com necessidade maior de uso de $\operatorname{NPP}^{(18,128)}$.

Alguns autores reportam melhor prognóstico neonatal com o fechamento primário da parede abdominal, cujos benefícios incluem: retorno precoce da função intestinal, diminuição do tempo de internação hospitalar, menor taxa de sepse e de mortalidade ${ }^{(151)}$. Mas não está claro se eles ocorrem devido a efeito direto da correção primária da parede ou como reflexo das melhores condições intestinais e/ou de aberturas pequenas que permitem reparo imediato ${ }^{(107)}$. O fechamento da parede abdominal em dois estágios ou mais sugere aumento de morbidade ${ }^{(122)}$, que pode estar associada ao pior prognóstico que o recém-nascido apresenta devido às condições intestinais e à necessidade de reabordagens cirúrgicas e não propriamente à técnica de fechamento da parede abdominal. Autores brasileiros descrevem risco aumentado de óbito neonatal (duas vezes maior) com o fechamento por silo (em dois estágios) em comparação ao fechamento primário, porém, a diferença não foi significativa $^{(152)}$. 
Em relação ao fechamento da parede abdominal, a maioria dos casos teve o fechamento primário $(76,6 \%)$. Porém, observa-se diferença significativa na comparação entre os grupos (DTA $\geq$ ou $<25 \mathrm{~mm}$ ). As crianças com dilatação intestinal foram menos submetidas ao fechamento primário da parede abdominal do que aquelas sem dilatação intestinal. Esse achado vai de encontro à descrição de Piper e Jaksic (2006), que apesar de a diferença não se mostrar significativa, houve tendência de menor taxa de fechamento primário da parede abdominal nas crianças com dilatação intestinal ${ }^{(128)}$. Mears et al. (2010) observam que quanto maior a dilatação e quanto mais precoce seu aparecimento, menor é a taxa de fechamento primário da parede ${ }^{(146)}$. Já Langer et al. $(1993)^{(36)}$ não relatam diferença estatística para o tipo de fechamento da parede abdominal entre grupos com dilatação intestinal $>17$ ou $<17 \mathrm{~mm}$, resultado confirmado por outros estudos ${ }^{(8,18,38,127)}$.

Na presente série, $11,7 \%$ crianças necessitaram de reabordagens cirúrgicas, após a correção por fechamento primário da parede abdominal, sendo 8 casos do grupo com resultados adversos $(8 / 16-50 \%)$ devido à: reconstrução programada do trânsito intestinal $(n=3)$, distensão abdominal no pós-operatório e necessidade de enterectomia $(n=4)$ ou obstrução intestinal por causa metabólica $(n=1)$. Os outros três casos são provenientes do grupo sem resultados adversos $(3 / 78-3,8 \%)$ devido à: distensão abdominal no pós-operatório e necessidade de enterectomia $(n=1)$ e obstrução metabólica $(\mathrm{n}=2)$.

Brantberg et al. encontram elevada taxa de fechamento primário $(92 \%)^{(122)}$, porém descrevem que $24 \%$ das crianças necessitaram de cirurgias subsequentes por suspeita de obstrução intestinal, após fechamento primário da parede abdominal. Alguns desses casos não apresentavam uma área de obstrução, apenas distúrbios na motilidade intestinal $^{(122)}$, similar às nossas observações.

O tempo de internação variou entre 10 (mínimo) e 150 dias (máximo), o que mostra como a evolução pós-natal dos recém-nascidos com gastrosquise é variável e de difícil predição.

Observamos que as crianças com dilatação intestinal ( $\geq 25 \mathrm{~mm}$ ) apresentaram tempo de internação hospitalar significativamente maior $(42,4 \pm 19,7$ dias $)$ em relação àqueles sem dilatação $(33,3 \pm 22,3$ dias $)$. $\mathrm{O}$ achado vai de encontro ao 
descrito anteriormente com valor de corte de $>17 \mathrm{~mm}^{(8,36)}$. Entretanto, é discordante de outros estudos, em que os autores não observam maior tempo de internação hospitalar no grupo com dilatação intestinal $\geq 10 \mathrm{~mm}^{(127)},>17 \mathrm{~mm}^{(18,38)}, \geq 6 \mathrm{~mm}^{(128)}$. Da mesma forma que para as outras complicações, o que difere entre os estudos pode ser a medida discriminatória de normalidade.

Nas 94 gestações avaliadas, a média do tempo de internação hospitalar foi de $34,9( \pm 22)$ dias, semelhante à descrita por Fratelli et al.(30 dias) ${ }^{(116)}$ e pouco menor que à descrita anteriormente por Brantberg et al. (40,3 dias) ${ }^{(122)}$ e Adra et al. (40,0 dias $)^{(127)}$. Alguns estudos descrevem média de tempo de internação maior, como Nick et al. ${ }^{(34)}$ (57 dias) e Badillo et al. (50 dias), atribuído ao baixo peso ao nascimento (média: 2000 g) nessas casuísticas em relação ao observado na presente série (média: $2441 \mathrm{~g}$ ).

A taxa de sobrevida, após o procedimento cirúrgico, foi de $94,4 \%$, semelhante ao encontrado por outros autores, variando de $89 \%^{(116)}, 93,6 \%{ }^{(146)}$ e $100 \%{ }^{(38)}$. Em contraste com estudos realizados em países desenvolvidos, pesquisa realizada em Recife (Brasil) demonstrou elevada taxa de mortalidade de 51,6\%, sendo sepse a principal causa de morte (15/16 - 93,8\%). Análise por regressão logística mostrou que a variável fortemente associada à morte neonatal era o peso ao nascimento menor que 2500 g com taxa de $21 \%$ de sobrevida. Já os $\mathrm{RN}>2500$ g apresentaram taxa de sobrevida de $70,6 \%{ }^{(152)}$. A elevada taxa de mortalidade é comparável com pesquisa realizada na Nigéria, país com condições sócioeconômicas semelhantes a do Nordeste brasileiro ${ }^{(153)}$. Os autores brasileiros acreditam que a elevada mortalidade esteve relacionada ao fato de que a maioria dos casos não possuía o diagnóstico prénatal, eram provenientes de cidades carentes em cuidados pré e perinatal e foram transferidos para o hospital de referência do estudo sem os cuidados adequados. Portanto, devido aos fatores citados, observam que os casos sem diagnóstico prénatal de gastrosquise estavam associados com maior mortalidade e maior taxa de parto pré-termo. Além disso, a prematuridade esteve fortemente associada a óbito neonatal, pois nenhum dos RN pré-termo sobreviveu ${ }^{(152)}$.

Fratelli et al. concluem que a maioria (90\%) dos fetos com diagnóstico prénatal de gastrosquise sobrevivem à cirurgia. A taxa de mortalidade referida foi de 
11\% (4/36). Entretanto, 27/36 (75\%) dos sobreviventes evoluíram com importante morbidade relacionada à gastrosquise e ao procedimento cirúrgico. As complicações mais frequentes foram sepse e transfusão. No período pós-natal, diagnosticou-se alguma patologia intestinal em 8/36 (22\%) RN, sendo que os quatro casos de óbito neonatal pertenciam a esse grupo ${ }^{(116)}$. A septicemia é considerada uma das principais e mais graves complicações, responsável pela mortalidade observada no longo pósoperatório $^{(17)}$.

É razoável pensar que a exposição direta da alça intestinal no líquido amniótico, durante a gestação, induza danos intestinais progressivos. Ao final, é possível que necessite de ressecções de segmentos intestinais e aumente o risco de síndrome do intestino curto, falência hepática pelo uso prolongado de NPP e manifestações crônicas de doenças gastrointestinais irreversíveis.

As características intestinais são tão importantes que alguns autores acreditam que os pacientes com gastrosquise podem ser divididos em duas categorias: aqueles complicados com a presença de patologias intestinais associadas (como atresia, estenose, perfuração e volvo) e aqueles com o defeito simples $(80 \% \text { casos })^{(26,114)}$. A morbidade no primeiro grupo é considerável e expressa por maior internação hospitalar, prolongado uso de NPP e longos períodos de ventilação mecânica ${ }^{(26)}$.

Desafio importante é encontrado nos recém-nascidos com atresia intestinal associada à gastrosquise $(10-20 \% \text { dos casos })^{(25,114,123,143)}$, pois costumam evoluir com prognóstico pobre, altas taxas de morbidade e/ou mortalidade ${ }^{(112,114)}$. Entretanto, nem todos os estudos concluem que a presença de atresia ou estenose intestinal afeta o prognóstico perinatal $^{(122)}$.

Na presente casuística, observamos seis casos de atresia $(6,4 \%)$, sendo que o grupo com dilatação intestinal $\geq 25 \mathrm{~mm}$ apresentou significantemente mais atresia intestinal que o grupo sem dilatação. Bond et al. (1988) foram os primeiros autores a investigar a correlação entre dilatação intestinal com a presença de segmentos de atresia e/ou com a predição do prognóstico da gestação. Descrevem 11 casos de gastrosquise e encontram 5 fetos com dilatação intestinal, nos quais foi diagnosticada atresia intestinal e evoluíram com necrose e pior prognóstico clínico. Entretanto, o estudo utilizou critérios subjetivos de avaliação das alças ${ }^{(35)}$. Após essa publicação, 
diversas pesquisas foram realizadas com o objetivo de analisar a associação entre dilatação intestinal e complicações perinatais, como Nick et al. que sugerem a presença de dilatação intestinal, durante o terceiro trimestre, como sinal de atresia ${ }^{(34)}$.

Langer et al., apesar de observarem significante necessidade de maiores ressecções intestinais nos casos com dilatação intestinal $\geq 18 \mathrm{~mm}$, comentam que não necessariamente a presença de atresia intestinal piora o prognóstico neonatal a longo prazo $^{(36)}$. Badillo et al. concluem que a dilatação intestinal nem sempre é preditiva de obstrução intestinal, e sugerem que a ausência de parede abdominal íntegra resultaria numa baixa pressão intra-abdominal permitindo que o intestino dilate mais facilmente ${ }^{(141)}$.

Ainda não é possível concluir que a dilatação intestinal é um indicativo de atresia. Recente revisão sistemática, analisando estudos com diferentes definições de dilatação intestinal na avaliação do prognóstico de gastrosquise, demonstra resultados e conclusões divergentes. Os autores não encontram correlação significante entre dilatação intestinal e presença de atresia, necessidade de ressecção intestinal e/ou aumento de risco para resultados adversos perinatais, independente da definição de dilatação intestinal utilizada. Entretanto, devido à insuficiência de estudos e à pequena amostra populacional dos estudos avaliados, os autores concluíram que a meta-análise estava subestimada para o desfecho de interesse ${ }^{(21)}$.

Assim, apesar de não ser consenso entre os autores, que a dilatação intestinal seja sinal patognomônico de atresia intestinal, é importante destacar que as crianças com atresia intestinal evoluem com maior morbidade, devido ao maior tempo de internação hospitalar, uso extenso de NPP e necessidade de procedimentos cirúrgicos adicionais $^{(24)}$. Nick et al. ${ }^{(34)}$ demonstram que a restrição do crescimento fetal foi o único fator independente associado à atresia intestinal. Seis de $10 \mathrm{RN}$ com atresia apresentavam restrição do crescimento fetal (60\%) comparados com 10 de 48 sem atresia $(21 \%)^{(34)}$.

Interessante notar que o índice de líquido amniótico esteve aumentado em três dos seis casos de atresia intestinal, possivelmente representando redução da absorção intestinal do líquido amniótico. Por essa razão, nossos resultados sugerem que a dilatação intestinal identificada no terceiro trimestre parece ser melhor preditora para 
as complicações intestinais como atresia, do que para óbito fetal ou neonatal, assim como Cohen-Overbeek et al. observam que um dos dois casos de poliidrâmnio apresentava atresia identificada ao nascimento ${ }^{(24)}$. Essa observação coincide com o observado por Japaraj et al., em que poliidrâmnio foi preditor significante para complicações intestinais e para resultados adversos pós-natais (complicações intestinais, necessidade de múltiplas laparotomias e óbito neonatal). No entanto, constatam igualmente que outros fetos sem poliidrâmnio na ultrassonografia também apresentavam complicações intestinais ${ }^{(18)}$.

Vale ressaltar que a presença de dilatação intestinal não necessariamente implica pior prognóstico em todos os casos. Alsulyman et al. publicam série com 21 casos de gastrosquise, 8 deles com dilatação intestinal $>17 \mathrm{~mm}$, sendo que três fetos apresentavam importante dilatação intestinal (entre 47 a $61 \mathrm{~mm}$ ). Porém, todos foram submetidos a fechamento primário da parede abdominal e seguiram com rápido curso pós-operatório, sem complicações. Por outro lado, outros dois casos, em que foi diagnosticado atresia intestinal no pós-natal, foram submetidos à ressecção intestinal e evoluíram com significante morbidade no pós-operatório (tempo de internação 141 e 75 dias), apresentando diâmetro da alça intestinal $<5 \mathrm{~mm}$ na ultrassonografia ${ }^{(38)}$. Em nossa série, menos de $15 \%$ das gestações com resultados favoráveis apresentavam algum achado ultrassonográfico.

O momento do parto também permanece como um ponto de controvérsia, já que a condição do intestino ao nascimento afeta o prognóstico pós-natal. Embora muitos autores sugiram que exista clara associação entre dilatação intestinal com pior prognóstico perinatal, poucos deles sugerem que uma intervenção terapêutica deva ser considerada, como a antecipação do parto, a fim de evitar a deterioração do intestino exteriorizado ${ }^{(8,19,36)}$. De fato, o parto eletivo pré-termo adicionaria riscos potenciais à inerente morbidade cirúrgica já existente nesses casos, enquanto o RN de termo é considerado como beneficiado por estar mais desenvolvido. Outros autores não defendem a antecipação do parto $^{(18,37-39,127,128)}$, pois essa conduta não mostrou benefícios para o prognóstico neonatal, apesar da tendência de pior prognóstico nos RN com dilatação intestinal antenatal ${ }^{(128)}$. 
O parto pré-termo espontâneo é comum nas gestações complicadas com gastrosquise $^{(107,154)}$. Na presente série, 3,2\% dos partos ocorreram abaixo de 34 semanas devido a trabalho de parto prematuro espontâneo. Snyder et al. reportam significante associação entre prematuridade e sepse em largo estudo de 185 casos de gastrosquise $^{(149)}$. Os três $\mathrm{RN}$ de $<34$ semanas, da atual casuística, tiveram longos períodos de internação hospitalar com episódios de sepse, sendo que dois deles evoluíram para óbito (com 109 e 64 dias de vida).

Ergun et al. compararam $40 \mathrm{RN}$ com gastrosquise nascidos antes de 36 semanas e $35 \mathrm{RN}$ nascidos após 36 semanas. Constatam que os RN pré-termo necessitaram de maior tempo de internação hospitalar e de uso de $\operatorname{NPP}^{(155)}$. CohenOverbeek et al. também mostram que os partos pré-termo ( $<37$ semanas) necessitaram de maior tempo de internação hospitalar comparado com aqueles nascidos a termo ( $\geq 37$ semanas). Entretanto, quando os casos de atresia intestinal foram excluídos do cálculo, a diferença entre os grupos mantinha uma tendência, mas deixava de ser estatisticamente significante ${ }^{(24)}$. Huang et al. avaliam 57 casos de gastrosquise e não observam benefícios no parto pré-termo para os $\mathrm{RN}$ com gastrosquise. O parto no termo ( $\geq 37$ semanas) resultou em fechamento definitivo da parede abdominal mais rápido e menos tempo de uso de NPP. Além disso, todos aqueles com atresia intestinal nascidos antes de 37 semanas (prematuridade somada à atresia) têm prognóstico desfavorável ${ }^{(156)}$.

Já Piper e Jaksic ${ }^{(128)}$ comparam RN nascidos antes de 35 semanas versus aqueles nascidos após 35 semanas, e não observam diferença estatística entre os grupos em relação a tempo de internação hospitalar e de uso de NPP. Estes autores sugerem que ocorra dano neurológico e motor das alças intestinais, expostas ao longo da gestação, piorando o prognóstico daqueles nascidos em idade gestacional avançada. Entretanto, não há respaldo na literatura para indicar a antecipação do parto, visando redução de tempo de exposição das alças ${ }^{(128)}$.

Moore et al., em 1999, observam que lactentes com gastrosquise partejados por cesareana no pré-termo, pré-trabalho de parto, tiveram menos formação inflamatória ("peel”) sobre a superfície serosa do intestino e menos complicações intestinais após o parto, em comparação aos lactentes de termo ${ }^{(157)}$. 
Nós acreditamos que não há benefícios em prolongar essas gestações além de 37 semanas, e o parto deve ser considerado após essa idade gestacional. Entretanto, séries prospectivas são necessárias para avaliar o prognóstico neonatal em fetos com dilatação intestinal. Atualmente, a indicação de realizar o parto prematuro iatrogênico não é baseada na dilatação intestinal, mas sim na presença de alterações da vitalidade fetal, principalmente dos parâmetros de sofrimento fetal. 


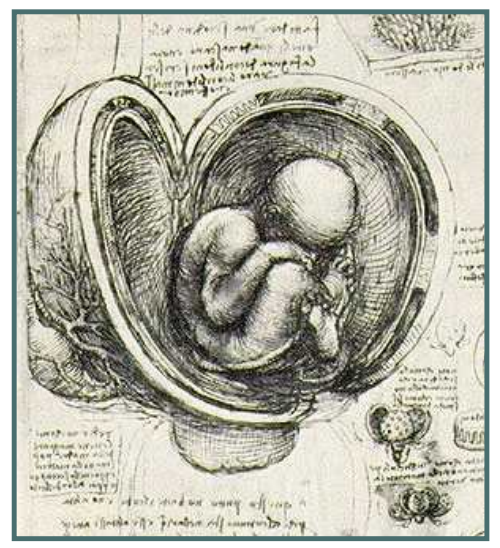

Um homem nunca sabe aquilo que é capaz até que o tenta fazer Charles Dickens 
O presente estudo, envolvendo fetos com gastrosquise isolada, permitiu concluir que:

- A dilatação da alça intestinal exteriorizada é preditiva de: complicações intestinais, menor taxa de fechamento primário da parede abdominal, longo período de uso de nutrição parenteral prolongada e maior tempo de internação hospitalar.

- A melhor medida de corte do diâmetro transverso da alça intestinal exteriorizada na predição de resultados perinatais adversos é $\geq 25 \mathrm{~mm}$ ou a razão do diâmetro transverso da alça observado/esperado (DTA O/E) $\geq 1,39$, em qualquer idade gestacional. 


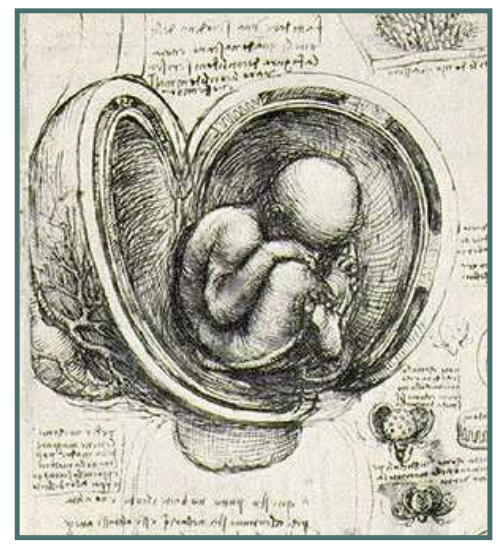




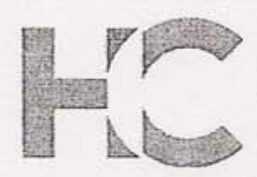

\section{APROVAÇÃO}

A Comissão de Ética para Análise de Projetos de Pesquisa CAPPesq da Diretoria Clínica do Hospital das Clínicas e da Faculdade de Medicina da Universidade de São Paulo, em sessão de 11/03/2009, APROVOU O Protocolo de Pesquisa $n^{\circ}$ 0007/09, intitulado: "GASTROSQUISE: AVALIAÇĀO PRÉNATAL DOS FATORES PROGNÓSTICOS, DAS COMPLICAÇŌES OBSTÉrRICAS E DOS RESULTADOS PÓS-NATAIS" apresentado pelo Departamento de OBSTETRíCIA E GINECOLOGIA

Cabe ao pesquisador elaborar e apresentar à CAPPesq, os relatórios parciais e final sobre a pesquisa (Resolução do Conselho Nacional de Saúde n 196, de 10/10/1996, inciso (X.2, letra "c").

Pesquisador (a) Responsável: Dra. Maria de Lourdes Brizot

Pesquisador (a) Executante: Luciana de Freitas Garcia

CAPPesq, 12 de Março de 2009

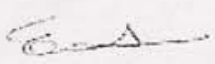

Prof. Dr. Eduardo Massad

Presidente da Comissão de

Ética para Análise de Projetos

de Pesquisa

Comissão de Ética para Análise de Projetos de Pesquisa do HCFMUSP e da FMUSP Diretoria Clinica do Hospital das Clinicas da Faculdade de Medicina da Universidade de São Paulo Rua Ovídio Pires de Campos, 225, $5^{\circ}$ andar - CEP 05403010 - São Paulo - SP Fone: 01130696442 Fax: 01130696492 e-mail: cappesq@hcnet.usp.br/secretariacappesq2@hcnet.usp.br JULIO CESAR 


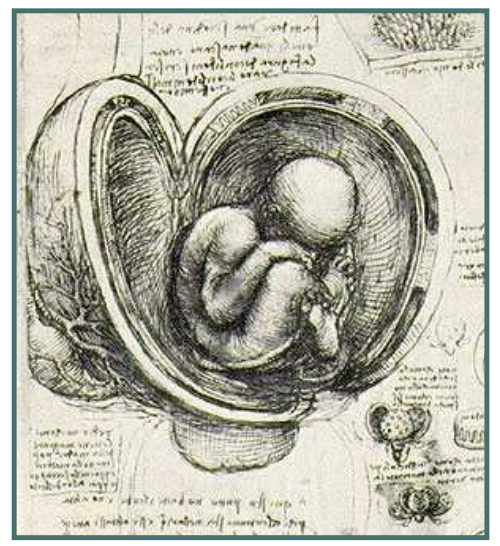


1. Tan KH, Kilby MD, Whittle MJ, Beattie BR, Booth IW, Botting BJ. Congenital anterior abdominal wall defects in England and Wales 1987-93: retrospective analysis of OPCS data. Bmj. 1996 Oct 12;313(7062):903-6.

2. Curry JI, McKinney P, Thornton JG, Stringer MD. The aetiology of gastroschisis. Bjog. 2000 Nov;107(11):1339-46.

3. Lammer EJ, Iovannisci DM, Tom L, Schultz K, Shaw GM. Gastroschisis: a gene-environment model involving the VEGF-NOS3 pathway. Am J Med Genet C Semin Med Genet. 2008 Aug 15;148C(3):213-8.

4. Suver D, Lee SL, Shekherdimian S, Kim SS. Left-sided gastroschisis: higher incidence of extraintestinal congenital anomalies. Am J Surg. 2008 May;195(5):663-6.

5. Albanese CT, Sydorak, RM, Harrison, MR. Cirurgia Pediátrica. In: Way LW, Doherty G.M., editor. Cirurgia Diagnóstico \& Tratamento. 11 ed; 2004. p. 1125.

6. Moore KL PT. The developing human: Clinically oriented embryology. 5th ed; 1993.

7. Guzman ER. Early prenatal diagnosis of gastroschisis with transvaginal ultrasonography. Am J Obstet Gynecol. 1990 May;162(5):1253-4.

8. Pryde PG, Bardicef M, Treadwell MC, Klein M, Isada NB, Evans MI. Gastroschisis: can antenatal ultrasound predict infant outcomes? Obstet Gynecol. 1994 Oct;84(4):505-10.

9. Hwang PJ, Kousseff BG. Omphalocele and gastroschisis: an 18-year review study. Genet Med. 2004 Jul-Aug;6(4):232-6.

10. Loane M, Dolk H, Bradbury I. Increasing prevalence of gastroschisis in Europe 1980-2002: a phenomenon restricted to younger mothers? Paediatr Perinat Epidemiol. 2007 Jul;21(4):363-9.

11. Green RF, Moore C. Incorporating genetic analyses into birth defects cluster investigations: strategies for identifying candidate genes. Birth Defects Res A Clin Mol Teratol. 2006 Nov;76(11):798-810. 
12. Rasmussen SA, Frias JL. Non-genetic risk factors for gastroschisis. Am J Med Genet C Semin Med Genet. 2008 Aug 15;148C(3):199-212.

13. Frolov P, Alali J, Klein MD. Clinical risk factors for gastroschisis and omphalocele in humans: a review of the literature. Pediatr Surg Int. 2010 Dec;26(12):1135-48.

14. Arnold MA, Chang DC, Nabaweesi R, Colombani PM, Fischer AC, Lau HT, et al. Development and validation of a risk stratification index to predict death in gastroschisis. J Pediatr Surg. 2007 Jun;42(6):950-5.

15. Santiago-Munoz PC, McIntire DD, Barber RG, Megison SM, Twickler DM, Dashe JS. Outcomes of pregnancies with fetal gastroschisis. Obstet Gynecol. 2007 Sep;110(3):663-8.

16. Jager LC, Heij HA. Factors determining outcome in gastroschisis: clinical experience over 18 years. Pediatr Surg Int. 2007 Aug;23(8):731-6.

17. Maksoud JG. Defeitos da região umbilical e paraumbilical. Cirurgia Pediátrica. $2^{\circ}$ ed. Rio de Janeiro; 2003.

18. Japaraj RP, Hockey R, Chan FY. Gastroschisis: can prenatal sonography predict neonatal outcome? Ultrasound Obstet Gynecol. 2003 Apr;21(4):32933.

19. Heinig J, Muller V, Schmitz R, Lohse K, Klockenbusch W, Steinhard J. Sonographic assessment of the extra-abdominal fetal small bowel in gastroschisis: a retrospective longitudinal study in relation to prenatal complications. Prenat Diagn. 2008 Feb;28(2):109-14.

20. Jeejeebhoy KN. Short bowel syndrome: a nutritional and medical approach. Cmaj. 2002 May 14;166(10):1297-302.

21. Tower C, Ong SS, Ewer AK, Khan K, Kilby MD. Prognosis in isolated gastroschisis with bowel dilatation: a systematic review. Arch Dis Child Fetal Neonatal Ed. 2009 Jul;94(4):F268-74.

22. Nathan JD, Rudolph JA, Kocoshis SA, Alonso MH, Ryckman FC, Tiao GM. Isolated liver and multivisceral transplantation for total parenteral nutritionrelated end-stage liver disease. J Pediatr Surg. 2007 Jan;42(1):143-7.

23. Lausman AY, Langer JC, Tai M, Seaward PG, Windrim RC, Kelly EN, et al. Gastroschisis: what is the average gestational age of spontaneous delivery? J Pediatr Surg. 2007 Nov;42(11):1816-21. 
24. Cohen-Overbeek TE, Hatzmann TR, Steegers EA, Hop WC, Wladimiroff JW, Tibboel D. The outcome of gastroschisis after a prenatal diagnosis or a diagnosis only at birth. Recommendations for prenatal surveillance. Eur $\mathrm{J}$ Obstet Gynecol Reprod Biol. 2007 Jul;139(1):21-7.

25. Driver CP, Bruce J, Bianchi A, Doig CM, Dickson AP, Bowen J. The contemporary outcome of gastroschisis. J Pediatr Surg. 2000 Dec;35(12):1719-23.

26. Molik KA, Gingalewski CA, West KW, Rescorla FJ, Scherer LR, Engum SA, et al. Gastroschisis: a plea for risk categorization. J Pediatr Surg. 2001 Jan;36(1):51-5.

27. Lao OB, Larison C, Garrison MM, Waldhausen JH, Goldin AB. Outcomes in neonates with gastroschisis in U.S. children's hospitals. Am J Perinatol. 2010 Jan;27(1):97-101.

28. Abdullah F, Arnold MA, Nabaweesi R, Fischer AC, Colombani PM, Anderson KD, et al. Gastroschisis in the United States 1988-2003: analysis and risk categorization of 4344 patients. J Perinatol. 2007 Jan;27(1):50-5.

29. Fonkalsrud EW. Gastroschisis. In: Nyhus LM, editor. Hernia. 4 ed. Philadelphia: J.B. Lippincott Company; 1995. p. 352.

30. Phillips JD, Raval MV, Redden C, Weiner TM. Gastroschisis, atresia, dysmotility: surgical treatment strategies for a distinct clinical entity. J Pediatr Surg. 2008 Dec;43(12):2208-12.

31. British Intestinal Failure Survey. 2009 [cited 2011 12/06]; Available from: http://www.bspghan.org.uk/working_groups/nutrition.shtml

32. Kelly DA. Intestinal failure-associated liver disease: what do we know today? Gastroenterology. 2006 Feb;130(2 Suppl 1):S70-7.

33. Wilson RD, Johnson MP. Congenital abdominal wall defects: an update. Fetal Diagn Ther. 2004 Sep-Oct;19(5):385-98.

34. Nick AM, Bruner JP, Moses R, Yang EY, Scott TA. Second-trimester intraabdominal bowel dilation in fetuses with gastroschisis predicts neonatal bowel atresia. Ultrasound Obstet Gynecol. 2006 Nov;28(6):821-5.

35. Bond SJ, Harrison MR, Filly RA, Callen PW, Anderson RA, Golbus MS. Severity of intestinal damage in gastroschisis: correlation with prenatal sonographic findings. J Pediatr Surg. 1988 Jun;23(6):520-5. 
36. Langer JC, Khanna J, Caco C, Dykes EH, Nicolaides KH. Prenatal diagnosis of gastroschisis: development of objective sonographic criteria for predicting outcome. Obstet Gynecol. 1993 Jan;81(1):53-6.

37. Babcook CJ, Hedrick MH, Goldstein RB, Callen PW, Harrison MR, Adzick NS, et al. Gastroschisis: can sonography of the fetal bowel accurately predict postnatal outcome? J Ultrasound Med. 1994 Sep;13(9):701-6.

38. Alsulyman OM, Monteiro H, Ouzounian JG, Barton L, Songster GS, Kovacs BW. Clinical significance of prenatal ultrasonographic intestinal dilatation in fetuses with gastroschisis. Am J Obstet Gynecol. 1996 Oct;175(4 Pt 1):982-4.

39. Sipes SL, Weiner CP, Williamson RA, Pringle KC, Kimura K. Fetal gastroschisis complicated by bowel dilation: an indication for imminent delivery? Fetal Diagn Ther. 1990;5(2):100-3.

40. Van Dorp DR, Malleis JM, Sullivan BP, Klein MD. Teratogens inducing congenital abdominal wall defects in animal models. Pediatr Surg Int. 2009 Feb;26(2):127-39.

41. Bax N. Exophalos and gastroschisis. In: Freeman NVB, D.M; Griffiths, D.M; Malone, P.S.J, editor. Surgery of the newborn: Churchil livingstone 1994. p. 301-20.

42. Nyhus LM, Condon, R.E. Gastroschisis. Hernia. $4^{\circ}$ ed. Philadelphia, Pennsylvania; 1995.

43. Moore TC, Stokes, G.E. Gastroschisis. Report of two cases treated by a modification of the Gross operation for omphalocele. Surgery. 1952;33:11220.

44. Classification of diseases. 2007 [cited 2011 23/06]; Available from: http://www.who.int/classifications/apps/icd/icd10online/

45. Duhamel B. Embryology of Exomphalos and Allied Malformations. Arch Dis Child. 1963 Apr;38(198):142-7.

46. Cyr DR, Mack LA, Schoenecker SA, Patten RM, Shepard TH, Shuman WP, et al. Bowel migration in the normal fetus: US detection. Radiology. 1986 Oct;161(1):119-21.

47. Moore KL, Persaud, T.V. The developing human: Clinically oriented embryology. 8th ed; 2008. 
48. Moore TC. Gastroschisis and omphalocele: clinical differences. Surgery. 1977 Nov;82(5):561-8.

49. Hoyme HE, Jones MC, Jones KL. Gastroschisis: abdominal wall disruption secondary to early gestational interruption of the omphalomesenteric artery. Semin Perinatol. 1983 Oct;7(4):294-8.

50. Shaw A. The myth of gastroschisis. J Pediatr Surg. 1975 Apr;10(2):235-44.

51. Glick PL, Harrison MR, Adzick NS, Filly RA, deLorimier AA, Callen PW. The missing link in the pathogenesis of gastroschisis. J Pediatr Surg. 1985 Aug;20(4):406-9.

52. Martin RW. Screening for fetal abdominal wall defects. Obstet Gynecol Clin North Am. 1998 Sep;25(3):517-26.

53. Rankin J, Dillon E, Wright C. Congenital anterior abdominal wall defects in the north of England, 1986-1996: occurrence and outcome. Prenat Diagn. 1999 Jul;19(7):662-8.

54. Nazer J, Margozzini J, Rodriguez M, Rojas M, Cifuentes L. [Disabling malformations in Chile. Latin American Cooperative Study of Congenital Malformations (ECLAMC), 1982-1997]. Rev Med Chil. 2001 Jan;129(1):6774.

55. Canfield MA, Honein MA, Yuskiv N, Xing J, Mai CT, Collins JS, et al. National estimates and race/ethnic-specific variation of selected birth defects in the United States, 1999-2001. Birth Defects Res A Clin Mol Teratol. 2006 Nov;76(11):747-56.

56. Fillingham A, Rankin J. Prevalence, prenatal diagnosis and survival of gastroschisis. Prenat Diagn. 2008 Dec;28(13):1232-7.

57. ECLAMC. South America Latin American Collaborative Study of Congenital Malformations. International Clearinghouse for Birth Defects Surveillance and Research: annual report 2008 With data for 2006 Rome. 2008:207-13.

58. Mac Bird T, Robbins JM, Druschel C, Cleves MA, Yang S, Hobbs CA. Demographic and environmental risk factors for gastroschisis and omphalocele in the National Birth Defects Prevention Study. J Pediatr Surg. 2009 Aug;44(8):1546-51.

59. Benjamin BG, Ethen MK, Van Hook CL, Myers CA, Canfield MA. Gastroschisis prevalence in Texas 1999-2003. Birth Defects Res A Clin Mol Teratol. 2009 Mar;88(3):178-85. 
60. Whitehall JS, Kandasamy Y, Stalewski H, Gill A. Perinatal demography of gastroschisis in North Queensland. J Paediatr Child Health. 2010 Dec;46(12):749-53.

61. Xu LL, Yuan XQ, Zhu J, Li XH, Wang YP, Zhou GX, et al. [Incidence and its trends on gastroschisis in some parts of China, 1996 - 2007.]. Zhonghua Liu Xing Bing Xue Za Zhi. 2011 Mar;32(3):268-70.

62. Nazer HJ, Cifuentes OL. [Congenital malformations in Latin America in the period 1995-2008]. Rev Med Chil. 2011 Jan;139(1):72-8.

63. Vu LT, Nobuhara KK, Laurent C, Shaw GM. Increasing prevalence of gastroschisis: population-based study in California. J Pediatr. 2008 Jun;152(6):807-11.

64. Kilby MD. The incidence of gastroschisis. Bmj. 2006 Feb 4;332(7536):250-1.

65. Collins SR, Griffin MR, Arbogast PG, Walsh WF, Rush MR, Carter BS, et al. The rising prevalence of gastroschisis and omphalocele in Tennessee. $\mathrm{J}$ Pediatr Surg. 2007 Jul;42(7):1221-4.

66. Sipek A, Gregor V, Horacek J. [Birth defects in the Czech Republic in the period 1961-2005--mean incidences]. Ceska Gynekol. 2007 May;72(3):18591.

67. Alvarez SM, Burd RS. Increasing prevalence of gastroschisis repairs in the United States: 1996-2003. J Pediatr Surg. 2007 Jun;42(6):943-6.

68. Mastroiacovo P, Lisi A, Castilla EE. The incidence of gastroschisis: research urgently needs resources. Bmj. 2006 Feb 18;332(7538):423-4.

69. Laughon M, Meyer R, Bose C, Wall A, Otero E, Heerens A, et al. Rising birth prevalence of gastroschisis. J Perinatol. 2003 Jun;23(4):291-3.

70. Calzolari E, Bianchi F, Dolk H, Milan M. Omphalocele and gastroschisis in Europe: a survey of 3 million births 1980-1990. EUROCAT Working Group. Am J Med Genet. 1995 Aug 28;58(2):187-94.

71. Chabra S, Gleason CA, Seidel K, Williams MA. Rising prevalence of gastroschisis in Washington State. $J$ Toxicol Environ Health A. 2011;74(5):336-45.

72. Jones KL, Benirschke K, Chambers CD. Gastroschisis: etiology and developmental pathogenesis. Clin Genet. 2009 Apr;75(4):322-5. 
73. Chen XK, Wen SW, Fleming N, Yang Q, Walker MC. Teenage pregnancy and congenital anomalies: which system is vulnerable? Hum Reprod. 2007 Jun;22(6):1730-5.

74. Werler MM, Mitchell AA, Shapiro S. Demographic, reproductive, medical, and environmental factors in relation to gastroschisis. Teratology. 1992 Apr;45(4):353-60.

75. Hougland KT, Hanna AM, Meyers R, Null D. Increasing prevalence of gastroschisis in Utah. J Pediatr Surg. 2005 Mar;40(3):535-40.

76. Drongowski RA, Smith RK, Jr., Coran AG, Klein MD. Contribution of demographic and environmental factors to the etiology of gastroschisis: a hypothesis. Fetal Diagn Ther. 1991;6(1-2):14-27.

77. Torfs CP, Velie EM, Oechsli FW, Bateson TF, Curry CJ. A population-based study of gastroschisis: demographic, pregnancy, and lifestyle risk factors. Teratology. 1994 Jul;50(1):44-53.

78. Goldbaum G, Daling J, Milham S. Risk factors for gastroschisis. Teratology. 1990 Oct;42(4):397-403.

79. Haddow JE, Palomaki GE, Holman MS. Young maternal age and smoking during pregnancy as risk factors for gastroschisis. Teratology. 1993 Mar;47(3):225-8.

80. Torfs CP, Katz EA, Bateson TF, Lam PK, Curry CJ. Maternal medications and environmental exposures as risk factors for gastroschisis. Teratology. 1996 Aug;54(2):84-92.

81. Lam PK, Torfs CP. Interaction between maternal smoking and malnutrition in infant risk of gastroschisis. Birth Defects Res A Clin Mol Teratol. 2006 Mar;76(3):182-6.

82. Draper ES, Rankin J, Tonks AM, Abrams KR, Field DJ, Clarke M, et al. Recreational drug use: a major risk factor for gastroschisis? Am J Epidemiol. 2008 Feb 15;167(4):485-91.

83. Torfs CP, Christianson RE, Iovannisci DM, Shaw GM, Lammer EJ. Selected gene polymorphisms and their interaction with maternal smoking, as risk factors for gastroschisis. Birth Defects Res A Clin Mol Teratol. 2006 Oct;76(10):723-30.

84. Werler MM, Mitchell AA, Shapiro S. First trimester maternal medication use in relation to gastroschisis. Teratology. 1992 Apr;45(4):361-7. 
85. Richardson S, Browne ML, Rasmussen SA, Druschel CM, Sun L, Jabs EW, et al. Associations between periconceptional alcohol consumption and craniosynostosis, omphalocele, and gastroschisis. Birth Defects Res A Clin Mol Teratol. 2011 May 31.

86. Forrester MB, Merz RD. Comparison of trends in gastroschisis and prenatal illicit drug use rates. J Toxicol Environ Health A. 2006 Jul;69(13):1253-9.

87. Mastroiacovo P. Risk factors for gastroschisis. Bmj. 2008 Jun 21;336(7658):1386-7.

88. Feldkamp ML, Reefhuis J, Kucik J, Krikov S, Wilson A, Moore CA, et al. Case-control study of self reported genitourinary infections and risk of gastroschisis: findings from the national birth defects prevention study, 19972003. Bmj. 2008 Jun 21;336(7658):1420-3.

89. Torfs CP, Lam PK, Schaffer DM, Brand RJ. Association between mothers' nutrient intake and their offspring's risk of gastroschisis. Teratology. 1998 Dec;58(6):241-50.

90. Nelson TC, Toyama WM. Familial gastroschisis: a case of mother-and son occurrence. J Pediatr Surg. 1995 Dec;30(12):1706-8.

91. Torfs CP, Curry CJ. Familial cases of gastroschisis in a population-based registry. Am J Med Genet. 1993 Feb 15;45(4):465-7.

92. Roeper PJ, Harris J, Lee G, Neutra R. Secular rates and correlates for gastroschisis in California (1968-1977). Teratology. 1987 Apr;35(2):203-10.

93. Kohl M, Wiesel A, Schier F. Familial recurrence of gastroschisis: literature review and data from the population-based birth registry "Mainz Model". J Pediatr Surg. 2010 Sep;45(9):1907-12.

94. Moore KL, Persaud, T.V. The developing human: Clinically oriented embryology. 5th ed; 1993.

95. Benacerraf B. Differential diagnosis: in Ultrasound of Fetal Syndromes. Churchill Livingstone. 1998;Sect. pg.33.

96. Balmann F, Merz, E., Weber, G., Macchiella, D. Prenatal diagnosed and management of gastroschisis and omphalocele. Pediatr Surg Int. 1996;11:6771.

97. Ledbetter DJ. Gastroschisis and omphalocele. Surg Clin North Am. 2006 Apr;86(2):249-60. 
98. Kilby MD, Lander A, Usher-Somers M. Exomphalos (omphalocele). Prenat Diagn. 1998 Dec;18(12):1283-8.

99. Jones KL. Smith's recognizable patterns of human malformations. Philadelphia: Elsevier Saunders. 2006:924-6.

100. Stoll C, Alembik Y, Dott B, Roth MP. Omphalocele and gastroschisis and associated malformations. Am J Med Genet A. 2008 May 15;146A(10):12805.

101. Eurenius K, Axelsson O. Outcome for fetuses with abdominal wall defects detected by routine second trimester ultrasound. Acta Obstet Gynecol Scand. 1994 Jan;73(1):25-9.

102. Walkinshaw SA, Renwick M, Hebisch G, Hey EN. How good is ultrasound in the detection and evaluation of anterior abdominal wall defects? $\mathrm{Br} \mathrm{J}$ Radiol. 1992 Apr;65(772):298-301.

103. Mastroiacovo P, Lisi A, Castilla EE, Martinez-Frias ML, Bermejo E, Marengo L, et al. Gastroschisis and associated defects: an international study. Am J Med Genet A. 2007 Apr 1;143(7):660-71.

104. Ruano R, Picone O, Bernardes L, Martinovic J, Dumez Y, Benachi A. The association of gastroschisis with other congenital anomalies: how important is it? Prenat Diagn. 2011 Apr;31(4):347-50.

105. Barisic I, Clementi M, Hausler M, Gjergja R, Kern J, Stoll C. Evaluation of prenatal ultrasound diagnosis of fetal abdominal wall defects by 19 European registries. Ultrasound Obstet Gynecol. 2001 Oct;18(4):309-16.

106. Torfs CP, Christianson RE. Anomalies in Down syndrome individuals in a large population-based registry. Am J Med Genet. 1998 Jun 5;77(5):431-8.

107. Paidas MJ, Crombleholme TM, Robertson FM. Prenatal diagnosis and management of the fetus with an abdominal wall defect. Semin Perinatol. 1994 Jun;18(3):196-214.

108. Morrow RJ, Whittle MJ, McNay MB, Raine PA, Gibson AA, Crossley J. Prenatal diagnosis and management of anterior abdominal wall defects in the west of Scotland. Prenat Diagn. 1993 Feb;13(2):111-5.

109. Nicolaides KH, Snijders RJ, Cheng HH, Gosden C. Fetal gastro-intestinal and abdominal wall defects: associated malformations and chromosomal abnormalities. Fetal Diagn Ther. 1992;7(2):102-15. 
110. Van de Geijn EJ, Van Vugt JM, Sollie JE, Van Geijn HP. Ultrasonographic diagnosis and perinatal management of fetal abdominal wall defects. Fetal Diagn Ther. 1991;6(1-2):2-10.

111. Wilson RD, Chitayat D, McGillivray BC. Fetal ultrasound abnormalities: correlation with fetal karyotype, autopsy findings, and postnatal outcome-five-year prospective study. Am J Med Genet. 1992 Nov 15;44(5):586-90.

112. Hoehner JC, Ein SH, Kim PC. Management of gastroschisis with concomitant jejuno-ileal atresia. J Pediatr Surg. 1998 Jun;33(6):885-8.

113. Cusick E, Spicer RD, Beck JM. Small-bowel continuity: a crucial factor in determining survival in gastroschisis. Pediatr Surg Int. 1997;12(1):34-7.

114. Snyder CL, Miller KA, Sharp RJ, Murphy JP, Andrews WA, Holcomb GW, 3rd, et al. Management of intestinal atresia in patients with gastroschisis. J Pediatr Surg. 2001 Oct;36(10):1542-5.

115. Nicholas SS, Stamilio DM, Dicke JM, Gray DL, Macones GA, Odibo AO. Predicting adverse neonatal outcomes in fetuses with abdominal wall defects using prenatal risk factors. Am J Obstet Gynecol. 2009 Oct;201(4):383 e1-6.

116. Fratelli N, Papageorghiou AT, Bhide A, Sharma A, Okoye B, Thilaganathan B. Outcome of antenatally diagnosed abdominal wall defects. Ultrasound Obstet Gynecol. 2007 Sep;30(3):266-70.

117. Henrich K, Huemmer HP, Reingruber B, Weber PG. Gastroschisis and omphalocele: treatments and long-term outcomes. Pediatr Surg Int. 2008 Feb;24(2):167-73.

118. Netta DA, Wilson RD, Visintainer P, Johnson MP, Hedrick HL, Flake AW, et al. Gastroschisis: growth patterns and a proposed prenatal surveillance protocol. Fetal Diagn Ther. 2007;22(5):352-7.

119. Crawford RA, Ryan G, Wright VM, Rodeck CH. The importance of serial biophysical assessment of fetal wellbeing in gastroschisis. $\mathrm{Br} \mathrm{J}$ Obstet Gynaecol. 1992 Nov;99(11):899-902.

120. Towers CV, Carr MH. Antenatal fetal surveillance in pregnancies complicated by fetal gastroschisis. Am J Obstet Gynecol. 2008 Jun;198(6):686 e1-5.

121. Horton AL, Powell MS, Wolfe HM. Intrauterine growth patterns in fetal gastroschisis. Am J Perinatol. 2009 Mar;27(3):211-7. 
122. Brantberg A, Blaas HG, Salvesen KA, Haugen SE, Eik-Nes SH. Surveillance and outcome of fetuses with gastroschisis. Ultrasound Obstet Gynecol. 2004 Jan;23(1):4-13.

123. Dixon JC, Penman DM, Soothill PW. The influence of bowel atresia in gastroschisis on fetal growth, cardiotocograph abnormalities and amniotic fluid staining. Bjog. 2000 Apr;107(4):472-5.

124. Api A, Olguner M, Hakguder G, Ates O, Ozer E, Akgur FM. Intestinal damage in gastroschisis correlates with the concentration of intraamniotic meconium. J Pediatr Surg. 2001 Dec;36(12):1811-5.

125. Hakguder G, Ates O, Olguner M, Api A, Ozdogan O, Degirmenci B, et al. Induction of fetal diuresis with intraamniotic furosemide increases the clearance of intraamniotic substances: An alternative therapy aimed at reducing intraamniotic meconium concentration. J Pediatr Surg. 2002 Sep;37(9):1337-42.

126. Lenke RR, Persutte WH, Nemes J. Ultrasonographic assessment of intestinal damage in fetuses with gastroschisis: is it of clinical value? Am J Obstet Gynecol. 1990 Sep;163(3):995-8.

127. Adra AM, Landy HJ, Nahmias J, Gomez-Marin O. The fetus with gastroschisis: impact of route of delivery and prenatal ultrasonography. Am J Obstet Gynecol. 1996 Feb;174(2):540-6.

128. Piper HG, Jaksic $\mathrm{T}$. The impact of prenatal bowel dilation on clinical outcomes in neonates with gastroschisis. J Pediatr Surg. 2006 May;41(5):897900 .

129. Snijders RJ, Nicolaides KH. Fetal biometry at 14-40 weeks' gestation. Ultrasound Obstet Gynecol. 1994 Jan 1;4(1):34-48.

130. Philipson EH, Sokol RJ, Williams T. Oligohydramnios: clinical associations and predictive value for intrauterine growth retardation. Am J Obstet Gynecol. 1983 Jun 1;146(3):271-8.

131. Phelan JP, Smith CV, Broussard P, Small M. Amniotic fluid volume assessment with the four-quadrant technique at 36-42 weeks' gestation. J Reprod Med. 1987 Jul;32(7):540-2.

132. Miyadahira S. Avaliação da vitalidade fetal. In: Zugaib M, Pedreira D.A.L, Brizot, M.L, Bunduki, V, editor. Medicina Fetal. 2a ed; Atheneu, 1997. p. 479-85. 
133. Manning FA, Platt LD, Sipos L. Antepartum fetal evaluation: development of a fetal biophysical profile. Am J Obstet Gynecol. 1980 Mar 15;136(6):78795.

134. Forouzan I, Cohen AW, Arger P. Measurement of systolic-diastolic ratio in the umbilical artery by continuous-wave and pulsed-wave Doppler ultrasound: comparison at different sites. Obstet Gynecol. 1991 Feb;77(2):209-12.

135. Robinson HP, Fleming JE. A critical evaluation of sonar "crown-rump length" measurements. Br J Obstet Gynaecol. 1975 Sep;82(9):702-10.

136. Hadlock FP, Harrist RB, Martinez-Poyer J. How accurate is second trimester fetal dating? J Ultrasound Med. 1991 Oct;10(10):557-61.

137. Brizot ML, Liao AW, Nomura RM, Francisco RP, Zugaib M. Changes in amniotic fluid index after maternal oral hydration in pregnancies with fetal gastroschisis: initial observations. Fetal Diagn Ther. 2010;28(2):87-91.

138. Alexander GR, Himes JH, Kaufman RB, Mor J, Kogan M. A United States national reference for fetal growth. Obstet Gynecol. 1996 Feb;87(2):163-8.

139. Bussab WO, Morettin PA. Estatística Básica. 4a ed. São Paulo: Atual; 1987.

140. Agresti A. Categorical Data Analysis. 1a ed. New York: Wiley; 1990.

141. Badillo AT, Hedrick HL, Wilson RD, Danzer E, Bebbington MW, Johnson MP, et al. Prenatal ultrasonographic gastrointestinal abnormalities in fetuses with gastroschisis do not correlate with postnatal outcomes. J Pediatr Surg. $2008 \mathrm{Apr} ; 43(4): 647-53$.

142. Ministério da Saúde. [cited 2011 04/09]; Available from:http://www.inca.gov.br/tabagismo/frameset.asp?item=jovem\&link=nam ira.htm

143. Sydorak RM, Nijagal A, Sbragia L, Hirose S, Tsao K, Phibbs RH, et al. Gastroschisis: small hole, big cost. J Pediatr Surg. 2002 Dec;37(12):1669-72.

144. Nyberg DA, Mack LA, Patten RM, Cyr DR. Fetal bowel. Normal sonographic findings. J Ultrasound Med. 1987 Jan;6(1):3-6.

145. Abuhamad AZ, Mari G, Cortina RM, Croitoru DP, Evans AT. Superior mesenteric artery Doppler velocimetry and ultrasonographic assessment of fetal bowel in gastroschisis: a prospective longitudinal study. Am J Obstet Gynecol. 1997 May;176(5):985-90. 
146. Mears AL, Sadiq JM, Impey L, Lakhoo K. Antenatal bowel dilatation in gastroschisis: a bad sign? Pediatr Surg Int. 2010 Jun;26(6):581-8.

147. Adair CD, Rosnes J, Frye AH, Burrus DR, Nelson LH, Veille JC. The role of antepartum surveillance in the management of gastroschisis. Int J Gynaecol Obstet. 1996 Feb;52(2):141-4.

148. Fries MH, Filly RA, Callen PW, Goldstein RB, Goldberg JD, Golbus MS. Growth retardation in prenatally diagnosed cases of gastroschisis. J Ultrasound Med. 1993 Oct;12(10):583-8.

149. Snyder CL. Outcome analysis for gastroschisis. J Pediatr Surg. 1999 Aug;34(8):1253-6.

150. Anteby EY, Sternhell K, Dicke JM. The fetus with gastroschisis managed by a trial of labor: antepartum and intrapartum complications. J Perinatol. 1999 Oct-Nov;19(7):521-4.

151. Stringer MD, Brereton RJ, Wright VM. Controversies in the management of gastroschisis: a study of 40 patients. Arch Dis Child. 1991 Jan;66(1 Spec No):34-6.

152. Vilela PC, Ramos De Amorim MM, Falbo GH, Santos LC. Risk factors for adverse outcome of newborns with gastroschisis in a Brazilian hospital. J Pediatr Surg. 2001 Apr;36(4):559-64.

153. Agugua NE, Nwako FA. Gastroschisis a fifteen-year experience. West Afr J Med. 1990 Apr-Jun;9(2):147-50.

154. Molenaar JC, Tibboel D. Gastroschisis and omphalocele. World J Surg. 1993 May-Jun;17(3):337-41.

155. Ergun O, Barksdale E, Ergun FS, Prosen T, Qureshi FG, Reblock KR, et al. The timing of delivery of infants with gastroschisis influences outcome. $\mathrm{J}$ Pediatr Surg. 2005 Feb;40(2):424-8.

156. Huang J, Kurkchubasche AG, Carr SR, Wesselhoeft CW, Jr., Tracy TF, Jr., Luks FL. Benefits of term delivery in infants with antenatally diagnosed gastroschisis. Obstet Gynecol. 2002 Oct;100(4):695-9.

157. Moore TC, Collins DL, Catanzarite V, Hatch EI, Jr. Pre-term and particularly pre-labor cesarean section to avoid complications of gastroschisis. Pediatr Surg Int. 1999;15(2):97-104. 